\title{
Taxonomic revision and cladistic analysis of ghost spiders of the genus Tafana Simon, 1903 (Araneae: Dionycha, Anyphaenidae), with the descriptions of twelve new species
}

\author{
Luiz Fernando M. DE OLIVEIRA ${ }^{\circledR 1, *}$ \& Antonio Domingos BRESCOVIT ${ }^{\circledR 2}$ \\ ${ }^{1,2}$ Laboratório de Coleções Zoológicas, Instituto Butantan - Av. Vital Brazil, 1500, \\ 05503-900, São Paulo, SP, Brazil. \\ ${ }^{1}$ Instituto de Biociências, Universidade de São Paulo, Rua do Matão, 321, \\ 05508-090, São Paulo, SP, Brazil. \\ *Corresponding author: luiz.moura.lfm@gmail.com \\ ${ }^{2}$ Email: antonio.brescovit@butantan.gov.br \\ ${ }^{1}$ urn:1sid:zoobank.org:author:06C42876-2925-4007-A19D-053BD0058F25 \\ ${ }^{2}$ urn:1sid:zoobank.org:author:D5B81D79-AFAE-47B1-8A6E-DAB448A24BCC
}

\begin{abstract}
The diversity of the genus Tafana Simon, 1903 is poorly known in the Neotropical regions. In this work we provide a taxonomic review of the genus as well as a phylogenetic analysis. The ingroup of the analysis is composed of sixteen species of Tafana and the outgroup is composed of five representatives of Anyphaenidae. The sister-group recovered for Tafana is the clade Aysha + Xiruana, being supported by the embolic process on the male bulb. Two species groups within Tafana are herein proposed, the silhavyi group and the riveti group, based on two exclusive synapomorphies in the male bulb. We redescribe Tafana quelchi and present a description of the previously unknown female of Tafana silhavyi, both from Venezuela. In addition, we describe the first adult specimens of Tafana straminea. Twelve new species, along with several previously described species, are described, illustrated and mapped: T. riveti, T. straminea, T. quelchi, T. kunturmarqa sp. nov., T. humahuaca sp. nov., T. pastaza sp. nov., T. nevada sp. nov., T. huatanay sp. nov. and T. ruizi sp. nov. from the riveti species group; T. maracay sp. nov., T. arawak sp. nov., T. chimire sp. nov. and T. pitieri sp. nov. from the silhavyi species group; T. oliviae sp. nov. from Argentina and T. orinoco sp. nov. from Venezuela, neither of which belongs to any species group. We also discuss the genital morphology of the species groups based on the results of the phylogenetic analysis. Furthermore, distribution maps for all species, including new records for $T$. riveti, $T$. straminea and $T$. quelchi, are presented.
\end{abstract}

Keywords. Anyphaeninae, taxonomy, Neotropical region.

de Oliveira L.F.M. \& Brescovit A.D. 2021. Taxonomic revision and cladistic analysis of ghost spiders of the genus Tafana Simon, 1903 (Araneae: Dionycha, Anyphaenidae), with the descriptions of twelve new species. European Journal of Taxonomy 742: 1-77. https://doi.org/10.5852/ejt.2021.742.1291

\section{Introduction}

Spiders of the family Anyphaenidae Bertkau, 1878 are known as ghost spiders because of their rapid movement. They frequently inhabit leaf-litter, and are found up to the treetops in forests and even in 
some semi-arid regions (Brescovit 1997; Labarque et al. 2015). Currently, the family is divided in the subfamilies Amaurobioidinae Hickman, 1949 and Anyphaeninae Bertkau, 1878 (Ramírez 2003, 2014).

The subfamily Amaurobioidinae has been widely studied in the morphological and molecular phylogenetic analyses of Ramírez (1995a, 1995b, 2003, 2007), Ramírez et al. (2004), Werenkraut \& Ramírez (2009), González Márquez \& Ramírez (2012), Laborda et al. (2013), Labarque et al. (2015) and Rúbio \& Ramírez (2015); and in the biogeographic analyses of Ceccarelli et al. $(2016,2019)$ and Soto et al. (2017). Currently, the subfamily comprises 23 genera and 171 species, with representatives in the Americas, South Africa, Tasmania (Australia) and New Zealand (Ramírez 2003; World Spider Catalog 2020). So far, Anyphaeninae has only been studied using morphological characters, by Brescovit (1991a, 1991b, 1992a, 1992b, 1993a, 1993b, 1997, 1999), Oliveira \& Brescovit (2015a, 2015b, 2016) and Brescovit \& Oliveira (2019). Brescovit (1997) revised and redescribed all known genera of the subfamily in the Neotropical region. Currently, Anyphaeninae includes 32 genera and 385 species, and is widely distributed throughout the Americas, with representatives in the Palearctic, Oriental and Polynesian regions (World Spider Catalog 2020).

The genus Tafana was proposed by Simon (1903) with Tafana riveti Simon, 1903 as the type species. Brescovit (1997) redescribed T. riveti and transferred three additional species from Anyphaena Sundevall, 1833 to Tafana: T. quelchi (Pocock, 1895), T. silhavyi (Caporiacco, 1955) and T. straminea (L. Koch, 1866). Tafana is easily distinguished from other genera of Anyphaeninae by an apophysis at the base of the embolus, a ventral tegular process near the median apophysis and in the margin of the tegulum on the male palp, as well as a female epigynum with sinuous and transversal sclerotized lateral lobes, and an atrium with or without a septum in the female genitalia.

In this contribution, we present a phylogenetic analysis of the genus and propose two distinct species groups, the riveti group and the silhavyi group. The genus Tafana is revised with the description of twelve new species, and descriptions are provided for the previously unknown female of Tafana silhavyi and adult specimens of Tafana straminea. We also provide a new diagnosis of the genus and a diagnosis for all the species herein reviewed.

\section{Material and methods}

The examined specimens are deposited in the following collections (curators in parentheses):

$\begin{aligned} \text { AMNH }= & \text { American Museum of Natural History, New York, USA (L. Prendini) } \\ \text { CAS }= & \text { Californian Academy of Sciences, San Francisco, USA (L. Esposito) } \\ \text { FMNH }= & \text { Field Museum of Natural History, Chicago, USA (P. Sierwald) } \\ \text { IBNP } & \text { Inventario Biologico Nacional, Museo Nacional de Historia Natural del Paraguay, San } \\ & \text { Lorenzo, Paraguay (J.A. Kochalka) } \\ \text { IBSP } & \text { Instituto Butantan, São Paulo, Brazil (A.D. Brescovit) } \\ \text { ICN-Ar = } & \text { Universidad Nacional de Colombia, Instituto de Ciencias Naturales, Bogotá, Colombia } \\ & \text { (E. Florez) } \\ \text { MACN-Ar = } & \text { Museo Argentino de Ciências Naturales Bernardino Rivadavia, Buenos Aires, Argentina } \\ & \text { (M. Ramírez) } \\ \text { MCN }= & \text { Museu de Ciências Naturais, SEMA, Porto Alegre, Brazil (R. Ott) } \\ \text { MCZ }= & \text { Museum of Comparative Zoology, Harvard University, Cambridge, USA (G. Giribet) } \\ \text { MIZA }= & \text { Museo del Instituto de Zoologia Agricola, Universidad Central de Venezuela, Aragua, } \\ & \text { Venezuela (F.F. Yépez) } \\ \text { MNHN }= & \text { Muséum national d'histoire naturelle, Paris, France (C. Rollard) } \\ \text { MUCV = } & \text { Museo de Biologia, Universidad Central de Venezuela, Caracas, Venezuela (R. Candia) } \\ \text { MUSM = } & \text { Museo de Historia Natural de San Marcos, Lima, Peru (D. Silva) } \\ \text { USNM = } & \text { National Museum of Natural History, Smithsonian Institution, Washington D.C., USA } \\ & \text { (J. Coddington and H. Wood) }\end{aligned}$




\section{Morphology}

Specimens described in this work were examined in the Laboratório de Coleções Zoológicas, Instituto Butantan. All measurements are in millimeters. The terminology and format of the descriptions follow Oliveira \& Brescovit (2015a, 2015b). Descriptions of the leg. spination mention only those spines which differ from the general formula presented by Brescovit (1997: 84-85). The male and female genitalia were examined and illustrated using an M125 Leica stereo microscope with lucida camera. All drawings were scanned and edited with the help of the program Photoshop CS6. Extended focal range photos were taken using a Leica 500 digital camera attached to a Leica MZ16A stereo microscope. The photographs were assembled using Leica Application Suite ver. 3.3.0. Descriptions of the process of the male palp expansion follow Brescovit (1997: 6). Tracheae were observed and photographed after digestion of tissues with a $10-20 \% \mathrm{KOH}$ solution at approximately $100^{\circ} \mathrm{C}$ in a double boiler or on a hot plate. After dissection, in order to photograph, the female genitalia, the vulva, was submerged for 24 hours in one tablet of an enzymatic eye lens cleaner (Ultrazyme ${ }^{\circledR}$ enzymatic cleaner) diluted in $5 \mathrm{~mL}$ of distilled water, to digest the non-chitinous tissue, before being submerged in clove oil for clarification. For scanning electron microscopy (SEM) images, legs, carapace, chelicerae, palpi and epigynum were removed and dehydrated through a series of graded ethanol (80-100\%), dried by critical-point drying, mounted on metal stubs using adhesive copper tape and nail polish for fixation, and sputter coated with gold. SEM images were taken with a FEI Quanta 250 scanning electron microscope at the Laboratório de Biologia Celular of the Instituto Butantan, São Paulo. Geographical coordinates are given as latitude and longitude (DMS); coordinates in brackets were obtained with Google Earth (Lat/Lon-WGS84) and Google Maps. The geographic distribution of each species was mapped using the software ArcMap ver. 10.1.

\section{Abbreviations}

Somatic morphology

Ac $=$ aciniform gland spigot

$\mathrm{ALE}=$ anterior lateral eyes

$\mathrm{ALS}=$ anterior lateral spinnerets

$\mathrm{AME}=$ anterior median eyes

$\mathrm{CL}=$ colulus

$\mathrm{MaAm}=$ major ampullate gland spigot

MiAm = minor ampullate glad spigot

$\mathrm{Pi} \quad=$ piriform gland spigot

$\mathrm{p} \quad=$ prolateral

PLE $=$ posterior lateral eyes

PLS $=$ posterior lateral spinnerets

$\mathrm{PME}=$ posterior median eyes

PMS $=$ posterior median spinnerets

$\mathrm{r} \quad=$ retrolateral

$\mathrm{Tp}=$ tartipore

$\mathrm{TrSp}=$ tracheal spiracle

$\mathrm{v} \quad=$ ventral

$1 \mathrm{stB}=$ first bifurcation of median tracheae

Genitalia $($ đ $)$

$\mathrm{ABE}=$ apophysis at the base of embolus

APE $=$ apophysis of embolic process

aPTA $=$ apical prolateral tibial apophysis

aRTA $=$ anterior branch of the retrolateral tibial apophysis

$\mathrm{BH}=$ basal haematodocha 


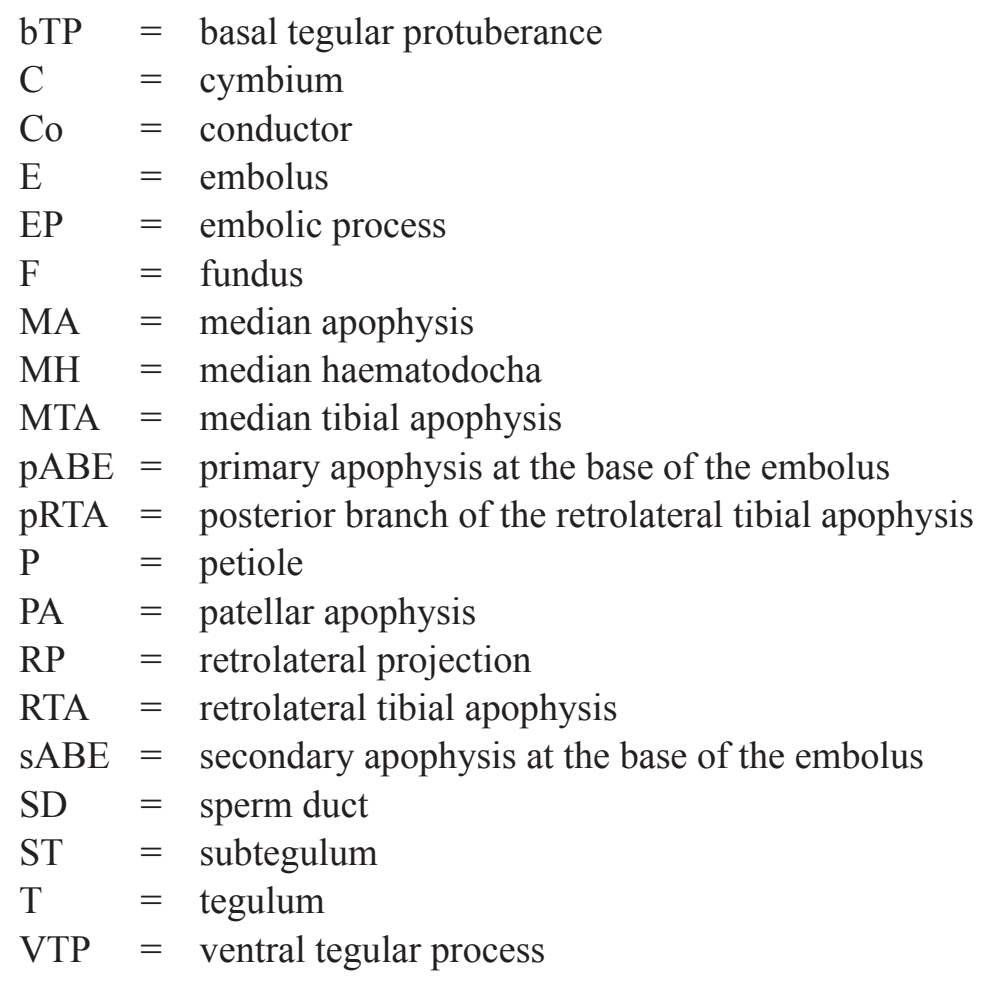

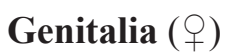

$\mathrm{A}=$ atrium

$\mathrm{AS}=$ atrial septum

$\mathrm{CD}=$ copulatory ducts

$\mathrm{CG}=$ cuticular glands

$\mathrm{CO}=$ copulatory opening

$\mathrm{FD}=$ fertilization ducts

$\mathrm{GD}=$ gland ducts

$\mathrm{LL}=$ lateral lobes (= borda lateral in Brescovit 1997: 11; lateral lobe in Ramírez 2003: 7)

$\mathrm{H}=\operatorname{hood}(=\mathrm{aba}$ in Brescovit 1997: 11; epigynal flap in Duppéré \& Tapia 2016: 4)

$\mathrm{S} 1$ = primary spermatechae

S2 = secondary spermathecae (= receptáculos seminais in Brescovit 1997: 12; accessory bulbs in Ramírez 2003: 7)

\section{Phylogenetic analysis}

All 16 recognized species in the genus Tafana (12 described in this work and 4 described previously), were included in the cladistic analysis. The outgroup selection was based on the phylogenetic hypothesis by Ramírez (2003) and taxonomic studies of Brescovit (1997) on Anyphaenidae. Arachosia praesignis (Keyserling, 1891) (Amaurobioidinae) was used to root the phylogeny. Our other outgroups consist of Anyphaena accentuata (Walckenaer, 1802), Patrera fulvastra (Simon, 1903), Aysha prospera (Keyserling, 1891) and Xiruana gracilipes (Keyserling, 1891), all Anyphaeninae. The list of material examined is available in Appendix 1.

A total of 43 parsimony-informative morphological characters were used (Appendix 2). They refer to the cephalothorax (3 characters), chelicerae (2), scopulae (1), spines (1), tracheae (1), male palp (6), copulatory bulb (15) and female genitalia (14). Sixteen of these characters were scored based on previous phylogenetic analyses by Ramírez $(2003,2014)$ and Azevedo et al. (2018). 
The characters were defined following Sereno (2007). They are all binary except for four multi-state, non-additive characters (Fitch 1971). The character matrix (Appendix 3) was constructed in Excel 2013, edited in Notepad++ and saved in TNT format. Non-applicable states were scored as '-' and unknown states as '?'.

Heuristic searches for the most parsimonious trees (MPTs) were carried out in TNT ver. 1.5 (Goloboff \& Catalano 2016), under equal weighting (EW) in "traditional search", with 300 being the number of additional sequences, followed by rounds of tree bisection reconnection (TBR) saving 100 trees per replication. To analyze concordance between characters and their effect on the tree topologies, we performed a sensitivity analysis (Goloboff 2008) on different values of the constant of concavity $(k)$ for implied weighting (IW). The similarity between topologies recovered by EW and IW (Appendix 3) was quantified using subtree pruning and regrafting (SPR-distances) (Goloboff 2008). Branch supports were estimated by Goodman-Bremer support (BS) (Goodman et al. 1982; Bremer 1988, 1994) and relative Bremer support (RB) (Goloboff \& Farris 2001), searching for suboptimal trees with 1-10 steps more than the MPTs and retaining 1000-10000 trees, respectively (sub 1 hold 1000; bb = tbr fillonly;

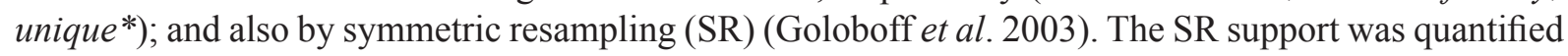
by means of 4000 pseudo-replicates with 4000 RAS followed by TBR, saving 100 trees per replication, with a probability of elimination $(\mathrm{P})=0.33$. Character optimization was performed in Winclada ver. 1.00.08 (Nixon 2002) and when state changes were ambiguous ACCTRAN (accelerated transformation) was utilized. The final topologies were modified for publication in Photoshop CS6.

\section{Results}

\section{Phylogeny}

In the analysis under equal weighing a most parsimonious tree was obtained with 106 steps $(\mathrm{CI}=47$; $\mathrm{RI}=61)$. The genus Tafana was recovered as a monophyletic group with support $(\mathrm{BS}=3, \mathrm{RB}=50 \%$, $\mathrm{SR}=45 \%$ ) (Fig. 1).

In the sensitivity analysis using different values of the concavity constant $(k)$ for implied weighting of characters, different $k$ values result in different numbers of MPTs and steps. These results are provided in Table 1.

The analysis under implied weighting resulted in four similar topologies (Fig. 2). The main difference between the trees involves the relationships and monophyly of Tafana orinoco sp. nov. and clade $\mathrm{G}$ (Figs 2, 5). We decided to choose the tree obtained with $k=7$, because it shares the highest number of nodes with the other trees and was considered the most stable (Figs 2, 5). The analysis with $k=7$ resulted in one MPT with total fit $27.319(\mathrm{CI}=0.46$; $\mathrm{RI}=0.60)$. Support values and sensitivity of this tree to concavity changes are presented in Figs 3 and 4. The synapomorphies of Tafana and its internal clades are listed in Table 2.

In the chosen tree $(k=7)$, and indeed in all tree topologies recovered in the sensitivity analysis, Tafana Simon, 1903 was recovered as a monophyletic group (Figs 4-5). The genus has five unambiguous synapomorphies. Four of these are exclusive synapomorphies (Fig. 5, Clade A): presence of an apophysis at the base of the embolus (character 23[1]); presence of an anterior fold with the posterior extension forming the lateral lobes (character 31[1], several reversals within the genus); the sinuous shape of lateral lobes of the epigynum (character 32[1]); region of epigynum covered by cuticle (character 36[1]). One is a homoplastic synapomorphy (Fig. 5, Clade A): primary spermathecae contiguous (character $38[0]$, several reversals within the genus).

Within Tafana, two reciprocally monophyletic species groups, including most species in the genus, were recovered: the silhavyi group and the riveti group. 
Table 1. Statistics obtained in the maximum parsimony phylogenetic analysis of different parameters. Abbreviations: $\mathrm{EW}=$ equal weights; $k=$ concavity constant; $\mathrm{MPT}=$ most parsimonious tree; $\mathrm{CI}=$ consistency index; RI = retention index.

\begin{tabular}{cccccc}
\hline $\begin{array}{c}\text { Parameter } \\
\text { of analysis }\end{array}$ & $\begin{array}{c}\text { Number of } \\
\text { MPTs }\end{array}$ & $\begin{array}{c}\text { Number of } \\
\text { steps }\end{array}$ & CI & RI & Total Fit \\
\hline EW & 1 & 106 & 0.47 & 0.61 & 23.135 \\
$k=1$ & 4 & 111 & 0.45 & 0.57 & 17.651 \\
$k=2$ & 2 & 108 & 0.46 & 0.60 & 21.160 \\
$k=3$ & 2 & 108 & 0.46 & 0.60 & 23.335 \\
$k=4$ & 2 & 108 & 0.46 & 0.60 & 24.800 \\
$k=5$ & 1 & 108 & 0.46 & 0.60 & 25.863 \\
$k=6$ & 1 & 108 & 0.46 & 0.60 & 26.673 \\
$k=7$ & 1 & 107 & 0.46 & 0.60 & 27.319 \\
$k=8$ & 1 & 107 & 0.46 & 0.60 & 27.844 \\
$k=9$ & 1 & 107 & 0.46 & 0.60 & 28.279 \\
$k=10$ & 1 & 107 & 0.46 & 0.60 & 28.645 \\
$k \geq 15$ & 1 & 106 & 0.47 & 0.61 & $29.870-32.456$ \\
\hline
\end{tabular}

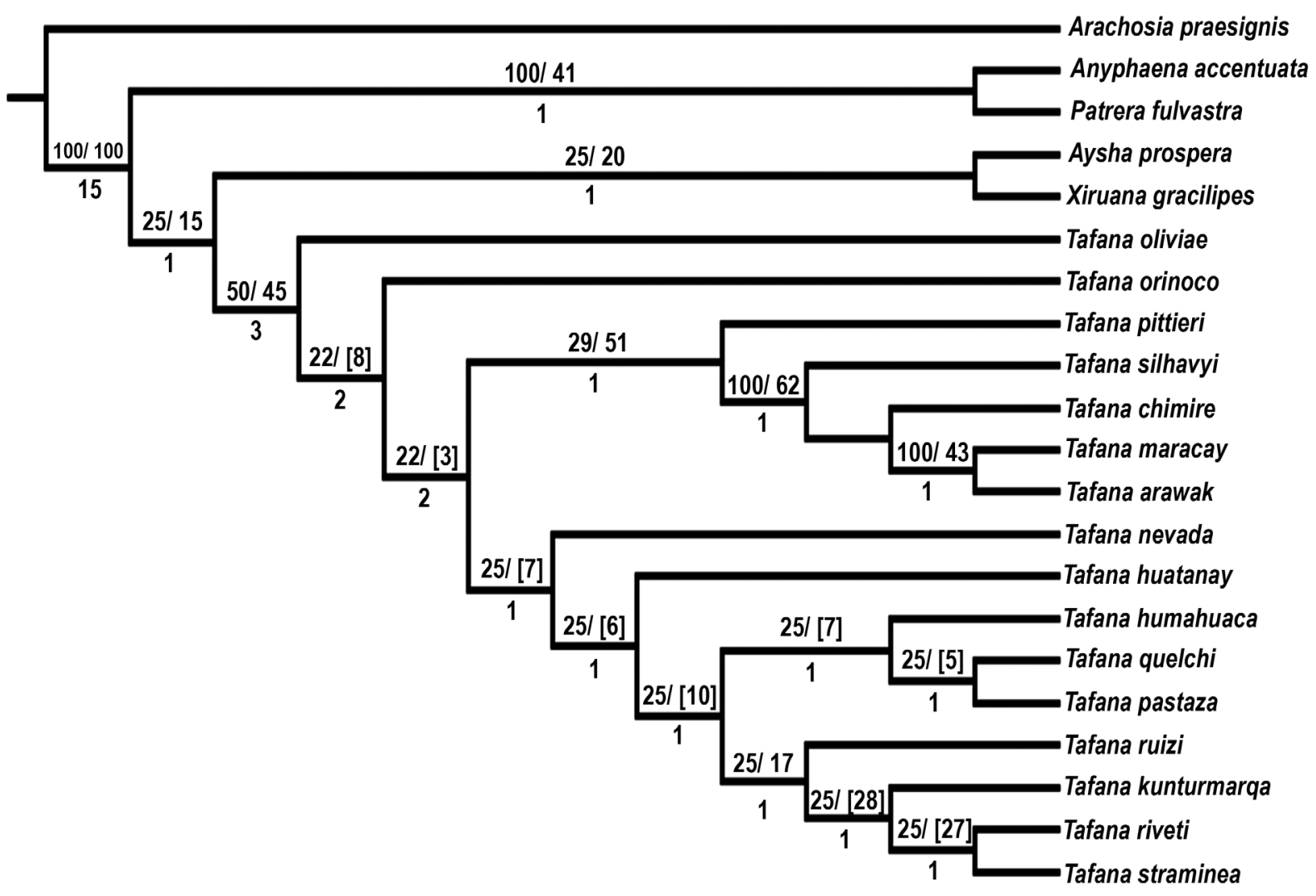

Fig. 1. The most parsimonious tree recovered under equal weights ( 106 steps, $C I=0.47, R I=0.61)$. Numbers above branches are relative Goodman-Bremer support values (left) and Symmetric resampling values (right). Numbers below branches are Goodman-Bremer values. 

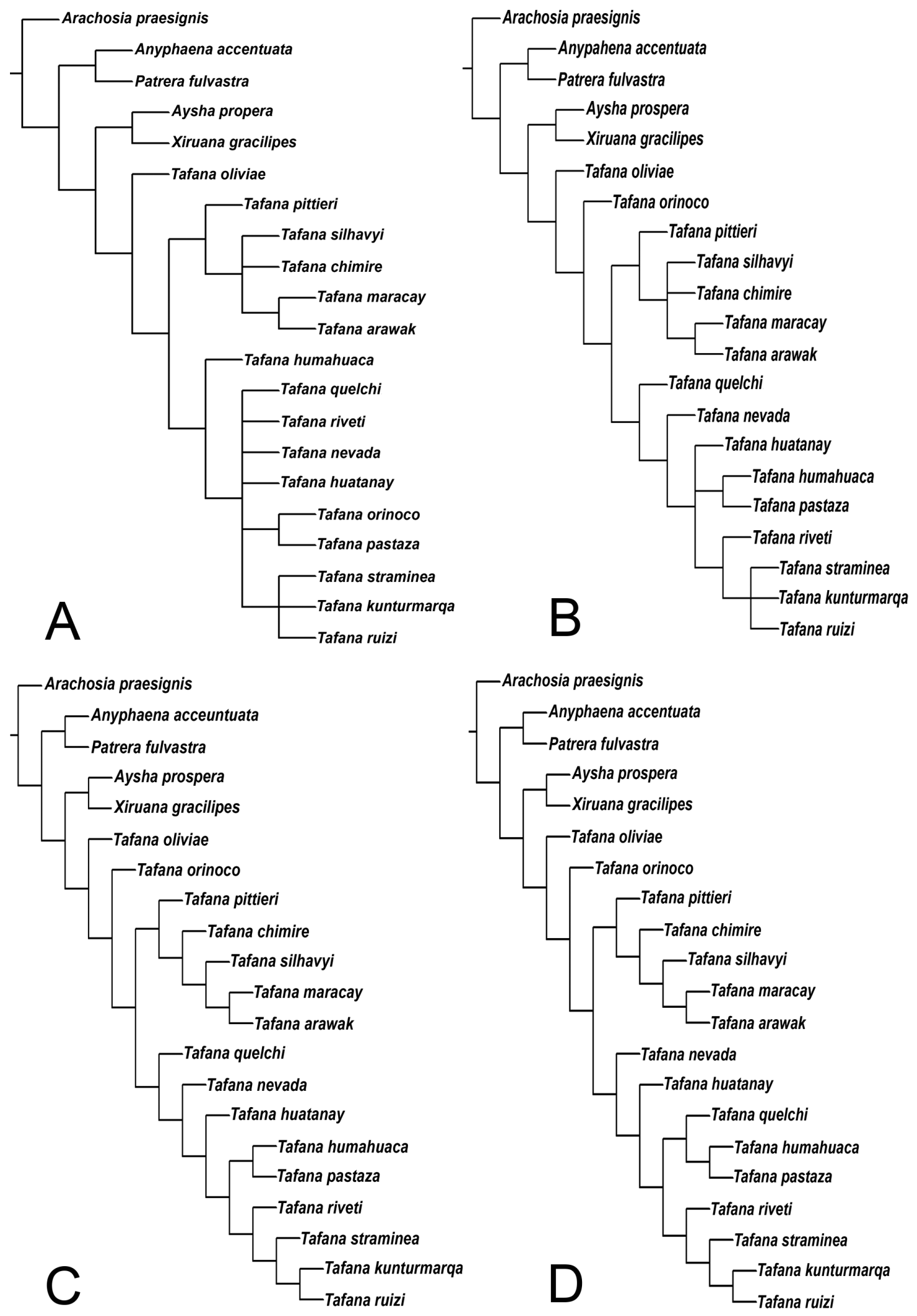

Fig. 2. Strict consensus of the most parsimonious trees obtained under implied weighting. A. Under $k=1(\mathrm{CI}=0.45, \mathrm{R}=0.57)$. B. $k=2-4(\mathrm{CI}=0.46, \mathrm{RI}=0.60)$. C. $k=5-10(\mathrm{CI}=0.46, \mathrm{RI}=0.60) . \mathrm{D}$. Under $k=15-100(\mathrm{CI}=0.47, \mathrm{IR}=0.61)$. 
Table 2. Non-homoplastic and homoplastic synapomorphies supporting the main relationships within the clades Anyphaeninae and Tafana (see Fig. 5).

\begin{tabular}{cc}
\hline Clade & Synapomorphies \\
\hline Anyphaeninae & Chelicerae, paturon, number of promarginal teeth (Ch. 4): three $\rightarrow$ four \\
Aysha + Xiruana & Palp, tibiae, median tibial apophysis (Ch. 11): absent $\rightarrow$ present \\
+ Tafana & Bulb, tegulum, embolic process (Ch. 21): absent $\rightarrow$ present \\
\hline
\end{tabular}

Bulb embolus, apophysis at the base of the embolus (Ch. 23): absent $\rightarrow$ present Epigynum, anterior fold, posterior extension forming the lateral fold (Ch. 31): absent $\rightarrow$ present

Tafana [A] Epigynum, shape of lateral lobes (Ch. 32): straight $\rightarrow$ sinuous

Epigynum, posterior region covered by cuticle (Ch. 36): absent $\rightarrow$ present

Vulva, primary spermathecae contiguous (Ch. 38): contiguous, up to $1 / 3$ diameter $\rightarrow$ separate, $1 / 2$ to 1 diameter

\begin{tabular}{|c|c|}
\hline Tafana $[\mathrm{B}]$ & $\begin{array}{l}\text { Palp, cymbium, retrolateral projection (Ch. 8): absent } \rightarrow \text { present } \\
\text { Vulva, secondary spermathecae (Ch. 42): irregular } \rightarrow \text { approximately rounded }\end{array}$ \\
\hline Tafana $[\mathrm{C}]$ & $\begin{array}{l}\text { Scopulae on anterior tibiae (Ch. 5): present } \rightarrow \text { absent } \\
\text { Palp, tibiae, median tibial apophysis (Ch. 11): present } \rightarrow \text { absent } \\
\text { Bulb, tegulum, ventral tegular process (Ch. 18): absent } \rightarrow \text { present }\end{array}$ \\
\hline Tafana $[\mathrm{D}]$ & 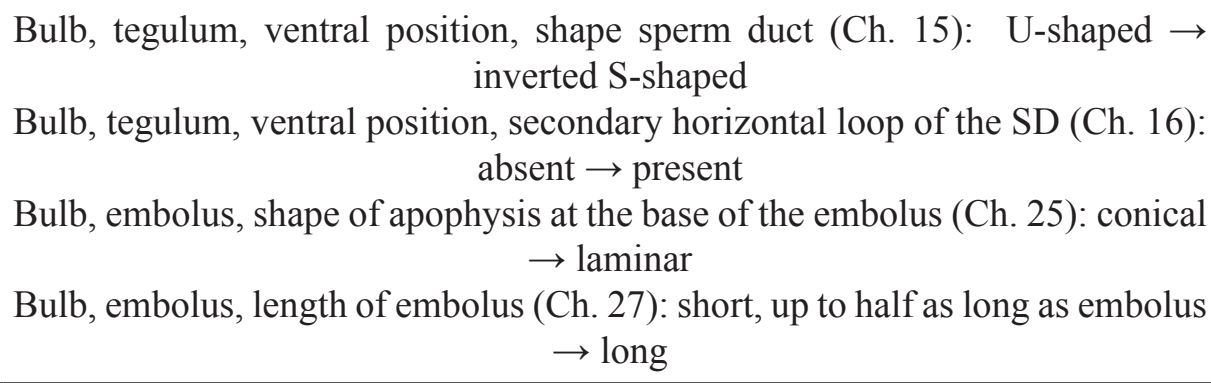 \\
\hline Tafana $[\mathrm{E}]$ & Bulb, tegulum, basal protuberance of tegulum (Ch. 17): absent $\rightarrow$ present \\
\hline Tafana $[\mathrm{F}]$ & $\begin{array}{l}\text { Chelicerae, paturon, number of promarginal teeth }(\mathrm{Ch} .4): \text { four } \rightarrow \text { five or more } \\
\text { Vulva, primary spermathecae contiguous (Ch. } 38) \text { : separate, } 1 / 2 \text { the } 1 \text { diameter } \\
\qquad \rightarrow \text { contiguous, up to } 1 / 3 \text { diameter }\end{array}$ \\
\hline Tafana $[\mathrm{G}]$ & $\begin{array}{l}\text { Bulb, tegulum, ventral tegular process, position (Ch. 19): apical margin of } \\
\text { tegulum } \rightarrow \text { near median apophysis } \\
\text { Vulva, primary spermathecae contiguous (Ch. } 38) \text { : separate, } 1 / 2 \text { to } 1 \text { diameter } \rightarrow \\
\text { contiguous, up to } 1 / 3 \text { diameter }\end{array}$ \\
\hline Tafana $[\mathrm{H}]$ & Epigynum, atrial septum (Ch. 35): absent $\rightarrow$ present \\
\hline
\end{tabular}

The silhavyi group presents one exclusive synapomorphy (Figs 4-5, Clade D): the laminar shape of the apophysis at the base of the embolus (character 25[1]), and three homoplastic synapomorphies: tegulum, ventral position, sperm duct an inverted S-shape (character 15[2]); tegulum, ventral position, secondary horizontal loop of the sperm duct present (character 16[1]); and long length of the embolus (character $27[0]$ ). This clade presents $\mathrm{RB}<50 \%$ (Fig. 3). The riveti group presents one exclusive synapomorphy (Figs 4-5, Clade G): ventral tegular process, positioned near median apophysis (character 19[1]), and one homoplastic synapomorphy, primary spermathecae contiguous (character 38[1]), convergent in other clades. This clade presents RB $>50 \%$ (Fig. 3). 
DE OLIVEIRA L.F.M. \& BRESCOVIT A.D., Revision and cladistis analysis of Tafana (Araneae)

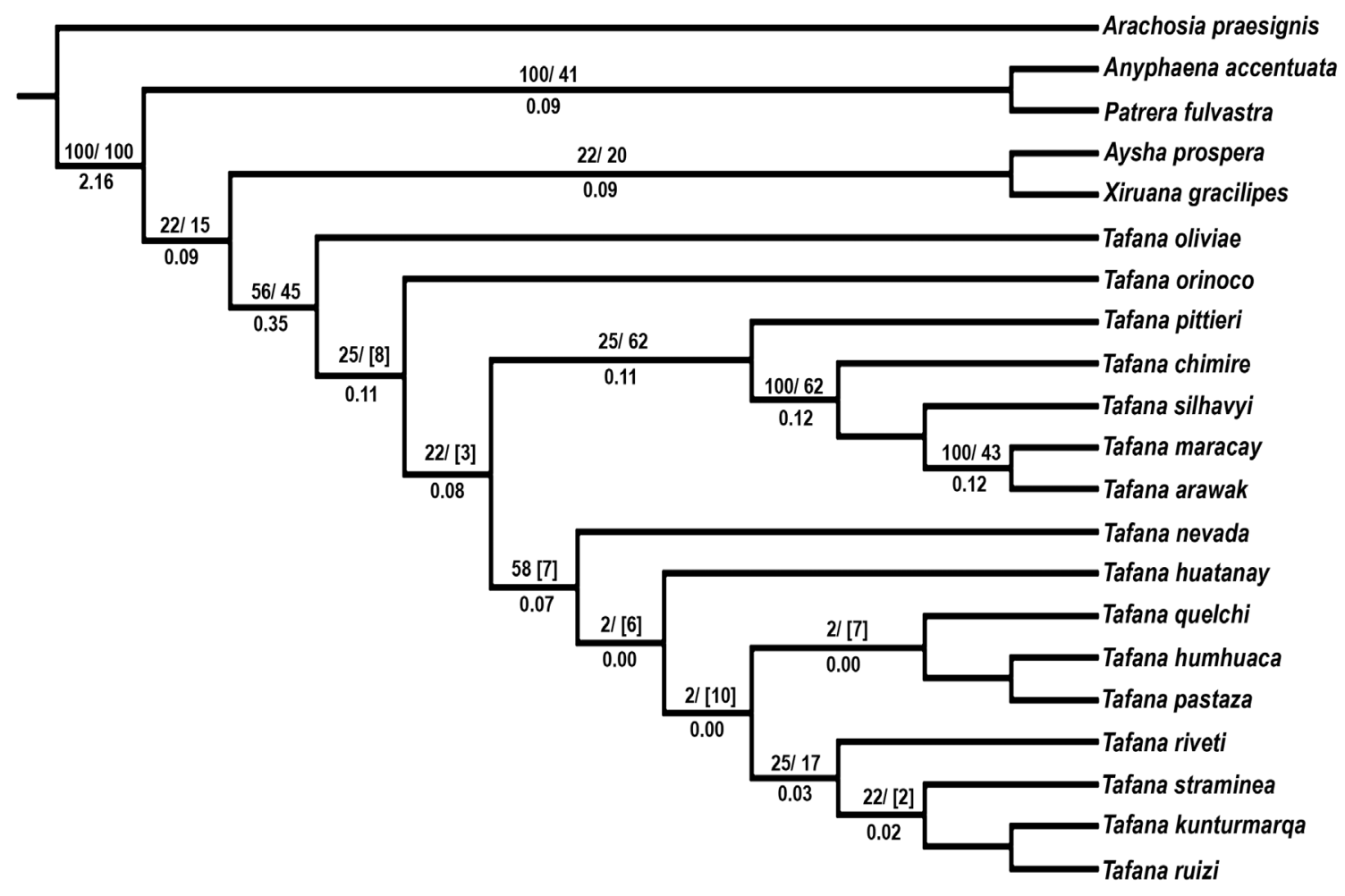

Fig. 3. Topology obtained under $k=7(\mathrm{CI}=0.46, \mathrm{RI}=0.60$, $\mathrm{Fit}=27.319)$. Numbers above branches are relative Goodman-Bremer values (left) and Symmetric resampling values (right). Numbers below branches are Goodman-Bremer support values.

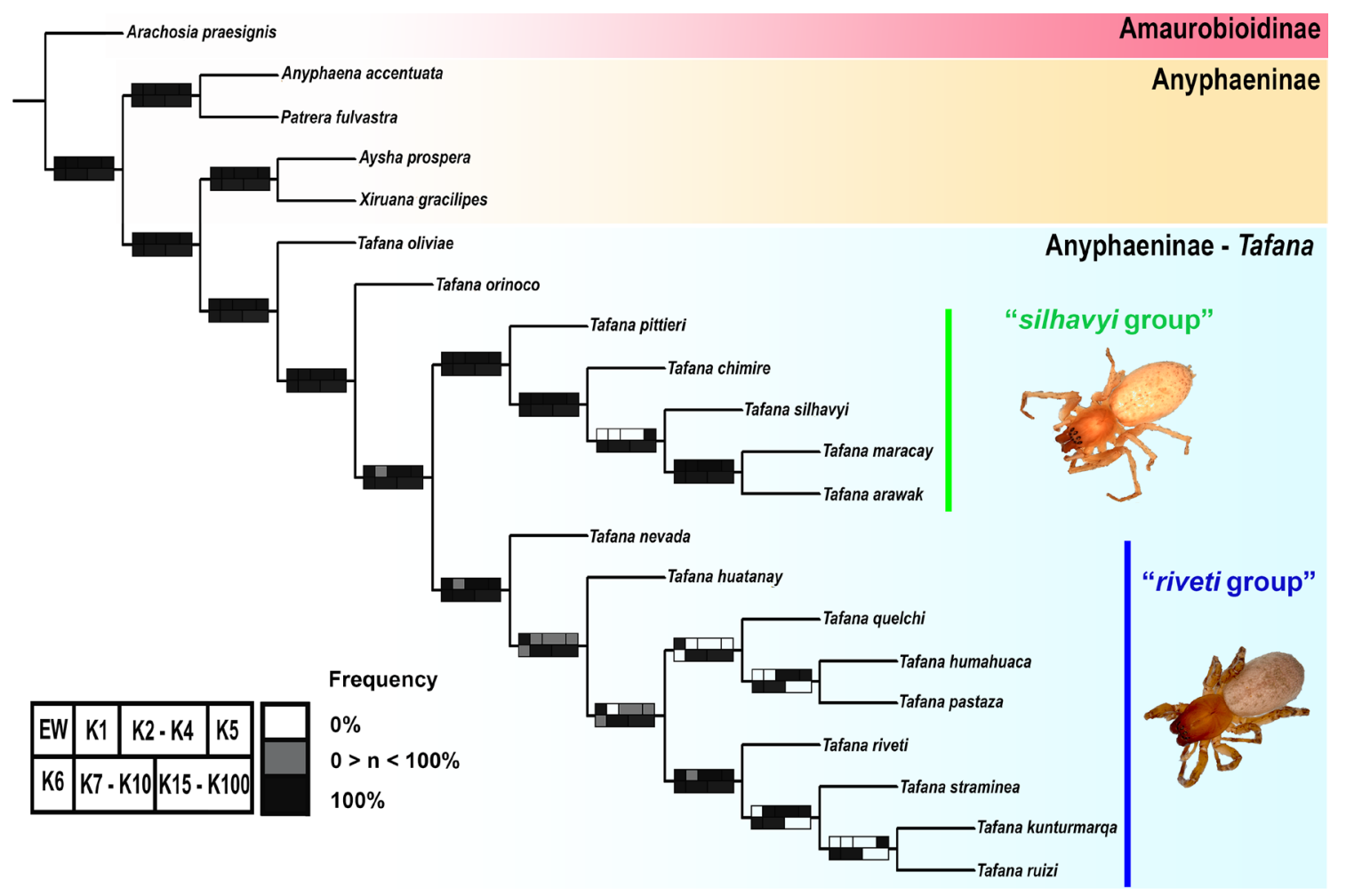

Fig. 4. Topology obtained under $k=7$ (Fit=27.319). The squares on the branches represent the sensitivity of the clade to different $k$ values. 


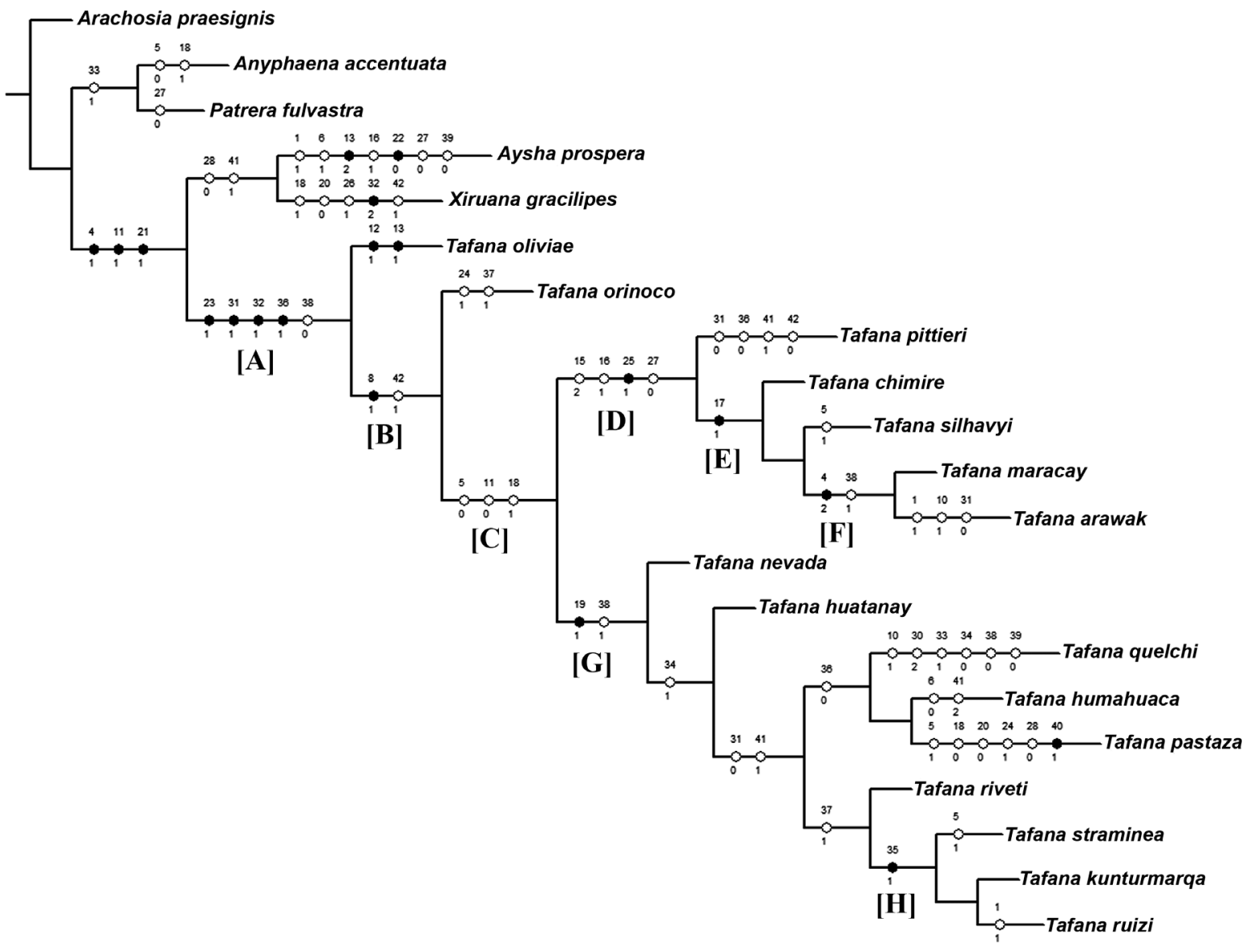

Fig. 5. Topology obtained under $k=7$. Black circles indicate non-homoplastic synapomorphies. White circles indicate homoplastic synapomorphies. The code number of each character is indicated above and its respective state below. Letters denote clade names as referred to in the text.

\section{Taxonomy}

Class Arachnida Cuvier, 1812

Order Araneae Clerck, 1757

Family Anyphaenidae Bertkau, 1878

Subfamily Anyphaeninae Bertkau, 1878

Genus Tafana Simon, 1903

Tafana Simon, 1903:124 (type species by original designation: T. riveti Simon, 1903: 124).

Tafana-Petrunkevitch 1911: 514; 1928: 174. — Roewer 1954: 546. — Bonnet 1959: 4232. — Brescovit 1997: 80, 90, figs 225-238.

\section{Diagnosis}

Males of species of the genus Tafana resemble those of the genera Aljassa Brescovit, 1997, Aysha Keyserling, 1891, Hibana Brescovit, 1991, Hatitia Brescovit, 1997, Osoriella Mello-Leitão, 1922, Pippuhana Brescovit, 1997, Temnida Simon, 1896, Umuara Brescovit, 1997 and Xiruana Brescovit, 1997 by having an embolic process in the internal male palp (see Brescovit 1997: 176-187, figs 221, 
247, 265, 272, 280), an apophysis at the base of the embolus (see Oliveira \& Brescovit 2015a: 209, fig. 5a-b) and further resemble Umuara by having a ventral tegular process near the median apophysis in the male palp (see Oliveira \& Brescovit 2015b: 438, figs 2a-b), but differ by the presence of a conical or coiled laminar apophysis at the base of the embolus (Figs 9C-F, 12B, C, 23B, 26A-B). The females resemble those of Anyphaena, Patrera Simon, 1903, Iguarima Brescovit, 1997, Umuara and Pippuhana (see Brescovit 1997: 139-187), by having a hood on the anterior fold of the epigynum, but differ by having the posterior extension forming the lateral lobes (Figs 7D, 10F, 22F, 32E-F, 33D-E), lateral lobes sinuous (Figs 17F, 19F) and posterior region of the epigynum covered by cuticle (Figs 10F, 17F, 21F).

\section{Description}

Body from pale white to orange and reddish brown (Figs 10A, 11A, 22A). Legs orange or pale and darker at tarsi (Figs 22B, 25A). Carapace sub-rectangular, narrow in anterior region, and enlarged near coxae I-III, cephalic region high, highest behind the posterior eye row (Figs 8A, 10A). Eyes, in dorsal view, anterior row slightly recurved and posterior row procurved (Figs $8 \mathrm{~A}, 10 \mathrm{~B}$ ). Chelicerae robust and projected, with vertical length approximately half the length of the carapace, basal condyle conspicuous (Fig. 11A-B), with 3-5 promarginal teeth and 4-7 retromarginal (Fig. 8B). Two rows of trichobothria with striated base in dorsal view on the metatarsus and tarsus I-IV (Fig. 8J). Tarsal organ with teardrop shape on the distal region of tarsus and male palp (Figs 8I, 20D), slit sensilla elongated on the tarsus (Fig. 8K). Paired tarsal claws with 8-14 teeth (Fig. 8G-H). Male palp: patellar apophysis short and rounded (Figs 10D, 16D-E, 24D); distal prolateral tibial apophysis short (Fig. 13C, E); retrolateral tibial apophysis with large base and conical apex (Fig. 22D-E), usually exhibiting anterior branches and posterior branches (Fig. 13C-D) or only one branch (Figs 10D, 11D, 24D-E); median tibial apophysis branched (Fig. 29D-E) or unique (Fig. 30D-E); cymbium oval with retrolateral projection (Figs 9A-B, $10 \mathrm{C}, 12 \mathrm{~A}, 22 \mathrm{C}, 26 \mathrm{~A}, \mathrm{C})$, with small furrow under this projection, to accommodate the retrolateral tibial apophysis, or without (Figs 29C, 30C); chemosensory setae on the cymbium (Fig. 20D); subtriangular and ypsiloid petiole (Fig. 9C-D, F); subtegulum with 5-6 semicircular rings, short and exposed distal projection on the prolateral side on the palp when not expanded (Fig. 9D-E); tegulum with ventral tegular process narrow near the median apophysis (Figs 9B, 10C, 12B-C, 18B) and bordering the apex of the tegulum (Figs 9A, 22C, 26A-B, 28C); sclerotized median apophysis long, sharp and with a curved apex (Figs 18B, 20B, 23C); embolic process conical, sclerotized, covered by the tegulum, inserted at the base of the embolus (Fig. 9C-F); sperm duct presenting four or five loops in palp expanded (Fig. 9C-F) and in palp not expanded three loops in ventral view (Fig. 9A-B), internally traversing the embolic process reaching the embolus (Fig. 9E); embolus long (Figs 9D, 22C, 24C) or short (Figs 10C, 15C, 17C), filiform helical and curved retro-apically, connected to the embolic process (Figs 9D-E, 15C, 22C); apophysis at the base of the embolus, conical (Figs 9B, E, 10C, 12C, 18A-B) or laminar (Figs 23B, 24C, 26A-B). Oval abdomen, tracheal spiracle curved in the middle of the abdomen in ventral view (Figs 7B, 8L); anterior spinnerets bisegmented, with basal article large and distal article circular, with several spigots of piriform gland and one spigot of the ampullate gland (Fig. 8C-D); median spinnerets unsegmented, with several spigots of the aciniform gland and not presenting spigots of the cylindrical gland (Fig. 8C, E); posterior spinnerets bisegmented with basal and distal article cylindrical, one third longer than the others, with several spigots of the aciniform gland and one spigot of the ampullate gland without spigots of the cylindrical gland (Fig. 8C, F); colulus substituted by $8-10$ setae (Fig. 8C). Epigynum with sinuous lateral lobes, lobe parallel in the posterior region (Figs 10F, 22F); hood approximately triangular (Figs 10F, 16F, 25F, 27F), semicircular (Figs 11F, 14F, 32D) or circular (Figs 15F, 17F, 30F, 32J, 33G$\mathrm{H})$ in the anterior region; posterior region with cuticle covered the lateral lobes (Figs $10 \mathrm{~F}, 11 \mathrm{~F}, 17 \mathrm{~F}, 21 \mathrm{~F}$, $27 \mathrm{~F}$ ) or without (Figs 13F, 15F, 16F, 28F); atrium with septum in the anterior region (Figs 11F, 14F, 21F) or without (Figs 13F, 15F, 22F, 25F); copulatory ducts sinuous (Figs 10G, 11G, 19G, 32F-I) or coiled (Figs 13G, 16G, 32H, K), running along margin of the lateral lobes, reaching the spermathecae, visible through transparency; secondary spermathecae rounded (Figs 10G, 11G, 14G, 32F-G, I, 33B-C) but may be irregular or inconspicuous (Figs 13G, 28G, 29G, 32H, 33F-G); secondary spermathecae short, 

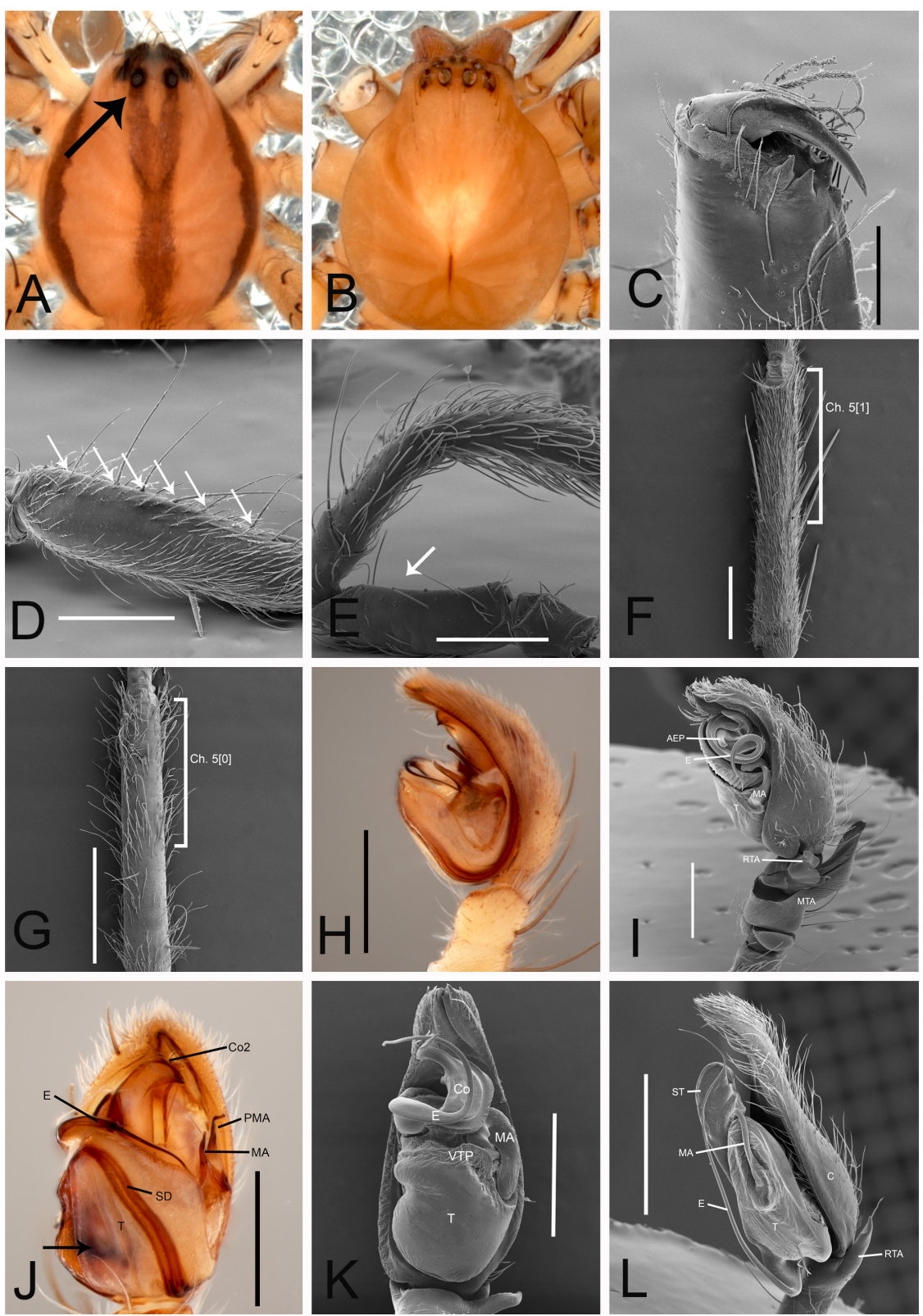

Fig. 6. A. Arachosia praesignis (Keyserling, 1891), Ô, cephalothorax, dorsal view (arrow shows row of the eyes) (IBSP 87975). B. Patrera fulvastra Simon, 1903, ô, cephalothorax, dorsal view (MCN 24207). C. Arachosia praesignis, $\widehat{0}$, chelicera, ventral view (IBSP 87975). D. Aysha prospera Keyserling, 1891, q, palp femur, prolateral view (arrows show setal row) (IBSP 19780). E. Tafana silhavyi (Caporiacco, 1955),, , prolateral view (arrow indicating the absence of setae) (MNHN 11312).

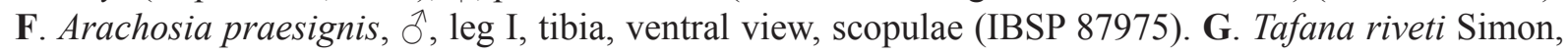
1903, đ̂, leg I, tibia, ventral view, scopulae (MCZ). H. Arachosia praesignis, ô, palp, retrolateral view (IBSP 87975). I. Aysha prospera, ô, palp, retrolateral view (IBSP 38914). J. Arachosia praesignis, ठิ, palp, ventral view (arrow shows the basal notch on the tegulum) (IBSP 87975). K. Xiruana gracilipes (Keyserling, 1891), Ô, palp, ventral view (IBSP 72660). L. Patrera fulvastra, đ, palp, retrolateral view ( $\mathrm{MCN}$ 24207). Abbreviations: $\mathrm{AEP}=$ apophysis of embolic process; $\mathrm{C}=$ cymbium; $\mathrm{Co}=$ conductor; $\mathrm{Co} 2=$ secondary conductor; $\mathrm{E}=$ embolus; $\mathrm{MA}=$ median apophysis; $\mathrm{MTA}=$ median tibial apophysis; $\mathrm{PMA}=$ paramedian apophysis; $\mathrm{RTA}=$ retrolateral tibial apophysis; $\mathrm{SD}=$ sperm duct; $\mathrm{ST}=$ subtegulum; $\mathrm{T}=$ tegulum; $\mathrm{VTP}=$ ventral tegular process. Scale bars: $\mathrm{C}=0.2 \mathrm{~mm} ; \mathrm{D}, \mathrm{K}=0.4 \mathrm{~mm} ; \mathrm{E}=0.3 \mathrm{~mm}$; $\mathrm{F}$, $\mathrm{H}-\mathrm{J}=0.5 \mathrm{~mm} ; \mathrm{G}, \mathrm{L}=1 \mathrm{~mm}$. 
near the primary spermathecae (Figs 15G, 17G, 22G, 26D, 32F, J, L), wide (Figs 11G, 13G, 14G, 32G, I) or in the middle of the copulatory ducts (Figs 16G, 21G, 29G, 32K, 33G); primary spermathecae oval, positioned together (Figs 10G, 15G, 20E, 22G, 26D, 32F-G) or separated from each other by almost a third of their diameter (Figs 13G, 28G, 29G, 33F-H); fertilization ducts near the epigastric furrow, originating from base of spermathecae (Figs 10G, 11G, 20E, 22G, 26D, 29G, 32F-L, 33A-H).

\section{Diagnosis}

\section{The riveti group}

Males of this group resemble those of the silhavyi group by the apophysis at the base of the embolus, but differ by presenting an apophysis at the base of the embolus that is short and conical (Fig. 12B-C); the sperm ducts are 'U-shaped' in the male palp when it is not expanded (Figs 9B, 10C). The females can be recognized by the short atrium, presenting a septum or not, and copulatory ducts narrow (Figs 10F-G, $11 \mathrm{~F}, 15 \mathrm{~F}-\mathrm{G})$.
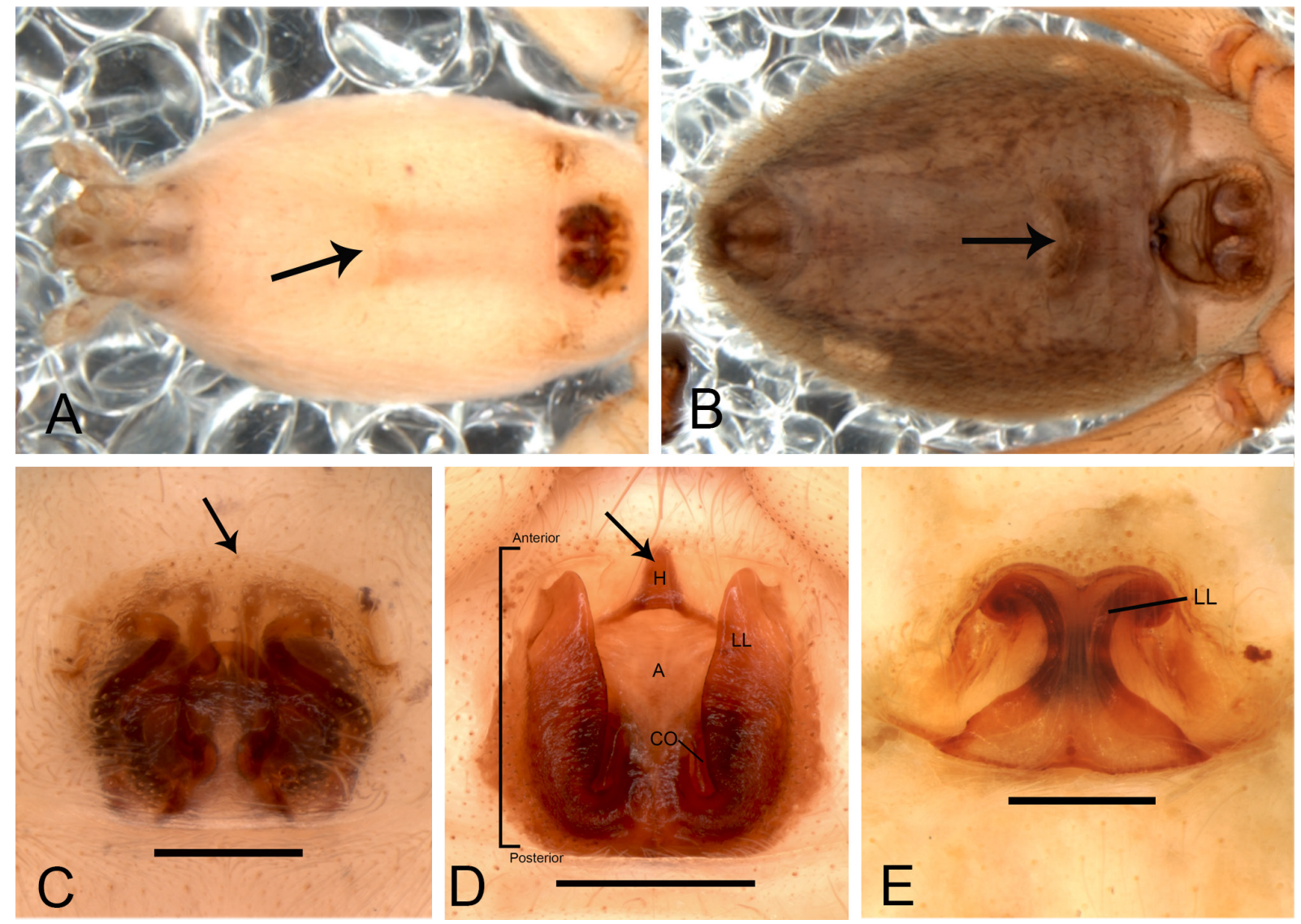

Fig. 7. A. Arachosia praesignis (Keyserling, 1891),, , abdomen, ventral view (arrow indicating position of tracheal spiracle) (IBSP 87975). B. Aysha prospera Keyserling, 1891, + , abdomen, ventral view (arrow indicating position of tracheal spiracle) (IBSP 19783). C. Arachosia praesignis, epigynal plate, dorsal view (arrow indicates the absence of a hood) (IBSP 87975). D. Patrera fulvastra Simon, 1903, epigynal plate, dorsal view, (arrow indicates the hood) (MCN 24208). E. Xiruana gracilipes (Keyserling, 1891), epigynal plate, dorsal view (IBSP 166120). Abbreviations: $A=$ atrium; $\mathrm{CO}=$ copulatory opening; $\mathrm{H}=$ hood; $\mathrm{LL}=$ lateral lobes. Scale bars: $\mathrm{D}=0.6 \mathrm{~mm}$;, $\mathrm{E}=0.25 \mathrm{~mm}$. 

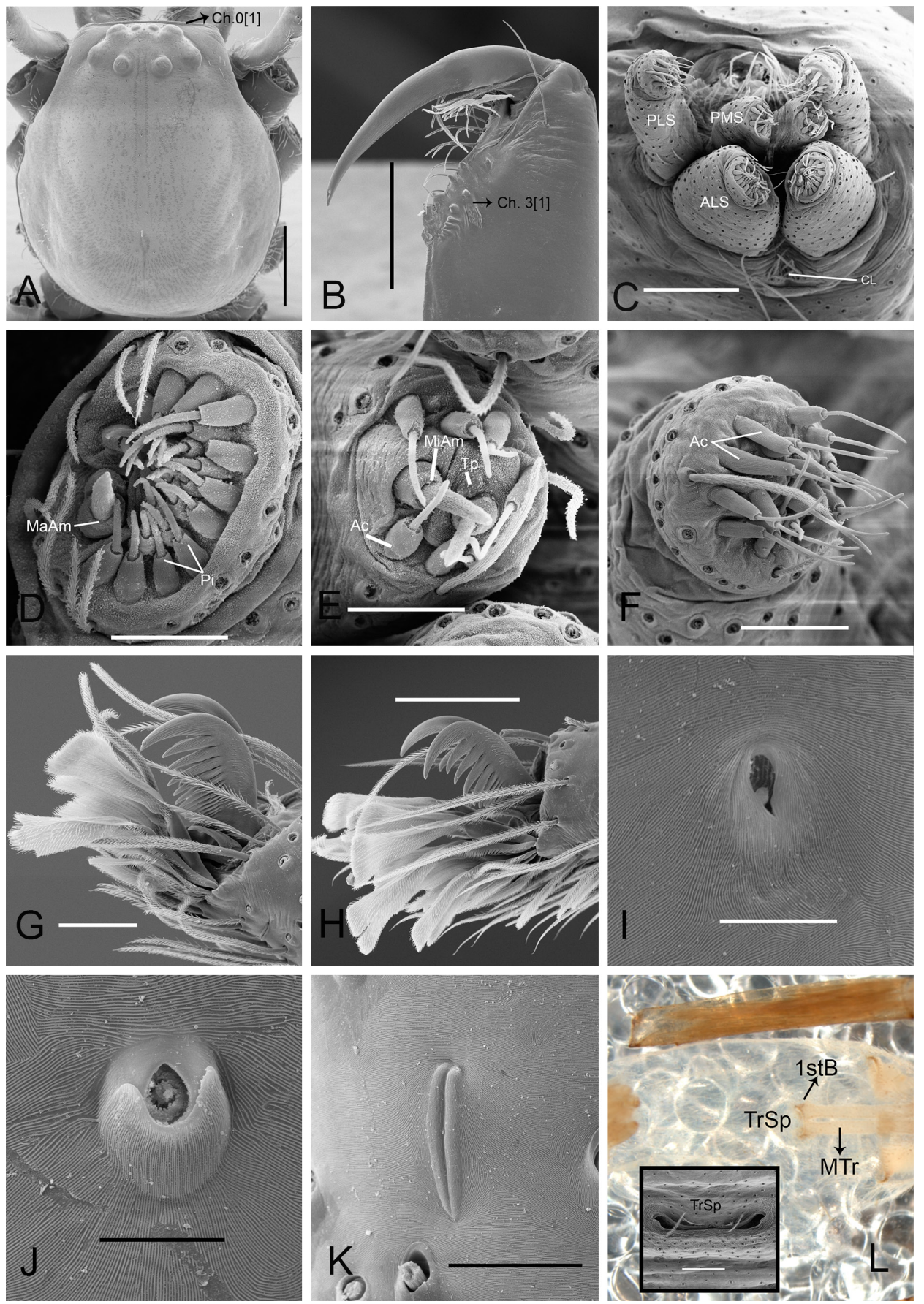

Fig. 8. A-B, G-K. Tafana silhavyi (Caporiacco, 1955), ð̊ (MNHN 11312). A. Cephalothorax, dorsal view. B. Chelicera, ventral view. G. Claws, tarsus I, prolateral view. H. Claws, tarsus IV, prolateral view. I. Tarsal organ, dorsal view. J. Tricobothrium, dorsal view. K. Slit sensilla, dorsal view. - C-F. Tafana maracay sp. nov. (MNHN 11314), ․ C. Spinnerets, frontal view. D. Anterior lateral spinneret. E. Posterior median spinneret. F. Posterior lateral spinneret. - L. Tafana pastaza sp. nov. (AMNH), $\hat{\jmath}$, abdomen, tracheal system, ventral view. Abbreviations: $\mathrm{Ac}=$ aciniform gland spigot; $\mathrm{ALS}=$ anterior lateral spinnerets; $\mathrm{CL}=$ colulus; $\mathrm{Ch}=$ character; $\mathrm{MaAm}=$ major ampullate gland spigot; $\mathrm{MiAm}=$ minor ampullate gland spigot; $\mathrm{MTr}=$ median tracheae; $\mathrm{PLS}=$ posterior lateral spinnerets; $\mathrm{PMS}=$ posterior median spinnerets; $\mathrm{Pi}=$ piriform gland spigot; $\mathrm{Tp}=$ tartipore; $\mathrm{TrSp}=$ tracheal spiracle; $1 \mathrm{stB}=$ first bifurcation of median trachea. Scale bars: $A=0.5 \mathrm{~mm} ; B=0.3 \mathrm{~mm} ; C=0.2 \mathrm{~mm} ; \mathrm{D}-\mathrm{E}=0.04 \mathrm{~mm}$; $\mathrm{F}-\mathrm{G}=0.05 \mathrm{~mm} ; \mathrm{H}-\mathrm{J}=0.01 \mathrm{~mm} ; \mathrm{K}=0.02 \mathrm{~mm}$. 


\section{Included species}

Tafana riveti Simon 1903, T. straminea (L. Koch 1866), T. quelchi (Pocock 1895), T. kunturmarqa sp. nov., T. humahuaca sp. nov., T. pastaza sp. nov., T. nevada sp. nov., T. huatanay sp. nov. and T. ruizi sp. nov.

Tafana riveti Simon, 1903

Figs 6G, 9B, E-F, 10, 32F, 34

Tafana riveti Simon, 1903: 124.

Tafana riveti - Berland 1913: 105, figs 91-96 (descr. of male). — Roewer 1954: 546. — Bonnet 1959: 4232. - Brescovit 1997: 90, figs 225-238.

\section{Diagnosis}

Males of Tafana riveti resemble those of $T$. straminea, T. kunturmarqa sp. nov., T. humahuaca sp. nov. and T. nevada sp. nov., by the apophysis at the base of the embolus short, but differ by retrolateral tibial apophysis short and with large base in retrolateral view and visible subtegulum on palp when not expanded (Fig. 10C-E). Females differ from those of other species by the short atrium, triangular hood and lateral lobe curved in the anterior region and sclerotized (Fig. 10F).

\section{Material examined}

\section{Holotype}

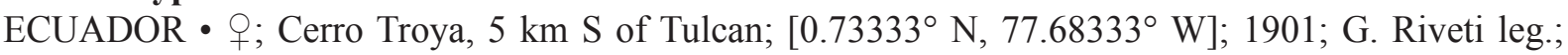
MNHN.

\section{Other material}

COLOMBIA - Valle del Cauca - 1 đo, Lago Calima; [353'44" N, 76²9'41" W]; Jan. 1979; W. Eberhard leg.; MCZ. - Magdalena • 1 O$^{\top}$; Sierra Nevada de Santa Marta; [1053'27.3" N, 7359'43.9" W]; 28 Sep. 2017; L. Martínez leg.; IBSP 223307.

ECUADOR - Quito • 1 क ; Pichincha, Monte Pichincha; [0¹5'00" S, 78 35'00" W]; Oct.1944; G.W.

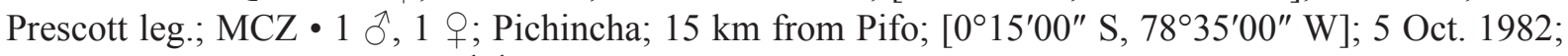

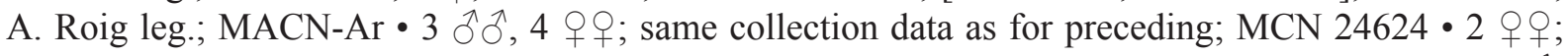

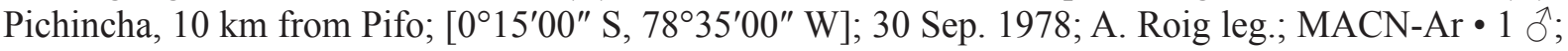
Pichincha, Eucalyptus forest; [ $0^{\circ} 15^{\prime} 00^{\prime \prime}$ S, $78^{\circ} 35^{\prime} 00^{\prime \prime}$ W]; 30 Sep. 1978; A. Roig leg.; MACN-Ar • $1{ }^{\top}$;

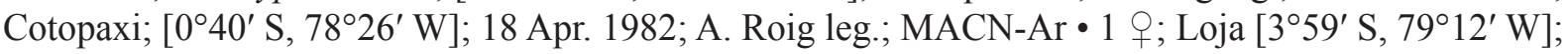
21-22 Aug. 1977; L.E. Peña leg.; AMNH • 1 o; Azuay; [253'57" S, 7900'55" W]; 20 Aug. 1988;

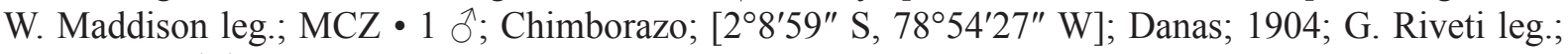
MNHN・ 2 ô $^{\wedge}$; Casitagua; [320'00" S, 78²9'00" W]; 1903; G. Riveti leg.; MNHN.

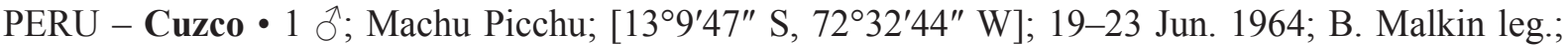
AMNH.

\section{Remark}

The type locality of Cerro Troya, $5 \mathrm{~km}$ south of Tulcan was defined using a database of Wharton Lab, Department of Entomology, Texas A\&M University from http://mx.speciesfile.org/projects/8/public/public_content/show/21273?content_template_id=88.

\section{Description}

Male and female described by Brescovit (1997: 90, figs 225-238). 

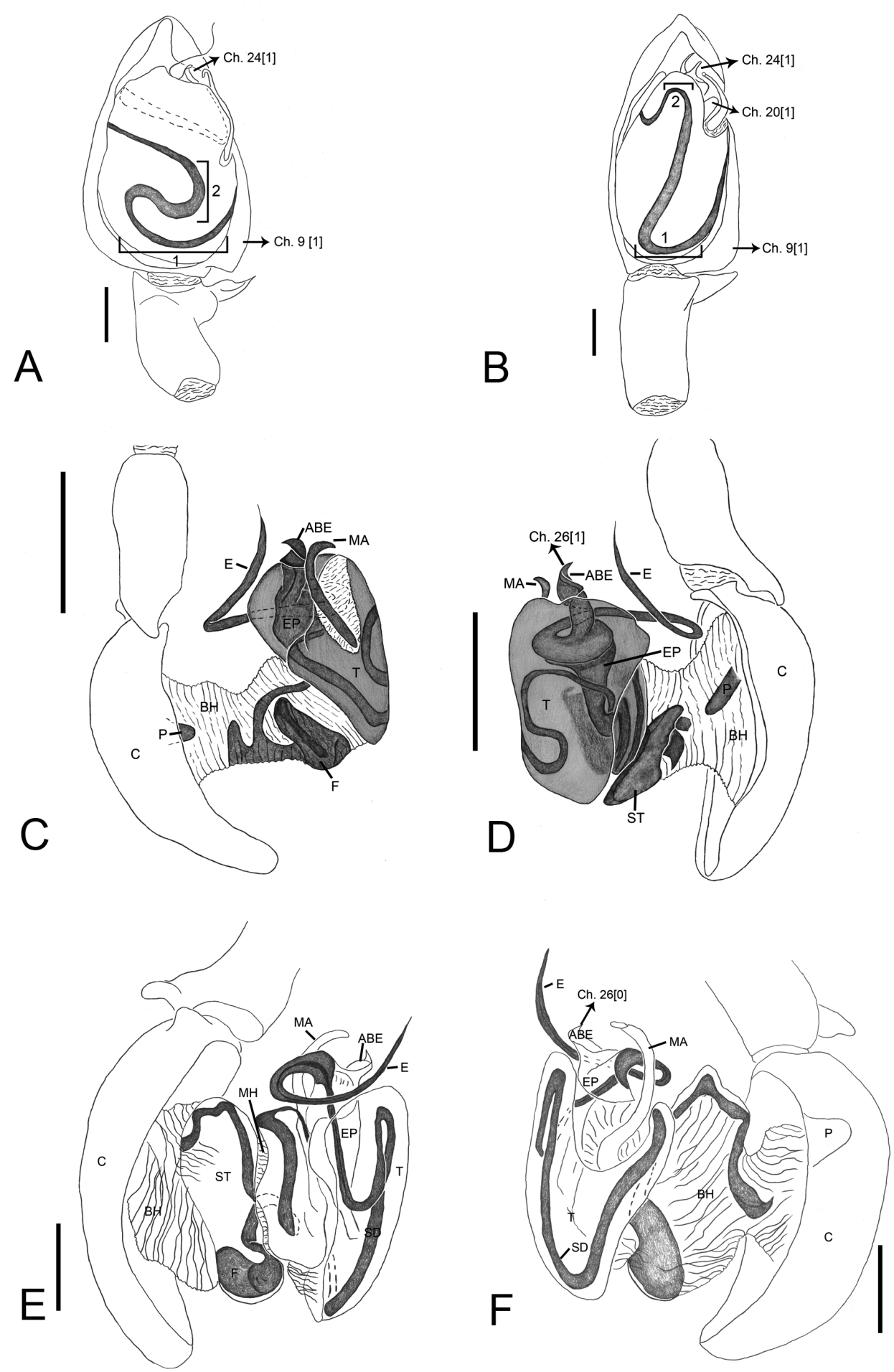

Fig. 9. A, C-D. Tafana silhavyi (Caporiacco, 1955), ð (MNHN 11312). A. Left palp unexpanded, ventral view (arrow indicating character). C. Left palp expanded, prolateral view. D. Left palp expanded, retrolateral view (arrow indicating character). B. Tafana riveti (MCZ), ô, left palp. E-F. Tafana riveti (MCZ), $\widehat{~}$. E. Left palp, retrolateral view. F. Left palp, prolateral view (arrow indicating character). Abbreviations: $1=$ primary loop of the sperm duct; $2=$ secondary loop of the sperm duct; $\mathrm{ABE}=$ apophysis of base of the embolus; $\mathrm{BH}=$ basal haematodocha; $\mathrm{C}=$ cymbium; $\mathrm{Ch}=$ character; $\mathrm{E}=$ embolus; $\mathrm{EP}=$ embolic process; $\mathrm{F}=$ fundus; $\mathrm{MA}=$ median apophysis; $\mathrm{MH}=$ median haematodocha; $\mathrm{P}=$ petiole; $\mathrm{SD}=$ sperm duct; $\mathrm{ST}=$ subtegulum; $\mathrm{T}=$ tegulum. Scale bars: $\mathrm{A}-\mathrm{B}, \mathrm{E}-\mathrm{F}=0.25 \mathrm{~mm} ; \mathrm{C}-\mathrm{D}=0.5 \mathrm{~mm}$. 


\section{Distribution}

Colombia, Peru and Ecuador (Fig. 34).

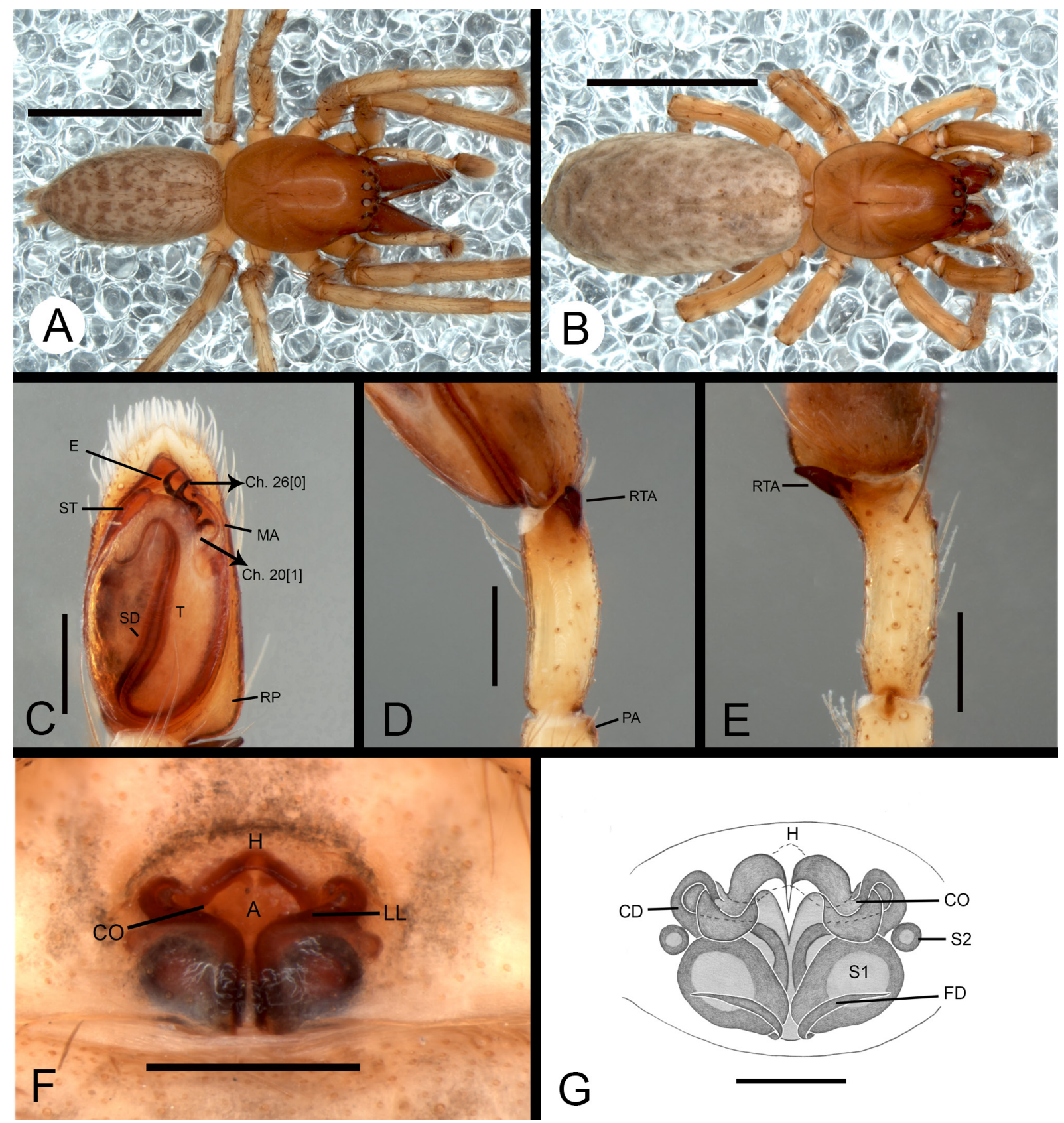

Fig. 10. Tafana riveti Simon, 1903 (A, C-E= $\hat{O}, \mathrm{MCZ} ; \mathrm{B}, \mathrm{F}-\mathrm{G}=+, \mathrm{MCZ}$ ). A. Habitus, dorsal view. B. Habitus, dorsal view. C. Left palp, ventral view (arrow indicating character). D. Left palp, retrolateral view. E. Left palp, dorsal view. F. Epigynum, ventral view. G. Vulva, dorsal view. Abbreviations: $\mathrm{A}=$ atrium; $\mathrm{Ch}=$ character; $\mathrm{CD}=$ copulatory ducts; $\mathrm{CO}=$ copulatory opening; $\mathrm{E}=$ embolus; $\mathrm{FD}=$ fertilization ducts; $\mathrm{H}=$ hood; $\mathrm{LL}=$ lateral lobes; $\mathrm{MA}=$ median apophysis; $\mathrm{PA}=$ patellar apophysis; $\mathrm{RP}=$ retrolateral projection; $\mathrm{RTA}=$ retrolateral tibial apophysis; $\mathrm{SD}=$ sperm duct; $\mathrm{ST}=$ subtegulum; $\mathrm{S} 1=$ primary spermathecae; $\mathrm{S} 2=$ secondary spermathecae; $\mathrm{T}=$ tegulum. Scale bars: $\mathrm{A}-\mathrm{B}=3.5 \mathrm{~mm}, \mathrm{C}-\mathrm{E}$, $\mathrm{G}=0.25 \mathrm{~mm}, \mathrm{~F}=0.4 \mathrm{~mm}$. 
Tafana straminea (L. Koch, 1866)

Figs 11-12, 32G, 34

Anyphaena straminea L. Koch, 1866: 207 (type: immature holotype from Santa Fé de Bogota, currently Bogotá, Colombia, deposited in BMNH, examined).

Tafana straminea - Brescovit 1997: 90.

\section{Diagnosis}

Males of Tafana straminea differ from those of other species by the long embolus and the secondary looping of sperm duct not reaching the border of the tegulum (Figs 11C, 12A-C). Females resemble those of T. kunturmarqa sp. nov. and T. ruizi sp. nov. by the epigynal plate shape with an atrial septum, but differ by the wide atrial septum and long fertilization ducts, ventrally overlapping the primary spermathecae (Figs 11F-G, 32G).

\section{Material examined}

\section{Holotype}

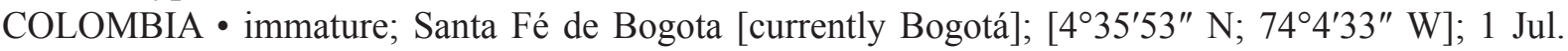
1890; BMNH 1890.7.1.583.

\section{Other material}

COLOMBIA - Boyacá • 1 đ̊; Tunja, Páramo Alto Belén; [559'22" N, 7254'44" W]; 23 Sep. 1985; H. Sturn leg.; MCZ. - Cundinamarca - 1 đ̃; Monte Redondo, La Calera, National Park Chingaza;

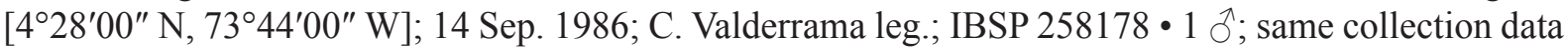
as for preceding; IBSP $258180 \bullet 1$ q ; same collection data as for preceding; IBSP 258181.

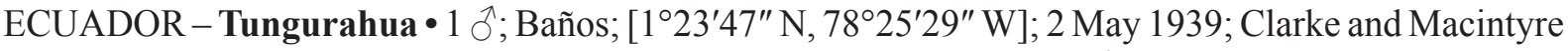
leg.; AMNH・ 2 우; same collection data as for preceding; AMNH・ 1 §; Apr. 1939; AMNH.

\section{Remark}

The holotype is an immature in last instar. In comparison with other adult specimens from Colombia, we noticed that the reddish brown color of the carapace is unique for this species. The spots on the abdomen and spination of the legs are similar. Therefore, we consider here that these specimens represent the adults of the species Tafana straminea.

\section{Description}

\section{Male (MCZ)}

Color. Carapace reddish brown, darker in cephalic region (Fig. 11A), labium, endites, sternum and chelicerae reddish brown. Legs I-IV yellow, darker at tarsi. Abdomen grayish with dorsal spots (Fig 11A).

Measurements. Total length 10.01, carapace length 4.3, width 3.4. Clypeus height 0.1. Eye diameters and interdistances: AME 0.2, ALE 0.18, PME 0.12, PLE 0.12; AME-AME 0.08, AME-ALE 0.08, PME-PME 0.2, PME-PLE 0.2, ALE-PLE 0.02. Chelicerae 2.7 long, with four promarginal teeth and five retromarginal denticles.

LEG MEASUREMENTS. I-femur 3.9/patella $1.7 /$ tibia 4.0 /metatarsus $3.3 /$ tarsus $1.4 /$ total 14.3 ; II3.6/1.8/3.6/3.0/1.3/13.3; III-2.1/1.0/1.43/1.6/0.7/6.83; IV—3.4/1.5/3.4/3.6/1.1/13.0.

Leg SPINATION. I- tibia v1-1-1, metatarsus v2-0-0; II-tibia v0-1-1; III-tibia p0-0-1, r0-0-1, metatarsus v2-1-2, p0-1-1; IV - tibia p0-0-0, metatarsus p0-1-1, r0-1-1. 
PALP. Retrolateral tibial apophysis in vertical position long and conical; cymbium with prolateral projection; ventral tegular process short near of the base of the median apophysis; apophysis at the base of the embolus short; sperm duct in vertical position with secondary looping without reaching the apex of the tegulum; median apophysis sharp and curved at the apex (Figs 11C-E, 12A-C).

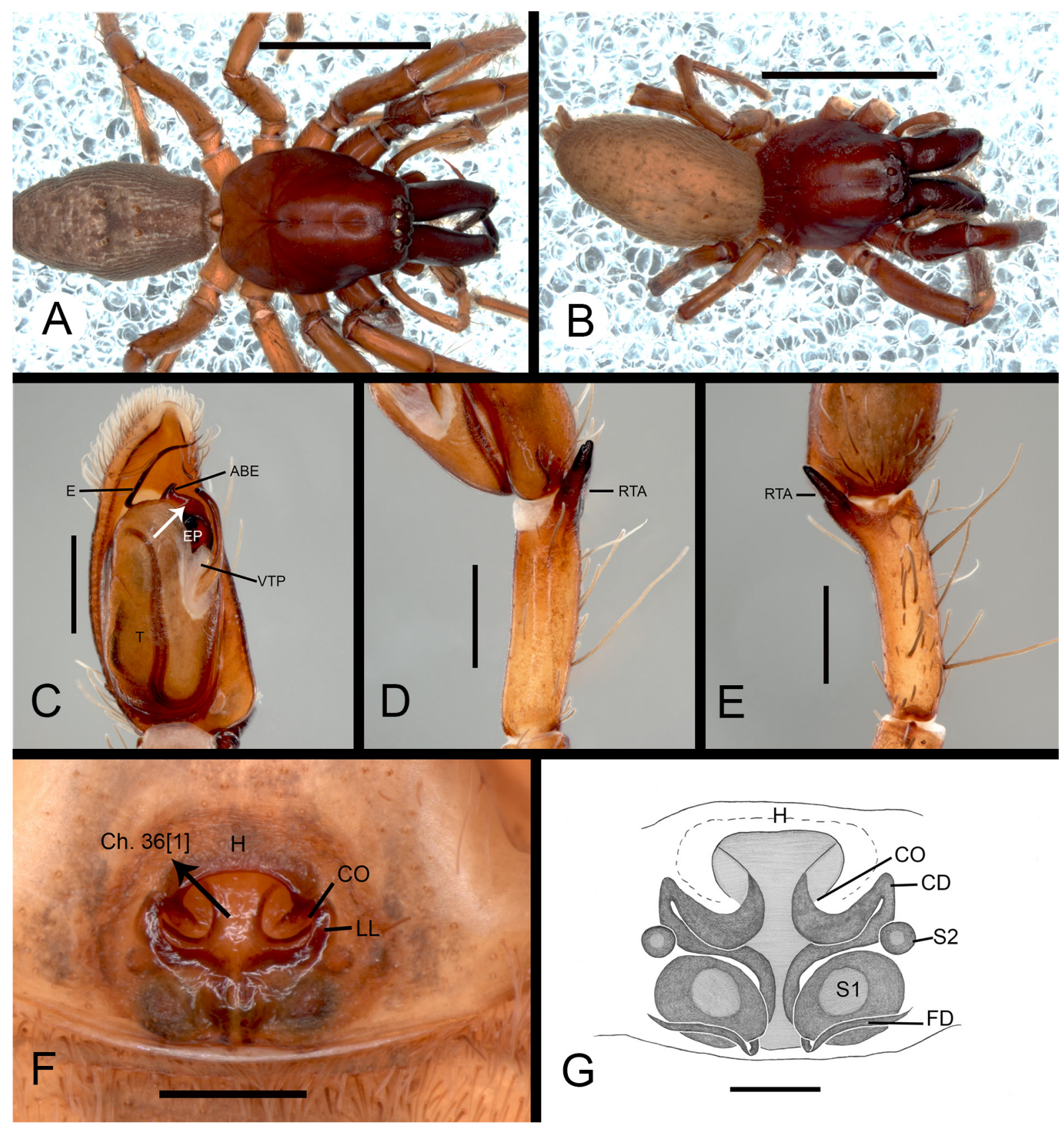

Fig. 11. Tafana straminea (L. Koch, 1866) (A, C-E $=\hat{O}, \mathrm{MCZ} ; \mathrm{B}, \mathrm{F}-\mathrm{G}=q$, IBSP 258181). A. Habitus, dorsal view. B. Habitus, dorsal view. C. Left palp, ventral view (arrow indicating the base of the embolus). D. Left palp, retrolateral view. E. Left palp, dorsal view. F. Epigynum, ventral view (arrow indicating character). G. Vulva, dorsal view. Abbreviations: $\mathrm{ABE}=$ apophysis of base of the embolus; $\mathrm{CD}=$ copulatory ducts; $\mathrm{CO}=$ copulatory opening; $\mathrm{E}=$ embolus; $\mathrm{EP}=$ embolic process; $\mathrm{FD}=$ fertilization ducts; $\mathrm{H}=$ hood; $\mathrm{LL}=$ lateral lobes; $\mathrm{RTA}=$ retrolateral tibial apophysis; $\mathrm{S} 1=$ primary spermathecae; $\mathrm{S} 2=$ secondary spermathecae; $\mathrm{T}=$ tegulum; $\mathrm{VTP}=$ ventral tegular process. Scale bars: $\mathrm{A}-\mathrm{B}=3.5 \mathrm{~mm} ; \mathrm{C}-\mathrm{G}=0.25 \mathrm{~mm}$. 
ABDOMEN. Length 5.7, epigastric furrow 1.3 from tracheal spiracle, spiracle 2.5 from base of spinnerets.

Female (IBSP 258181)

Color. As in males of this species (Fig. 11B).

Measurements. Total length 12.0, carapace length 5.8, width 4.3. Clypeus height 0.22 . Eye diameters and interdistances: AME 1.0, ALE 1.0, PME 1.1, PLE 0.9; AME-AME 0.9, AME-ALE 0.5, PMEPME 1.5, PME-PLE 1.8, ALE-PLE 0.7. Chelicerae 2.8 long, with three promarginal teeth and four retromarginal denticles.

LEG MEASUREMENTS. I-femur 5.23/patella $2.6 /$ tibia 5.2 /metatarsus $4.4 /$ tarsus $1.9 /$ total 19.33 ; II4.8/2.4/4.5/3.9/1.7/17.3; III-3.7/1.73/2.7/3.1/1.2/12.43; IV-3.7/1.1/3.3/3.7/1.1/12.9.

Leg SPINATION. I-tibia v0-1-0, metatarsus 2-0-0; II-tibia v0-1-0; III-tibia p1-1-0, r1-1-0, metatarsus v2-1-2; IV-tibia r1-1-0.

AвDOMEN. Length 6.1, epigastric furrow 1.1 from tracheal spiracle, spiracle 2.7 from base of spinnerets.

EPIGYNUm. Hood circular and sclerotized; epigynal plate with posterior region covered by cuticle; atrium with septum; lateral lobes extremely curved in the anterior region. Internally, copulatory ducts large in the anterior region; secondary spermathecae rounded in middle of the copulatory ducts, oval primary spermathecae; fertilization ducts long (Figs 11F-G, 32G).

\section{Variation}

Four males: total length 7.4-11.5; carapace 3.3-4.8; femur I 3.0-5.4. Two females: total length 7.8-8.4; carapace 3.4-3.5; femur I 2.8-3.0.

\section{Distribution}

Colombia and Ecuador (Fig. 34).
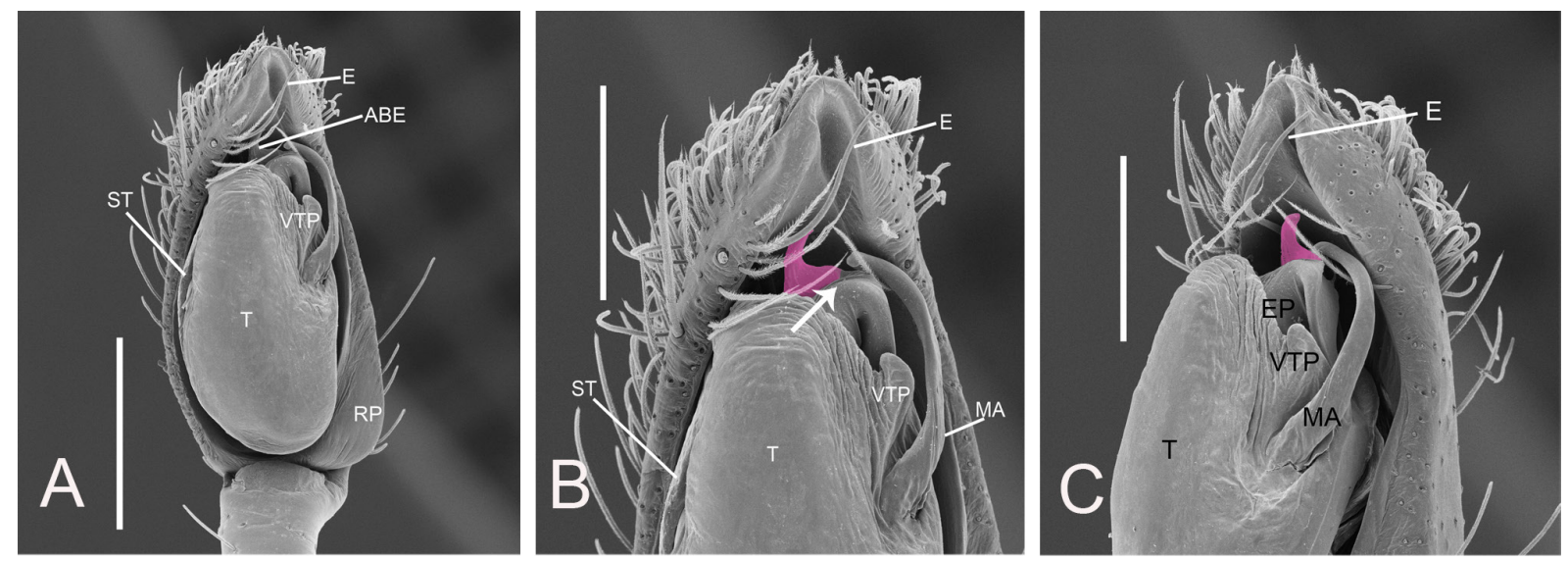

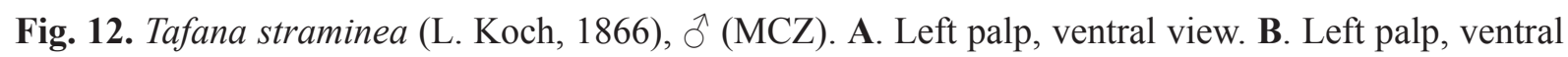
view (arrow indicating the base of the embolus). C. Left palp, retrolateral view. Abbreviations: $\mathrm{ABE}=$ apophysis of base of the embolus; $\mathrm{E}=$ embolus; $\mathrm{EP}=$ embolic process; $\mathrm{MA}=$ median apophysis; $\mathrm{RP}=$ retrolateral projection; $\mathrm{ST}=$ subtegulum; $\mathrm{T}=$ tegulum; $\mathrm{VTP}=$ ventral tegular process. Scale bars: $\mathrm{A}$, $\mathrm{C}=0.5 \mathrm{~mm} ; \mathrm{B}=0.3 \mathrm{~mm}$. 
Tafana quelchi (Pocock, 1895)

Figs 13, 32H, 34

Aysha quelchii Pocock, 1895: 140-143, fig. 1 (syntypes: adult male and immature male from Monte Roraima [frontier between Brazil and Venezuela], deposited in BMNH, examined).

Anyphaena quelchii - Pocock 1900: 67, figs 2c-d. — Bonnet 1955: 347.

Tafana quelchii-Brescovit 1997: 89 (designation of lectotype and paralectotype).

\section{Diagnosis}

Males of Tafana quelchi differ from those of all other species in the genus by the presence of a bifid retrolateral tibial apophysis and by the apical prolateral tibial apophysis (Fig. 13C-E). Females are readily recognized by having the copulatory ducts coiled, covering the primary spermathecae (Figs 13G, 32H).

\section{Material examined}

Syntypes

BRAZIL $\bullet 1$ §, 1 immature ${ }^{\lambda}$; Monte Roraima [frontier between Brazil and Venezuela]; J.J. Quelch leg.; BMNH 1895.3.30.1.

\section{Other material}

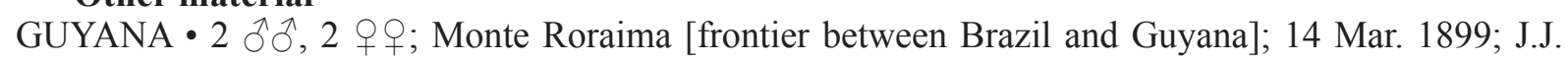
Quelch leg; BMNH 1899.3.14-23.

VENEZUELA - Bolívar - 1 ; Monte Roraima; Parque Nacional Canaima, Trilha Chirimatá;

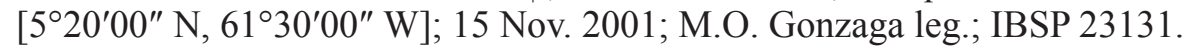

\section{Description}

\section{Male (BMNH 1895.3.30.1)}

COLOR. Exemplar probably discolored. Carapace reddish brown, darker in cephalic region (Fig. 13A). Labium, sternum and endites reddish brown. Chelicerae reddish brown. Legs I-III brown, darker at tarsi. The metatarsus and tarsus of leg IV are lost. Abdomen brown with dark dorsal spots (Fig. 13A).

Measurements. Total length 11.3, carapace length 5.3, width 4.2. Clypeus height 0.175. Eye diameters and interdistances: AME 0.15, ALE 0.22, PME 0.26, PLE 0.26; AME-AME 0.08, AME-ALE 0.05, PME-PME 0.18, PME-PLE 0.2, ALE-PLE 0.13. Chelicerae 1.95 long, with five promarginal teeth and seven retromarginal denticles.

LEG MEASUREMENTS. I-femur 5.1/patella 2.3 /tibia 5.2 /metatarsus $4.6 /$ tarsus 2.2 /total 19.4 ; II5.0/2.3/4.8/4.3/1.6/18.0; III-4.2/1.9/3.5/3.9/1.4/14.9; IV—5.3/2.1/4.6/12.0.

LEG SPINATION. I-tibia v2-2-2, p1-1-0, r1-1-0, metatarsus v2-0-0, p1-0-0, r1-0-0; II-tibia v2-2-2, p1-10, r1-1-0, metatarsus p1-0-0, r1-0-0; III-tibia p1-1-0, r1-1-0; IV-tibia r1-1-0.

PALP. Retrolateral tibial apophysis branching and prolateral tibial apophysis short; cymbium without retrolateral projection; embolus long; apophysis at the base of the embolus short with the apex curved; median apophysis slender and curved; ventral tegular process with hyaline area; projected subtegulum; sperm duct in vertical position with secondary looping reaching the apex of the tegulum (Fig. 13C-E).

AвDOMEn. Length 5.6, epigastric furrow 0.89 from tracheal spiracle, spiracle 2.75 from base of spinnerets.

Female (BMNH 1899.3.14)

COLOR. Exemplar probably discolored. Carapace brown, darker in cephalic region (Fig. 13B). Labium, sternum and endites reddish brown. Chelicerae reddish brown. Legs I-IV brown, darker at tarsi. Abdomen gray with dorsal spots (Fig. 13B). 
Measurements. Total length 11.8, carapace length 5.3, width 3.9. Clypeus height 0.17. Eye diameters and interdistances: AME 0.13, ALE 0.26, PME 0.25, PLE 0.25; AME-AME 0.38, AME-ALE 0.06,

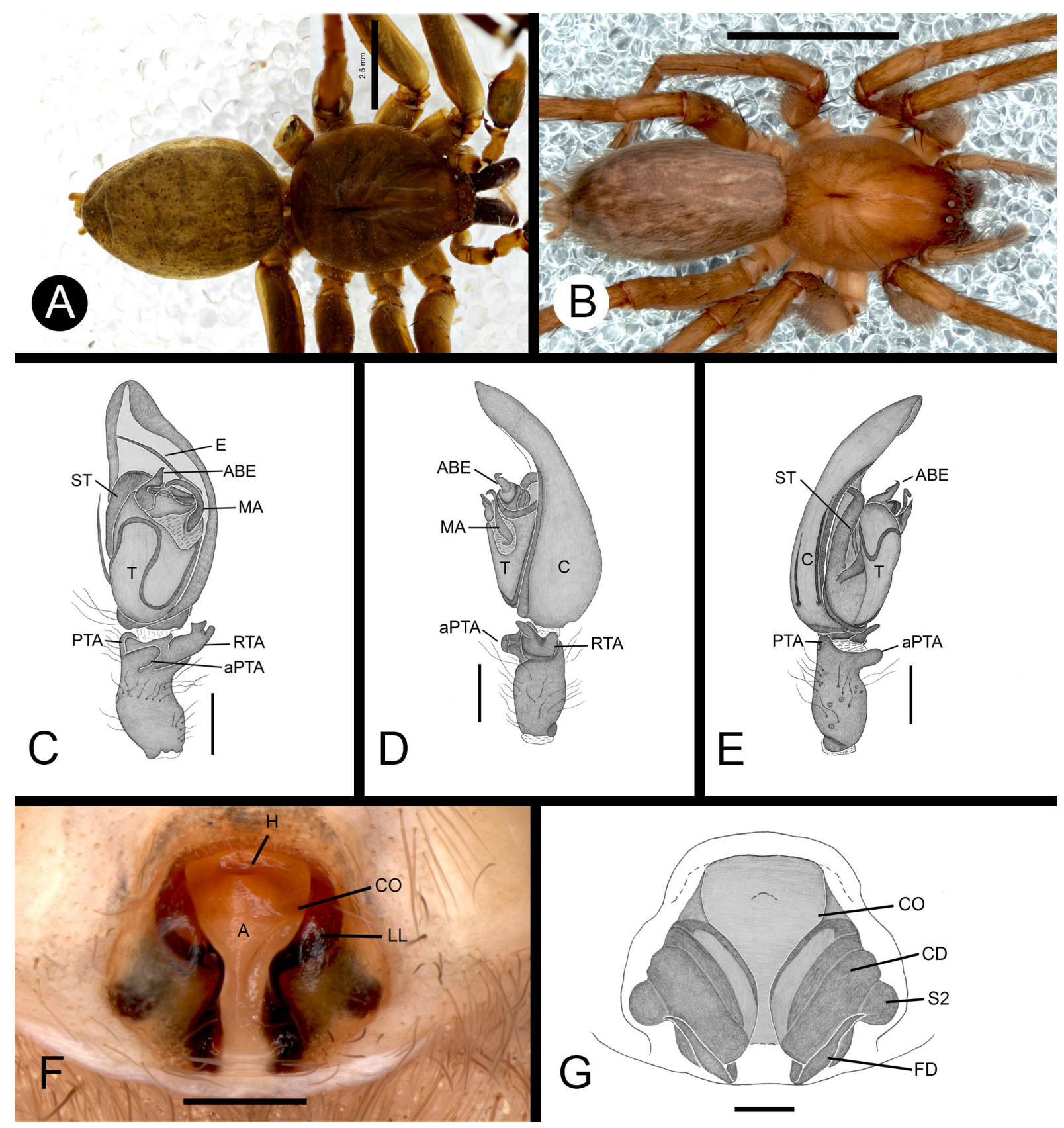

Fig. 13. Tafana quelchi (Pocock, 1895) (A, C-E= $\widehat{~}$, BMNH 1895.3.30.1; B + , IBSP 32131; $\mathrm{F}-\mathrm{G}=q$, IBSP 32131). A. Habitus, dorsal view. B. Habitus, dorsal view. C. Left palp, ventral view. D. Left palp, retrolateral view. E. Left palp, prolateral view. F. Epigynum, ventral view. G. Vulva, dorsal view. Abbreviations: $\mathrm{A}=$ atrium; $\mathrm{ABE}=$ apophysis of base of the embolus; aPTA=apical prolateral tibial apophysis; $\mathrm{C}=$ cymbium; $\mathrm{CD}=$ copulatory ducts; $\mathrm{CO}=$ copulatory opening; $\mathrm{E}=$ embolus; $\mathrm{FD}=$ fertilization ducts; $\mathrm{H}=$ hood; $\mathrm{LL}=$ lateral lobes; $\mathrm{MA}=$ median apophysis; $\mathrm{PTA}=$ prolateral tibial apophysis; $\mathrm{RTA}=$ retrolateral tibial apophysis; $\mathrm{ST}=$ subtegulum; $\mathrm{S} 2=$ secondary spermathecae; $\mathrm{T}=$ tegulum. Scale bars: $\mathrm{A}-\mathrm{B}=3.5 \mathrm{~mm} ; \mathrm{C}-\mathrm{G}=0.25 \mathrm{~mm}$. 
PME-PME 0.26, PME-PLE 0.22, ALE-PLE 0.12. Chelicerae 2.65 long, with four promarginal teeth and eight retromarginal denticles.

LeG MEASUREMENTS. I-femur 4.95/patella 2.3 /tibia 4.8 /metatarsus $4.1 /$ tarsus $0.0 /$ total 16.15 ; IIabsent; III—absent; IV—4.5/2.1/4.7/6.1/1.75/19.15.

Leg SPINATION. I-tibia v2-2-2, p0-1-0, r1-1-1, metatarsus v2-0-0, p1-0-0, r1-0-0; IV—tibia p1-1-1.

EPIGYNum. Anterior field, hood circular; lateral lobes sinuous, largest in the anterior region; atrium wide with depression in the median field. Internally, copulatory ducts large and coiled, covering the primary spermathecae; secondary spermathecae rounded and fertilization ducts long (Figs 13F-G, 32H).

ABDOMEn. Length 6.5, epigastric furrow 1.17 from tracheal spiracle, spiracle 3.25 from base of spinnerets.

\section{Distribution}

Venezuela (Fig. 34).

Tafana kunturmarqa sp. nov.

urn:1sid:zoobank.org:act:DF812485-CC76-40AF-A647-C36685CAEB9F

Figs 14, 32I, 35

\section{Diagnosis}

Males of Tafana kunturmarqa sp. nov. resemble those of T. straminea and T. ruizi sp. nov. by having the retrolateral tibial apophysis conical, but differs by having the embolus short and the apophysis at the base of the embolus larger (Fig. 14C-E). Females resemble those of T. straminea and T. ruizi sp. nov. by having the epigynal plate with atrial septum, but differ by having the secondary spermathecae above the primary spermathecae, rounded, and fertilization ducts smaller than primary spermathecae (Figs 14F-G, 32I).

\section{Etymology}

The specific name, a noun in apposition, is a tribute to the Pre-Colombian language 'Quechua', originated in the central Andes. The meaning of the expression 'Kuntur marqa' in this language is 'Condor's nest'.

\section{Material examined}

\section{Holotype}

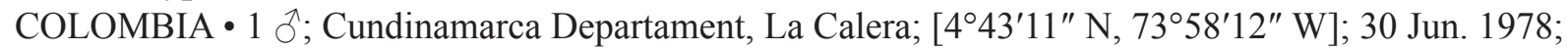

C. Hernandez leg.; ICN-Ar.

\section{Paratype}

COLOMBIA $・ 1$ \%; same collection data as for holotype; ICN-Ar.

\section{Other material}

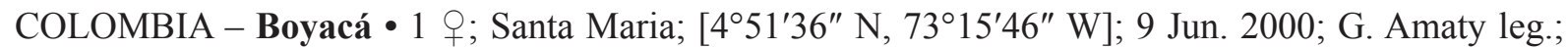
IBSP 258327.

\section{Description}

Male (holotype, ICN-Ar)

CoLOR. Exemplar probably discolored. Carapace orange, darker in cephalic region (Fig. 14A). Labium, sternum and endites reddish brown. Chelicerae reddish brown. Legs I-IV yellow, darker at tarsi. Abdomen yellow with dark longitudinal spots (Fig. 14A). 
MEAsuREMENTS. Total length 8.1, carapace length 3.6, width 2.6. Clypeus height 0.08. Eye diameters and interdistances: AME 0.1, ALE 0.14, PME 0.14, PLE 0.14; AME-AME 0.06, AME-ALE 0.08, PMEPME 0.2, PME-PLE 0.2, ALE-PLE 0.02. Chelicerae 1.8 long, with three promarginal teeth and four retromarginal denticles.

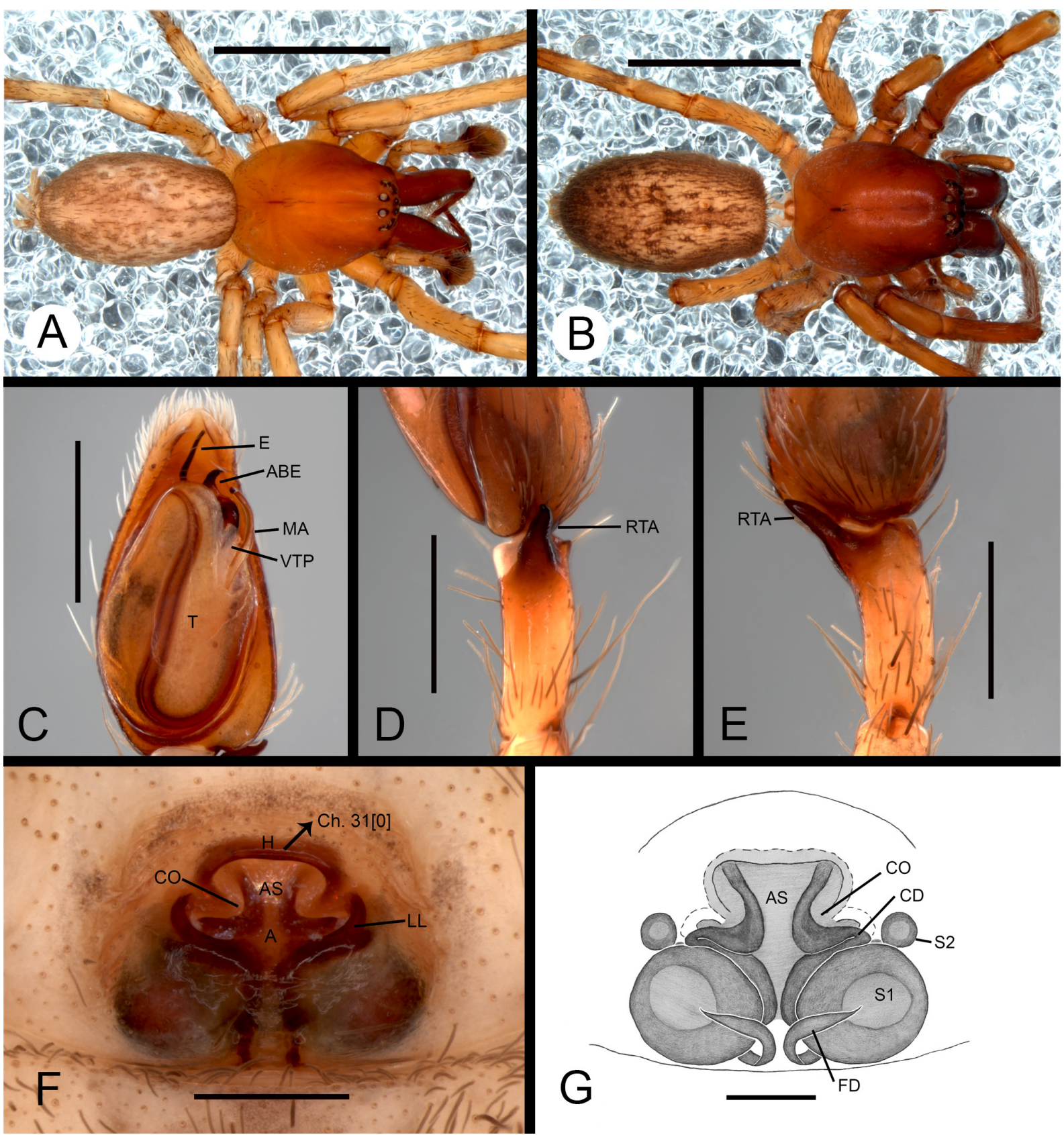

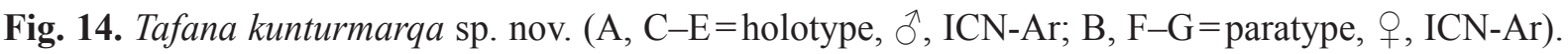
A. Habitus, dorsal view. B. Habitus, dorsal view. C. Left palp, ventral view. D. Left palp, retrolateral view. E. Left palp, dorsal view. F. Epigynum, ventral view (arrow indicating character). G. Vulva, dorsal view. Abbreviations: $\mathrm{A}=$ atrium; $\mathrm{ABE}=$ apophysis of base of the embolus; $\mathrm{AS}=$ atrial septum; $\mathrm{CD}=$ copulatory ducts; $\mathrm{Ch}=$ character; $\mathrm{CO}=$ copulatory opening; $\mathrm{E}=$ embolus; $\mathrm{FD}=$ fertilization ducts; $\mathrm{H}=$ hood; $\mathrm{LL}=$ lateral lobes; $\mathrm{MA}=$ median apophysis; $\mathrm{RTA}=$ retrolateral tibial apophysis; $\mathrm{S} 1=$ primary spermathecae; $\mathrm{S} 2=$ secondary spermathecae; $\mathrm{T}=$ tegulum; $\mathrm{VTP}=$ ventral tegular process. Scale bars: $\mathrm{A}-\mathrm{B}=3.5 \mathrm{~mm} ; \mathrm{C}-\mathrm{E}=0.66 \mathrm{~mm} ; \mathrm{F}=0.4 \mathrm{~mm} ; \mathrm{G}=0.25 \mathrm{~mm}$. 
Leg MEASUREMENTS. I-femur 2.6/patella 1.4 /tibia 2.53 /metatarsus $2.1 /$ tarsus $1.0 /$ total 9.63 ; II2.5/1.1/2.2/2.0/0.9/8.7; III—1.9/1.0/1.2/1.6/0.6/6.3; IV—2.5/1.22/2.3/2.6/0.7/9.32.

Leg SPINATIOn. I-tibia v1-1-0, metatarsus v2-0-0; II-tibia v0; III-tibia p0-0-1, r0-0-1, metatarsus v20-2, p0-0-1; IV-tibia v1-2-2, r1-1-0, metatarsus v2-1-2.

PALP. Retrolateral tibial apophysis conical with apex lightly curved; cymbium with retrolateral projection; short embolus; ventral tegular process near the median apophysis; sperm duct in vertical position with secondary loop reaching the apex of the tegulum; median apophysis long and curved at the apex (Fig. 14C-E).

ABDOMEN. Length 4.2, epigastric furrow 0.9 from tracheal spiracle, spiracle 1.8 from base of spinnerets.

Female (paratype, ICN-Ar)

Color. Exemplar probably discolored. Coloration as in males of this species (Fig. 14B).

Measurements. Total length 7.8, carapace length 3.4, width 2.9. Clypeus height 0.08. Eye diameters and interdistances: AME 0.12, ALE 0.14, PME 0.14, PLE 0.14; AME-AME 0.04, AME-ALE 0.06, PMEPME 0.16, PME-PLE 0.14, ALE-PLE 0.02. Chelicerae 2.1 long, with three promarginal teeth and four retromarginal denticles.

LEG MEASUREMENTS. I-femur 3.2/patella $1.5 /$ tibia 3.42 /metatarsus $3.1 /$ tarsus $1.2 /$ total 12.42 ; II3.0/1.5/3.0/2.8/1.1/11.4; III-2.2/1.1/1.5/1.9/0.6/7.3; IV-3.0/1.22/2.61/3.1/0.8/10.73.

Leg Spination. I- tibia v1-1-1, metatarsus v2-0-0; II-tibia v0-1-1; III-tibia v1-2-2, metatarsus v2-0-2; IV-tibia v1-2-2, p0-1-0, r1-1-0.

Epigynum. Hood circular and sclerotized; epigynal plate posterior region covered by cuticle; atrial septum present; lateral lobes sinuous. Internally, copulatory ducts narrow; primary spermathecae oval and large; secondary spermathecae rounded and large, with short fertilization ducts (Figs 14F-G, 32I).

ABDomen. Length 4.3, epigastric furrow 0.8 from tracheal spiracle, spiracle 1.8 from base of spinnerets.

\section{Distribution}

Known only from Colombia (Fig. 35).

Tafana humahuaca sp. nov.

urn:1sid:zoobank.org:act:16D23428-F7B9-48A6-93EE-95B3AE8F97DC

Figs 15, 32J, 35

\section{Diagnosis}

Males of Tafana humahuaca sp. nov. resemble those of T. riveti and T. nevada sp. nov. by having the short embolus, but differ by having the apophysis at the base of the embolus truncated, extremely short and with excavation between the base of the embolus and the apophysis (Fig. 15C-E). Females resemble those of Tafana nevada sp. nov. by having the epigynal plate, but differ by having atrium narrow in the anterior region, small hood with lateral lobes extremely curved in the anterior region (Figs 15F-G, 32J).

\section{Etymology}

The specific name, a noun in apposition, is a tribute to 'Quebrada de Humahuaca', a deep canyon located in Jujuy Province, the type locality. 


\section{Material examined}

Holotype

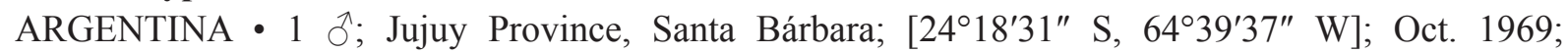
G. Williner leg.; MACN-Ar 41787.

\section{Paratype}

ARGENTINA • 1 \%; same collection data as for holotype; Oct. 1962; MACN-Ar 41788.

\section{Description}

Male (holotype, MACN-Ar 41787)

CoLor. Exemplar probably discolored. Carapace orange (Fig. 15A). Labium, sternum and endites yellow. Chelicerae yellow. Legs I-III yellow with spots on the articles. Abdomen with dark spots (Fig. 15A).

Measurements. Total length 5.3, carapace length 2.3, width 1.7. Clypeus height 0.06. Eye diameters and interdistances: AME 0.06, ALE 0.1, PME 0.1, PLE 0.08; AME-AME 0.02, AME-ALE 0.02, PMEPME 0.1, PME-PLE 0.08, ALE-PLE 0.02. Chelicerae 0.8 long, with five promarginal teeth and four retromarginal denticles.

LeG MEASUREMENTS. I-lost; II—femur 1.7 / patella 0.73 /tibia 1.7 / metatarsus $1.6 /$ tarsus 0.84 / total 6.57; III-1.6/0.7/1.4/1.4/0.7/5.8; IV—lost.

Leg SPINATION. II-tibia v2-1-2, p1-1-0; III-tibia v1-2-0, p0-1-0, metatarsus v2-1-0, p0-1-0.

PALP. Retrolateral tibial apophysis conical with apex curved; cymbium with retrolateral projection more rounded; embolus short; ventral tegular process near the median apophysis and sclerotized; sperm duct in vertical position with secondary looping reaching the apex of the tegulum; median apophysis slender and curved apically (Fig. 15C-E).

AвDOMEN. Length 2.7, epigastric furrow 0.6 from tracheal spiracle, spiracle 1.0 from base of spinnerets.

Female (paratype, MACN-Ar 41788)

Color. Exemplar probably discolored. Coloration as in males of this species (Fig. 15B).

Measurements. Total length 3.2, carapace length 2.4, width 1.3. Clypeus height 0.06. Eye diameters and interdistances: AME 0.08, ALE 0.1, PME 0.1, PLE 0.1; AME-AME 0.04, AME-ALE 0.04, PMEPME 0.16, PME-PLE 0.12, ALE-PLE 0.04. Chelicerae 1.1 long, with four promarginal teeth and five retromarginal denticles.

LeG MEASUREMENTS. I-femur 1.6 /patella 0.8 /tibia 1.4 /metatarsus $1.3 /$ tarsus $0.8 /$ total 5.9 ; II$1.9 / 0.8 / 1.1 / 1.15 / 0.6 / 5.55 ;$ III-1.3/0.63/0.8/1.2/0.5/4.43; IV-1.9/0.8/1.5/2.1/0.65/6.95.

Leg SpinAtion. I-tibia v2-2-0, metatarsus v2-0-0; II-tibia v1-1-0; III-tibia v1-2-2, p1-1-0, r1-1-0, metatarsus v2-1-2; IV-tibia v1-2-2, p1-1-1.

Epigynum. Hood semicircular and sclerotized; short atrium; lateral lobes over copulatory ducts. Internally, copulatory ducts narrow; primary spermathecae large and oval; secondary spermathecae above the primary spermathecae and rounded; fertilization ducts long (Fig. 15F-G).

ABdomEn. Length 3.2, epigastric furrow 0.7 from tracheal spiracle, spiracle 1.3 from base of spinnerets. 


\section{Distribution}

Known only from Jujuy, Argentina (Fig. 35).

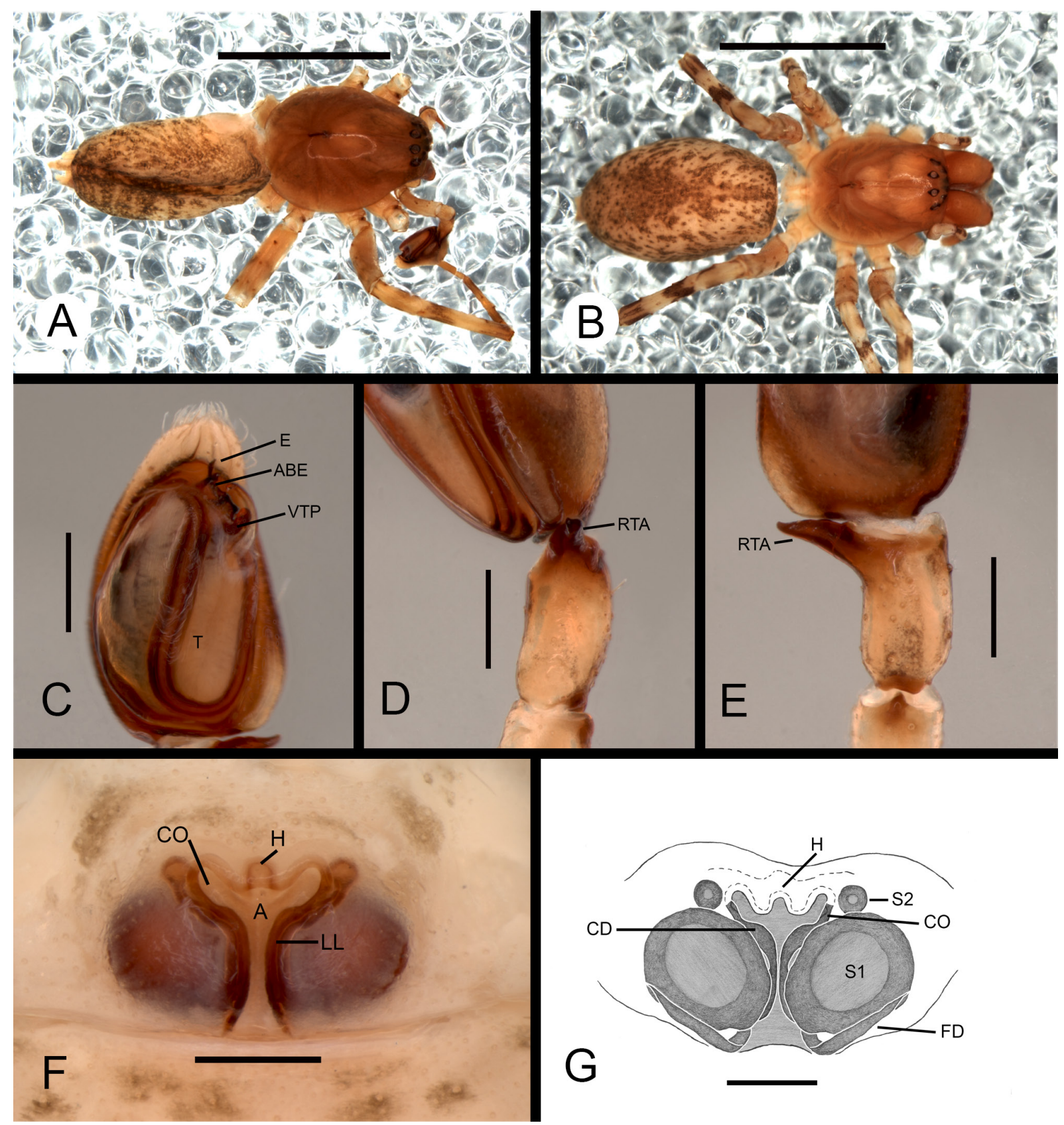

Fig. 15. Tafana humahuaca sp. nov. (A, C-E=holotype, đ, MACN-Ar 41787; B, F-G=paratype, q, MACN-Ar 41788). A. Habitus, dorsal view. B. Habitus, dorsal view. C. Left palp, ventral view. D. Left palp, retrolateral view. E. Left palp, dorsal view. F. Epigynum, ventral view. G. Vulva, dorsal view. Abbreviations: $\mathrm{A}=$ atrium; $\mathrm{ABE}=$ apophysis of base of the embolus; $\mathrm{CD}=$ copulatory ducts; $\mathrm{CO}=$ copulatory opening; $\mathrm{E}=$ embolus; $\mathrm{FD}=$ fertilization ducts; $\mathrm{H}=$ hood; $\mathrm{LL}=$ lateral lobes; $\mathrm{RTA}=$ retrolateral tibial apophysis; $\mathrm{S} 1=$ primary spermathecae; $\mathrm{S} 2=$ secondary spermathecae; $\mathrm{T}=$ tegulum; $\mathrm{VTP}=$ ventral tegular process. Scale bars: $\mathrm{A}-\mathrm{B}=3.5 \mathrm{~mm} ; \mathrm{C}-\mathrm{G}=0.25 \mathrm{~mm}$. 


\section{Tafana pastaza sp. nov. \\ urn:1sid:zoobank.org:act:89787AA8-5ECB-4826-BA94-616D473519D5}

Figs $8 \mathrm{~L}, 16,32 \mathrm{~K}, 35$

\section{Diagnosis}

Males of Tafana pastaza sp. nov. differ from those of the other species of this genus by having the apophysis at the base of the embolus bifid, primary apophysis 'S-shaped' and secondary apophysis large, retrolateral projection of the cymbium keel-shaped (Fig. 16C-E). Females differ from the others by presenting internal copulatory ducts long and sinuous, with a globose extension proximally of the copulatory ducts (Figs $16 \mathrm{~F}-\mathrm{G}, 32 \mathrm{~K}$ ).

\section{Etymology}

The specific name is a noun in apposition taken from the type locality, Pastaza Valley.

\section{Material examined}

Holotype

ECUADOR • 1 ภ; Tungurahua Province, Pastaza Valley, between Baños and Mera; $\left[01^{\circ} 04^{\prime} 00^{\prime \prime}\right.$ N, 7800'24" W]; 1 Mar. 1949; W.C. Macintyre leg.; AMNH.

\section{Paratype}

ECUADOR • 1 \%; same collection data as for holotype; AMNH.

\section{Remark}

The male specimen is in very bad shape, having lost the chelicerae and almost all the legs, and with the abdomen partially deteriorated (Fig. 16A).

\section{Description}

Male (holotype, AMNH)

COLOR. Exemplar discolored. Carapace reddish brown (16A). Labium, sternum and endites reddish brown. Legs reddish, only right femur IV and left femur III intact. Abdomen discolored (Fig. 16A).

MEASUREMENTS. Total length 8.5, carapace length 3.3, width 2.9. Clypeus height 0.08. Eye diameters and interdistances: AME 0.08, ALE 0.12, PME 0.12, PLE 0.1; AME-AME 0.06, AME-ALE 0.06, PMEPME 0.16, PME-PLE 0.20, ALE-PLE 0.06.

LEG MEASUREMENTS. III-femur 3.2; IV-femur 4.38.

PALP. Retrolateral tibial apophysis conical and curved, apical protuberance on the tibia in retrolateral view; cymbium with retrolateral projection keel-shaped; embolus long; subtegulum prolateral projected; ventral tegular process not present; sperm duct secondary loop reaching apex of the tegulum; median apophysis thick and curved at the apex (Fig. 16C-E).

ABDOMEN. Length 5.0, epigastric furrow 1.1 from tracheal spiracle, spiracle 3.2 from base of spinnerets.

Female (paratype, AMNH)

CoLor. Exemplar probably discolored. Carapace reddish brown (Fig. 16B). Labium, sternum and endites reddish brown. Chelicerae reddish brown. Legs I-IV yellow, darker at tarsi. Abdomen yellowish gray with dark spots (Fig. 16B).

Measurements. Total length 9.3, carapace length 3.8, width 3.2. Clypeus height 0.12. Eye diameters and interdistances: AME 0.1, ALE 0.18, PME 0.18, PLE 0.18; AME-AME 0.08, AME-ALE 0.04, PME- 
PME 0.2, PME-PLE 0.18, ALE-PLE 0.08. Chelicerae 1.6 long, with four promarginal teeth and five retromarginal denticles.

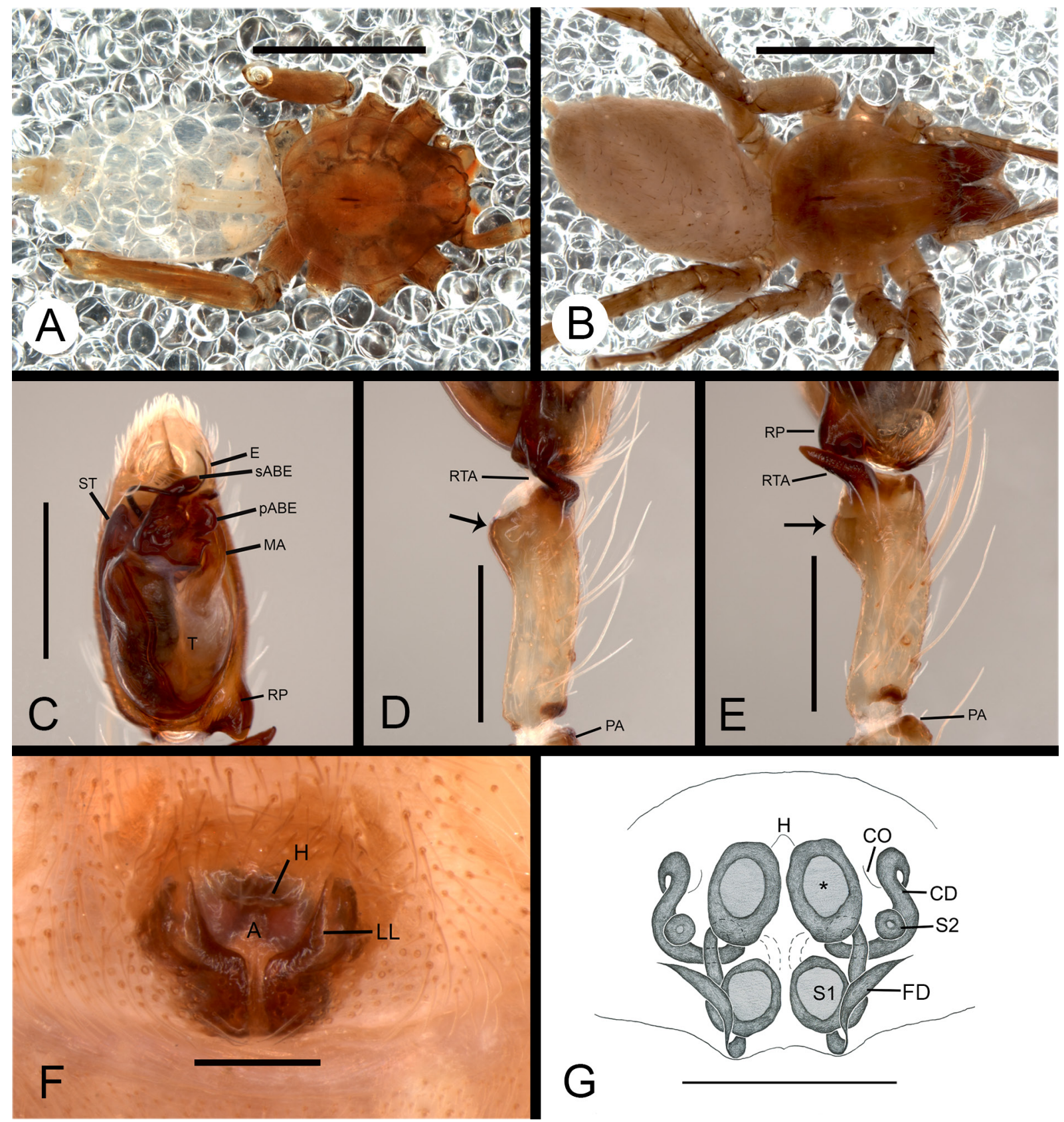

Fig. 16. Tafana pastaza sp. nov. (A, C-E=holotype, $\widehat{O}$, AMNH; $\mathrm{B}, \mathrm{F}-\mathrm{G}=$ paratype,, , AMNH). A. Habitus, dorsal view. B. Habitus, dorsal view. C. Left palp, ventral view. D. Left palp, retrolateral view (arrow indicating apical salience). E. Left palp, retrodorsal view (arrow indicating apical salience). F. Epigynum, ventral view. G. Vulva, dorsal view. Abbreviations: $A=$ atrium; $C D=$ copulatory ducts; $\mathrm{CO}=$ copulatory opening; $\mathrm{E}=$ embolus; $\mathrm{FD}=$ fertilization ducts; $\mathrm{H}=$ hood; $\mathrm{LL}=$ lateral lobes; $\mathrm{MA}=$ median apophysis; $\mathrm{PA}=$ patellar apophysis; $\mathrm{pABE}=$ primary apophysis of base of the embolus; $\mathrm{RP}=$ retrolateral projection; $\mathrm{RTA}=$ retrolateral tibial apophysis; $\mathrm{sABE}=$ secondary apophysis of base of the embolus; $\mathrm{S} 1$ = primary spermathecae; $\mathrm{S} 2=$ secondary spermathecae; $\mathrm{ST}=$ subtegulum, $\mathrm{T}=$ tegulum. Asterisks to globose membranous extension of proximal copulatory ducts. Scale bars: $\mathrm{A}-\mathrm{B}=3.5 \mathrm{~mm}$; $\mathrm{C}-\mathrm{E}=0.66 \mathrm{~mm} ; \mathrm{F}-\mathrm{G}=0.25 \mathrm{~mm}$. 
LEG MEASUREMENTS. I-femur 4.4 /patella $1.7 /$ tibia 4.7 /metatarsus $3.6 /$ tarsus $1.8 /$ total 16.2 ; II4.5/1.7/4.5/3.4/1.7/15.8; III-3.3/1.4/2.5/3.1/1.3/11.6; IV-3.9/1.4/3.3/4.0/1.4/14.0.

Leg Spination. I-tibia v2-2-2, p1-1-1, r1-1-1, metatarsus v2-0-0; II-tibia v2-2-2, p1-1-1, r1-1-1, metatarsus p1-0-0, r1-1-0; III- tibia p1-1-0, r1-1-0.

EPIGYNUm. Hood circular; atrium small; epigynal plate without posterior region covered with sclerotized cuticle; lateral lobes chalice-shaped. Internally, copulatory ducts long and narrow; primary spermathecae oval; secondary spermatechae in the middle of the copulatory ducts; fertilization ducts long, two times the length of primary spermathecae (Figs $16 \mathrm{~F}-\mathrm{G}, 32 \mathrm{~K}$ ).

AвDOMEn. Length 5.3, epigastric furrow 1.3 from tracheal spiracle, spiracle 2.0 from base of spinnerets.

\section{Distribution}

Known only from Pastaza Valley, Ecuador (Fig. 35).

Tafana nevada sp. nov.

urn:1sid:zoobank.org:act:ABEBEE44-6E38-47E3-A0BA-7C343EB73C9B

Figs $17-18,32 \mathrm{~L}, 35$

\section{Diagnosis}

Males of Tafana nevada sp. nov. resemble those of T. riveti and T. humahuaca sp. nov. by having the short embolus, but differ from the others by having the apophysis at the base of the embolus long and curved (Figs 17C-D, 18A-C). Females resemble those of T. humahuaca sp. nov. by having the epigynal plate with parallel lateral lobes, but differ by having a large atrium in the anterior region and a hyaline membrane in the posterior region (Figs 17F-G, 33L).

\section{Etymology}

The specific name is a noun in apposition taken from type locality, Sierra Nevada de Santa Marta.

\section{Material examined}

\section{Holotype}

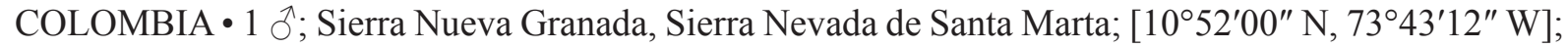
9 Apr. 1975; J.A. Kochalka leg.; AMNH.

\section{Paratype}

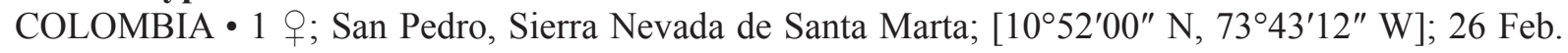
1975; J.A. Kochalka leg.; AMNH.

\section{Other material}

COLOMBIA - Magdalena Departament 1 1 ; Santa Marta, San Pedro, Carmelo, Sierra Nevada

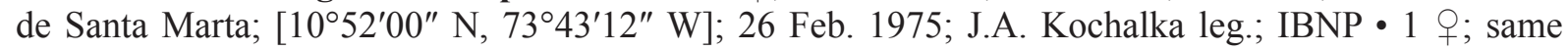
collection data as for preceding; 3 Mar. 1975; J.A. Kochalka leg.; IBNP • 1 đ; Santa Marta, SE of the Cerro, Yosagaca, Sierra Nevada de Santa Marta; [10 $52^{\prime} 00^{\prime \prime}$ N, $73^{\circ} 43^{\prime} 12^{\prime \prime}$ W]; 30 Dec. 1973; J.A. Kochalka leg.; IBNP • 1 ð̊; Sierra Nevada de Santa Marta, Serra Nueva Granada; [10 $52^{\prime} 00^{\prime \prime}$ N, 734'ㄹ" W]; 9 Apr. 1975; J.A. Kochalka leg.; IBNP • 1 q; Santa Marta, San Pedro, Carmelo, Sierra

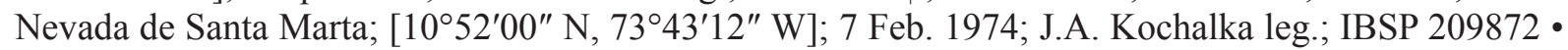

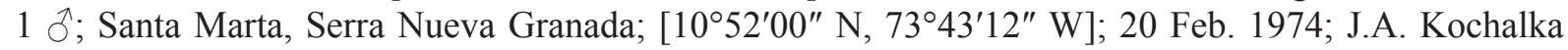
leg.; IBSP 209873. - Cordillera Oriental • 2 우; Scorpa Mission, Serra del Perijá; [1000'59" N, 7257'28" W]; 10-22 Aug. 1968; B. Malkin leg.; AMNH. - Cundinamarca • 1 +; Sasaima, Finca Bella Vista; [ $4^{\circ} 57^{\prime} 54^{\prime \prime}$ N, $74^{\circ} 26^{\prime} 05^{\prime \prime}$ W]; 16 Mar. 1965; P.R. Craig leg.; CAS. 


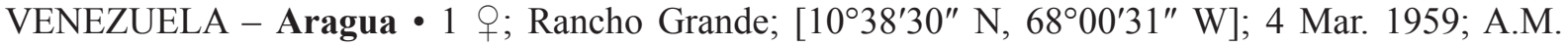

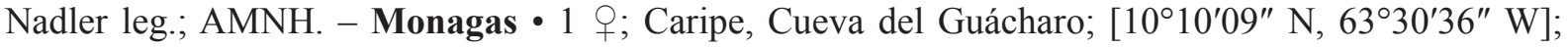
20-30 Jul. 1987; S. and J. Peck leg.; AMNH.

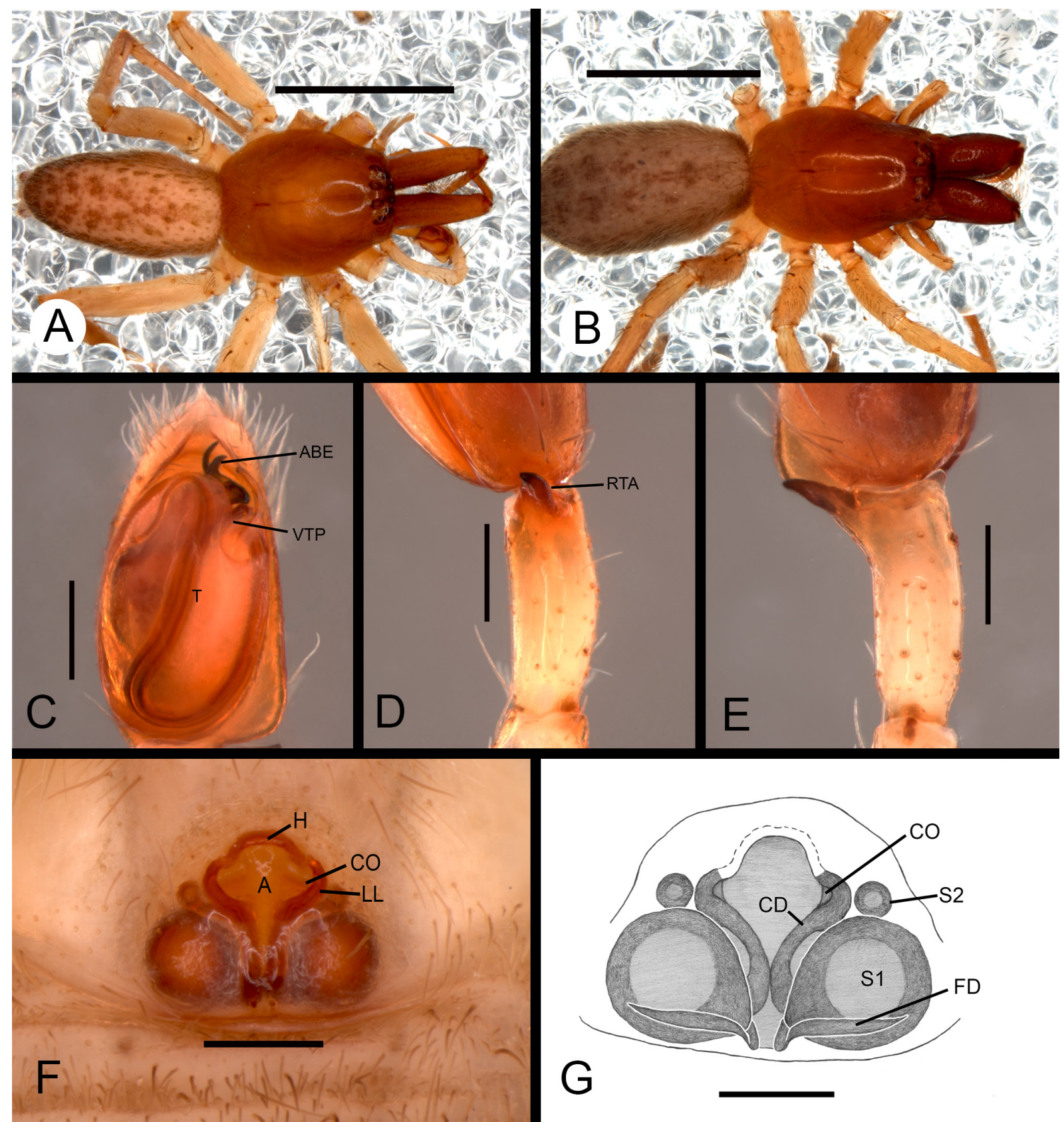

Fig. 17. Tafana nevada sp. nov. (A, $\mathrm{C}-\mathrm{E}=$ holotype, $\widehat{O}, \mathrm{AMNH} ; \mathrm{B}, \mathrm{F}-\mathrm{G}=$ paratype, + , $\mathrm{AMNH}$ ). A. Habitus, dorsal view. B. Habitus, dorsal view. C. Left palp, ventral view. D. Left palp, retrolateral view. E. Left palp, dorsal view). F. Epigynum, ventral view. G. Vulva, dorsal view. Abbreviations: $\mathrm{A}=$ atrium; $\mathrm{ABE}=$ apophysis of base of embolus; $\mathrm{CD}=$ copulatory ducts; $\mathrm{CO}=$ copulatory opening; $\mathrm{FD}=$ fertilization ducts; $\mathrm{H}=$ hood; $\mathrm{LL}=$ lateral lobes; $\mathrm{RTA}=$ retrolateral tibial apophysis; $\mathrm{S} 1=$ primary spermathecae; $\mathrm{S} 2=$ secondary spermathecae; $\mathrm{T}=$ tegulum, $\mathrm{VTP}=$ ventral tegular process. Scale bars: $\mathrm{A}-\mathrm{B}=3.5 \mathrm{~mm} ; \mathrm{C}-\mathrm{G}=0.25 \mathrm{~mm}$. 


\section{Description}

Male (holotype, AMNH)

CoLor. Exemplar probably discolored. Carapace reddish brown (Fig. 17A). Labium, sternum and endites reddish brown. Chelicerae reddish. Legs I-IV yellow, darker at tarsi. Abdomen yellow with dark spots (Fig. 17A).

MEASUREMENTS. Total length 5.6, carapace length 2.6, width 2.2. Clypeus height 0.06. Eye diameters and interdistances: AME 0.1, ALE 0.12, PME 0.14, PLE 0.12; AME-AME 0.06, AME-ALE 0.02, PMEPME 0.12, PME-PLE 0.14, ALE-PLE 0.02. Chelicerae 1.1 long, with four promarginal teeth and four retromarginal denticles.

LEG MEASUREMENTS. I-femur 2.5 / patella $1.0 /$ tibia 2.53 /metatarsus $2.2 /$ tarsus $0.9 /$ total 9.13 ; II$2.3 / 1.0 / 2.2 / 2.0 / 0.8 / 8.3 ;$ III-1.8/0.62/1.9/1.2/0.6/6.12; IV-2.4/0.9/2.0/2.6/0.62/8.52.

Leg SPINATION. I-tibia v1-1-0, metatarsus v2-0-0; II-tibia v0-2-0, p0-1-0; III-tibia v1-2-2, p0-1-1, r1-1-0, metatarsus v2-1-2; IV-tibia r1-1-0, metatarsus v2-1-2.

PALP. Retrolateral tibial apophysis conical and curved; cymbium with retrolateral projection; apophysis at the base of the embolus long and curved; embolus extremely short; ventral tegular process near the median apophysis; median apophysis slender and curved; subtegulum not projected; sperm duct with secondary looping reaching the apex of the tegulum (Figs 17C-D, 18A-C).

ABDomen. Length 3.0, epigastric furrow 0.7 from tracheal spiracle, spiracle 1.1 from base of spinnerets.

Female (paratype, AMNH)

CoLOr. Exemplar probably discolored. Carapace reddish brown (Fig. 17B). Labium, sternum and endites reddish brown. Chelicerae reddish brown. Legs I-IV yellow, darker at tarsi. Abdomen yellowish gray with dark spots (Fig. 17B).

MEAsurements. Total length 5.9, carapace length 2.6, width 2.0. Clypeus height 0.04. Eye diameters and interdistances: AME 0.1, ALE 0.12, PME 0.12, PLE 0.1; AME-AME 0.06, AME-ALE 0.06, PME-
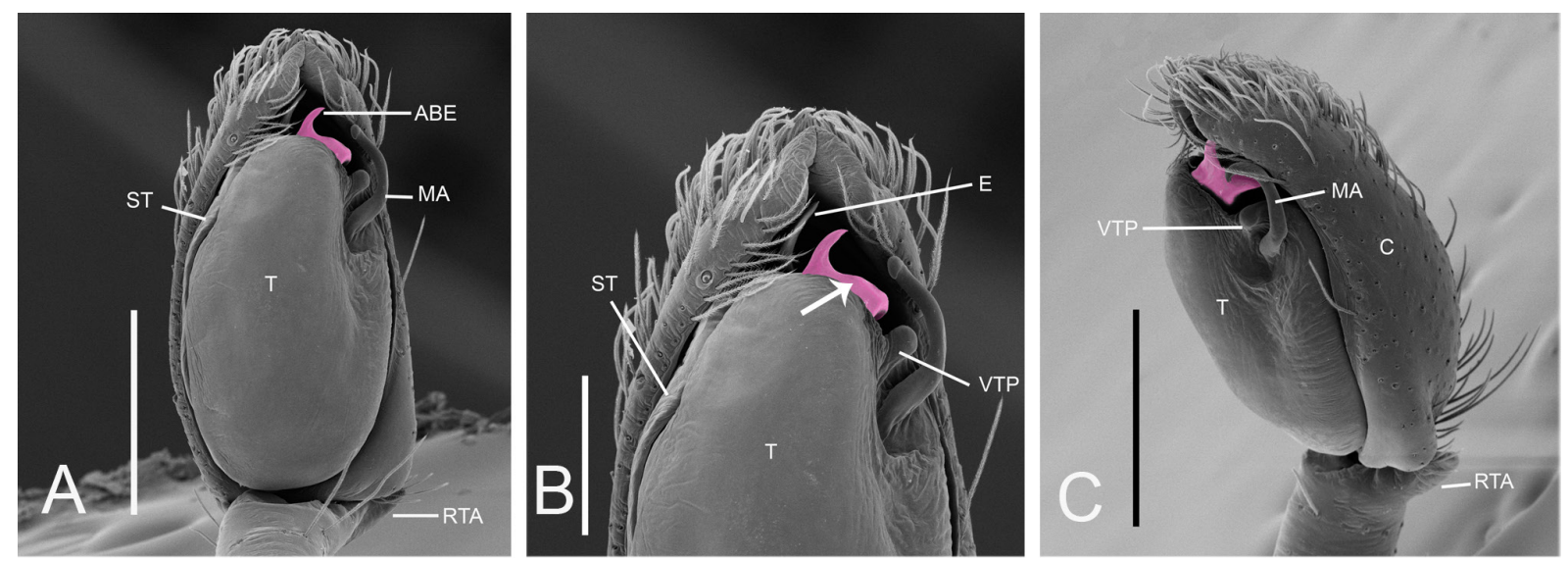

Fig. 18. Tafana nevada sp. nov., $\widehat{\jmath}$ (IBNP). A. Left palp, ventral view. B. Left palp, ventral view (arrow indicating the base of the embolus). C. Left palp, retrolateral view. Abbreviations: $A B E=$ apophysis of base of the embolus; $\mathrm{C}=$ cymbium; $\mathrm{E}=$ embolus; $\mathrm{MA}=$ median apophysis; $\mathrm{RTA}=$ retrolateral tibial apophysis; $\mathrm{ST}=$ subtegulum; $\mathrm{T}=$ tegulum; $\mathrm{VTP}=$ ventral tegular process. Scale bars: $\mathrm{A}, \mathrm{C}=0.4 \mathrm{~mm}$; $\mathrm{B}=0.2 \mathrm{~mm}$. 
PME 0.14, PME-PLE 0.12, ALE-PLE 0.04. Chelicerae 1.2 long, with four promarginal teeth and five retromarginal denticles.

LEG MEASUREMENTS. I-femur 1.88 /patella $1.0 /$ tibia 1.2 /metatarsus $1.1 /$ tarsus $0.7 /$ total 5.88 ; II1.7/0.9/1.4/1.2/0.6/5.8; III-1.1/0.6/0.9/1.1/0.4/4.1; IV-1.2/0.8/1.2/2.1/0.6/5.9.

Leg SpINATION. I- tibia v1-1-0, metatarsus v2-0-0; II-tibia v0-0-0; III-tibia v1-2-2, r1-1-0, metatarsus v2-1-2; IV-tibia v1-2-2, r1-1-0.

EPigynum. Hood semicircular and sclerotized; broad atrium; lateral lobes covering copulatory ducts; posterior region covered by cuticle. Internally, copulatory ducts short; primary spermathecae large and oval; secondary spermathecae above the primary spermathecae and rounded; long fertilization ducts in horizontal position (Figs 17F-G, 33L).

ABDomen. Length 3.3, epigastric furrow 0.45 from tracheal spiracle, spiracle 1.4 from base of spinnerets.

\section{Variation}

Two males: total length 4.2-4.9; carapace 1.9-1.9; femur I 1.7-1.9. Ten females: total length 4.3-6.7; carapace 1.6-2.4; femur I 1.3-1.9.

\section{Distribution}

Venezuela and Colombia (Fig. 35).

Tafana huatanay sp. nov. urn:1sid:zoobank.org:act:DE788AB4-AF1A-4605-8F07-9403EFF8DADD

Figs 19-20, 33A, 34

\section{Diagnosis}

Males of Tafana huatanay sp. nov. resemble those of T. riveti, T. humahuaca sp. nov. and T. nevada sp. nov. by having the short embolus, but differ by having the base of the embolus wide (Figs 19C, 20A-C). Females resemble those of T. riveti, T. humahuaca sp. nov. and T. nevada sp. nov. by having the epigynal plate with curved lateral lobes in anterior region, but differ by having the copulatory ducts medially flattened and secondary spermathecae on the sides of the primary spermathecae in dorsal view (Figs 19F-G, 33A).

\section{Etymology}

The specific name, a noun in apposition, is a tribute to the 'Sacred Valley of the Incas' called Huatanay.

\section{Material examined}

Holotype

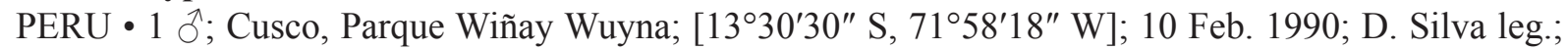
MUSM.

\section{Paratype}

PERU • 1 क; Paucartambo, Pilcopata, National Park Del Manu Carretera; [12 $08^{\prime} 00^{\prime \prime}$ S, $71^{\circ} 40^{\prime} 00^{\prime \prime}$ W]; 2700 m a.s.1.; 19 Feb. 1990; D. Silva leg.; MUSM.

\section{Other material}

BOLIVIA - La Paz • 2 우; Sainami, Valley of the Zongo; [16²9'39" S; 6808'51" W]; 4 Aug. 1993; A.D. Brescovit leg.; IBSP 258182. 
COLOMBIA - Neiva - 1 क; Huila, Finca Meremberg, $10 \mathrm{~km}$ E of Santa Leticia; [2 $59^{\prime} 55^{\prime \prime} \mathrm{N}$, $75^{\circ} 18^{\prime} 16^{\prime \prime}$ W]; Mar. 1979; W. Eberhard leg.; MCZ.

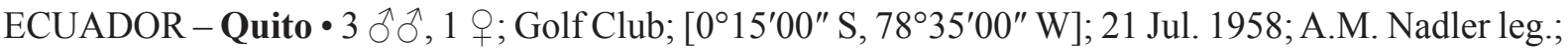
AMNH.

PERU - Cusco - 3 우; Carretera to Manu National Park, Paucartambo, Pilcopata; $\left[12^{\circ} 08^{\prime} 00^{\prime \prime}\right.$ S,

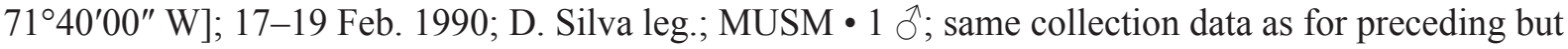

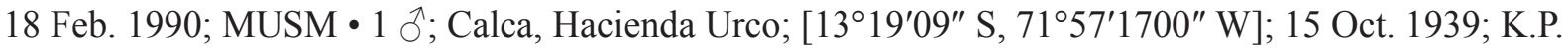
Schmidt leg.; FMNH.

\section{Description}

Male (holotype, MUSM)

CoLor. Carapace orange (Fig. 19A). Labium, sternum and endites yellow. Chelicerae reddish. Legs I-IV yellow, darker at tarsi. Abdomen gray with dark spots (Fig. 19A).

MeAsurements. Total length 5.6, carapace length 2.7, width 2.1. Clypeus height 0.06. Eye diameters and interdistances: AME 0.06, ALE 0.1, PME 0.12, PLE 0.1; AME-AME 0.06, AME-ALE 0.06, PMEPME 0.14, PME-PLE 0.14, ALE-PLE 0.04. Chelicerae 1.7 long, with four promarginal teeth and four retromarginal denticles.

Leg MEASUREMENTS. I-femur 2.2 /patella 0.9 /tibia $2.1 /$ metatarsus $1.8 /$ tarsus $1.0 /$ total 8.0 ; II2.0/1.0/1.9/1.7/0.9/7.5; III—1.8/0.9/1.3/1.5/0.5/6.0; IV—2.5/1.1/2.15/2.7/0.7/9.15.

Leg SPINATIOn. I-tibia v2-2-2, metatarsus v2-0-0; II-tibia v1-2-2, p0-1-0; III-tibia v1-2-2, p0-1-1, r0-1-1; IV-tibia p1-1-1.

PALP. Retrolateral tibial apophysis short and curved; cymbium with retrolateral projection; apophysis at the base of the embolus short and furrowed; embolus short; ventral tegular process near the median apophysis; sperm duct with secondary looping reaching the apex of the tegulum (Figs 19C-E, 20A-C).

АвDомEN. Length 2.8, epigastric furrow 0.7 from tracheal spiracle, spiracle 1.0 from base of spinnerets.

Female (paratype, MUSM)

COLOR. Coloration as in males of this species, except for reddish carapace and chelicerae reddish brown (Fig. 19B).

Measurements. Total length 6.0, carapace length 2.1, width 1.7. Clypeus height 0.06. Eye diameters and interdistances: AME 0.06, ALE 0.1, PME 0.1, PLE 0.1; AME-AME 0.04, AME-ALE 0.04, PMEPME 0.12, PME-PLE 0.12, ALE-PLE 0.04. Chelicerae 1.1 long, with four promarginal teeth and three retromarginal denticles.

LEG MEASUREMENTS. I-femur 1.5 / patella 0.63 /tibia $1.3 /$ metatarsus $1.1 /$ tarsus $0.6 /$ total 5.13 ; II$1.42 / 0.5 / 1.1 / 1.1 / 0.6 / 4.72 ;$ III-1.2/0.6/0.8/1.1/0.4/4.1; IV-1.6/0.6/1.3/1.4/0.6/5.5.

Leg Spination. I-tibia v2-2-0, metatarsus v2-0-0; II-tibia v2-2-0; III-tibia v1-2-2, p0-1-1, r0-1-1, metatarsus v2-1-2; IV-tibia p0-1-1, r0-1-1.

EpIGYNum. Hood semircular, with sclerotized lateral lobes; atrium narrow and elongated; epigynal plate covered by cuticle in the posterior region; lateral lobes extremely curved in anterior region. Internally, 
copulatory ducts sinuous and flattened; primary spermathecae large and oval; secondary spermathecae lateral to the primary spermathecae, rounded, and fertilization ducts long (Figs 19F-G, 20E, 33A).

Abdomen. Length 3.8, epigastric furrow 0.8 from tracheal spiracle, spiracle 1.7 from base of spinnerets.

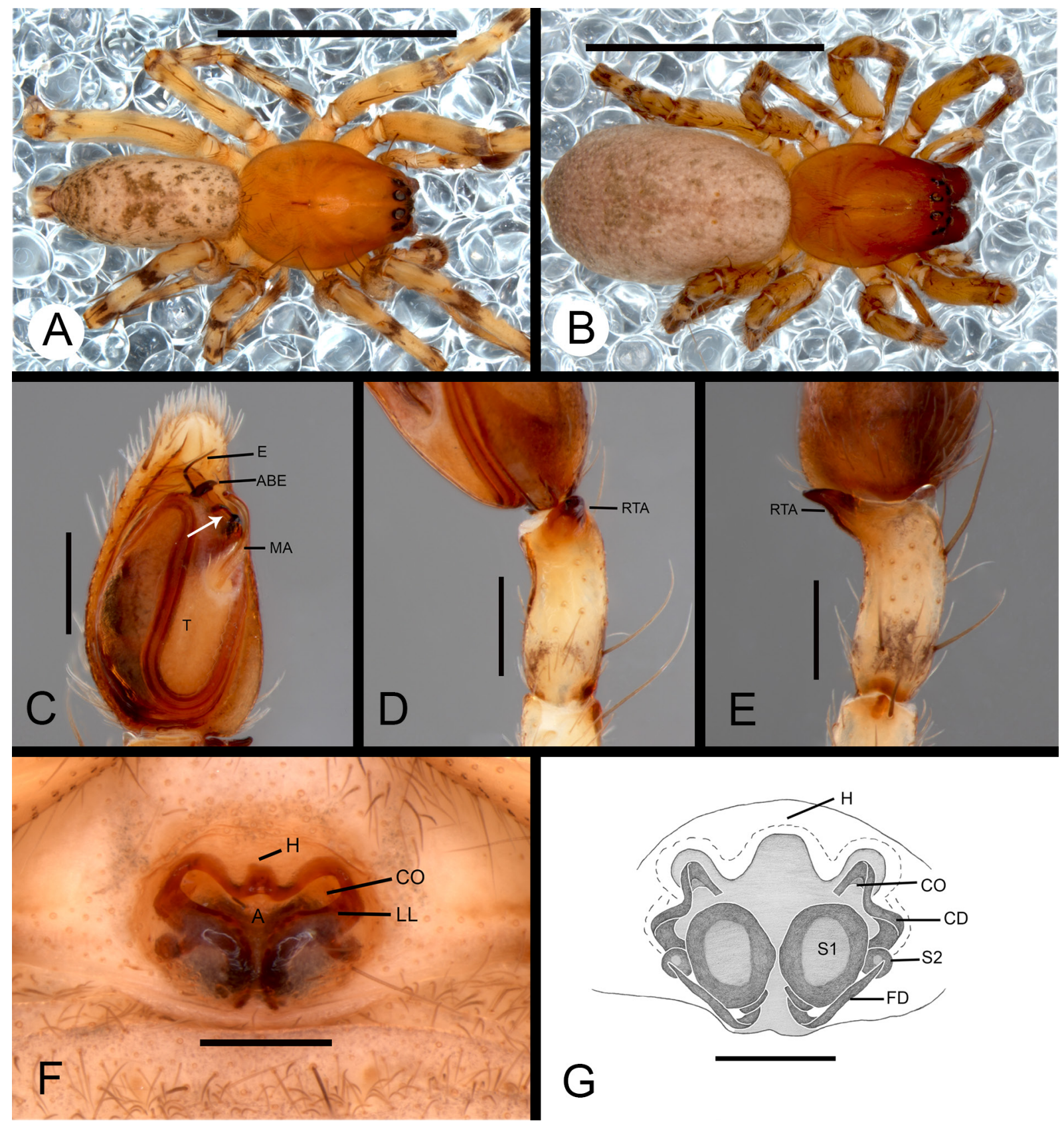

Fig. 19. Tafana huatanay sp. nov. (A, C-E=holotype, $\widehat{O}$, MUSM B, F-G=paratype,, , MUSM). A. Habitus, dorsal view. B. Habitus, dorsal view. C. Left palp, ventral view (arrow indicating the base of the embolus). D. Left palp, retrolateral view. E. Left palp, dorsal view. F. Epigynum, ventral view. G. Vulva, dorsal view. Abbreviations: $\mathrm{A}=$ atrium; $\mathrm{ABE}=$ apophysis of base of the embolus; $\mathrm{CD}=$ copulatory ducts; $\mathrm{CO}=$ copulatory opening; $\mathrm{E}=$ embolus; $\mathrm{FD}=$ fertilization ducts; $\mathrm{H}=$ hood; $\mathrm{LL}=$ lateral lobes; $\mathrm{MA}=$ median apophysis; RTA= retrolateral tibial apophysis; $\mathrm{S} 1=$ primary spermathecae; $\mathrm{S} 2=$ secondary spermathecae; $\mathrm{T}=$ tegulum. Scale bars: $\mathrm{A}-\mathrm{B}=2.16 \mathrm{~mm} ; \mathrm{C}-\mathrm{G}=0.25 \mathrm{~mm}$. 


\section{Variation}

Five males: total length 4.4-7.9; carapace 2.0-3.3; femur I 1.9-2.6. Six females: total length 4.3-5.3; carapace 1.8-2.0; femur I 1.3-1.5.

\section{Distribution}

Colombia, Ecuador, Peru and Bolivia (Fig. 34).
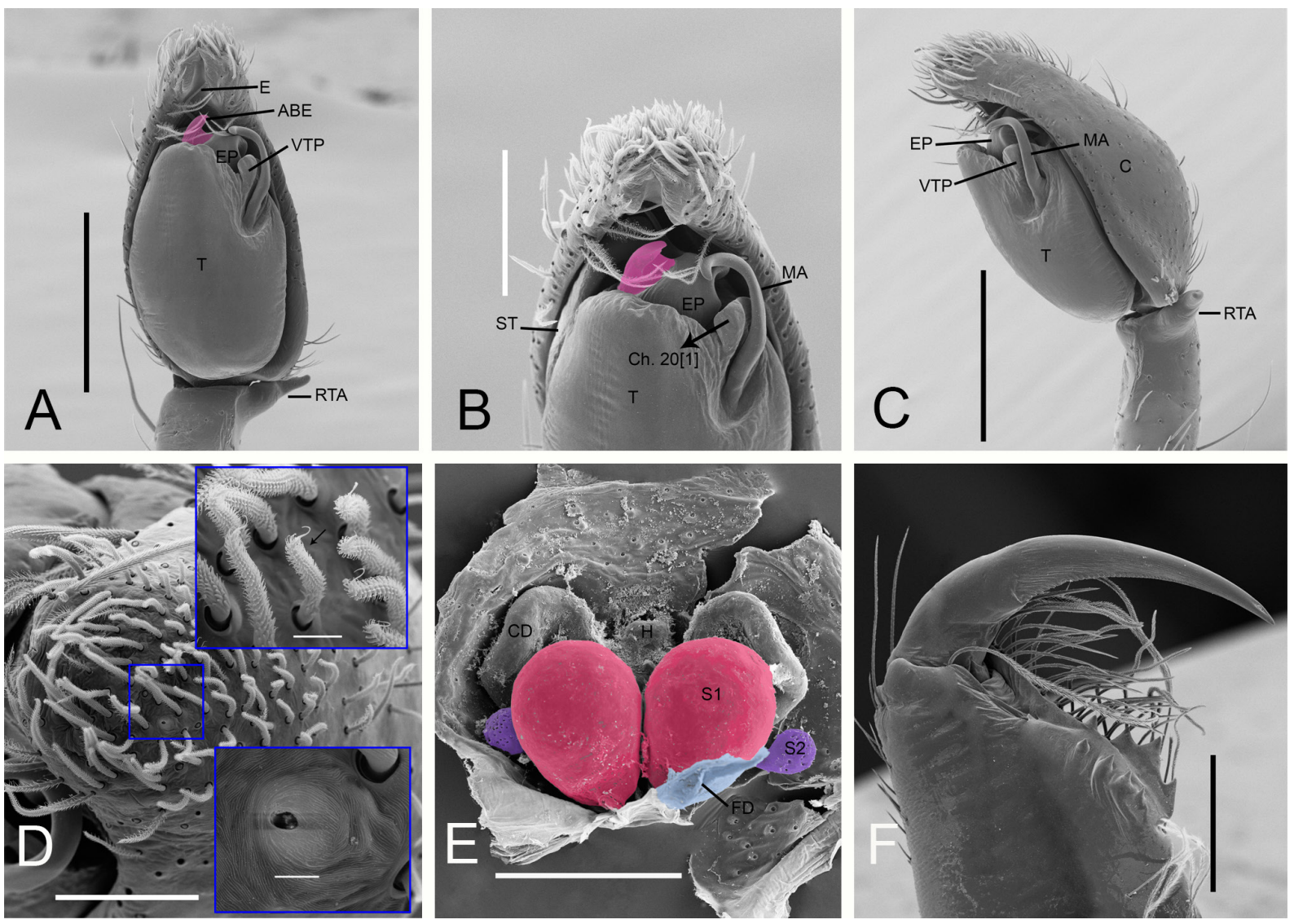

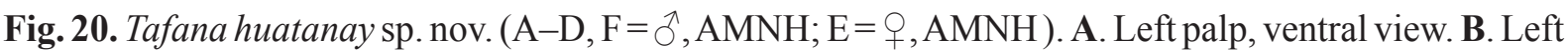
palp, ventral view (arrow indicating character). C. Left palp, retrolateral view. D. Left palp, frontal view (details of the patch of chemosensory setae and tarsal organ on the cymbium). E. Vulva, dorsal view. F. Right chelicera, ventral view. Abbreviations: $\mathrm{ABE}=$ apophysis of base of the embolus; $\mathrm{C}=$ cymbium; $\mathrm{CD}=$ copulatory ducts; $\mathrm{Ch}=$ character; $\mathrm{E}=$ embolus; $\mathrm{EP}=$ embolic process; $\mathrm{FD}=$ fertilization ducts; $\mathrm{H}=$ hood; $\mathrm{MA}=$ median apophysis; $\mathrm{RTA}=$ retrolateral tibial apophysis; $\mathrm{ST}=$ subtegulum; $\mathrm{S} 1=$ primary spermathecae; $\mathrm{S} 2=$ secondary spermathecae; $\mathrm{T}=$ tegulum; $\mathrm{VTP}=$ ventral tegular process. Scale bars: $\mathrm{A}$, $\mathrm{C}=0.4 \mathrm{~mm} ; \mathrm{B}=0.2 \mathrm{~mm} ; \mathrm{D}=0.1 \mathrm{~mm}$ (details chemosensory setae $=0.01 \mathrm{~mm}$; tarsal organ $=0.05 \mathrm{~mm}$ ); $\mathrm{E}-\mathrm{F}=0.2 \mathrm{~mm}$. 


\section{Tafana ruizi sp. nov. urn:lsid:zoobank.org:act:DAF38D70-D874-40E0-9C78-A041F4B36B88}

Figs 21, 33B, 34

\section{Diagnosis}

Males of Tafana ruizi sp. nov. resemble those of T. straminea and T. kunturmarqa sp. nov. by having the base of the embolus large and inclined, but differ by having the ventral tegular process large and apex of tegulum not rounded (Fig. 21C). Females resemble those of T. straminea and T. kunturmarqa sp. nov. by having the atrial septum, but differ by having the wide atrium, showing the copulation openings and hood long and circular (Figs 21F-G, 33B).

\section{Etymology}

The specific name is a patronym in honor of the Cuban arachnologist Alexandre Sánchez-Ruiz for his contributions to the taxonomy of spiders.

\section{Material examined}

\section{Holotype}

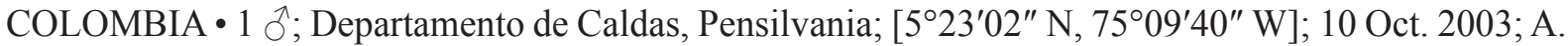
Sánchez-Ruiz leg.; IBSP 258183.

\section{Paratype}

COLOMBIA • 1 ; ; same collection data as for holotype; IBSP 258183.

\section{Description}

Male (holotype, IBSP 258183)

Color. Carapace reddish brown (Fig. 21A). Labium, sternum and endites yellow. Chelicerae reddish brown. Legs I-IV yellow with spots, darker at tarsi. Abdomen dark with spots yellow in dorsal view (Fig. 21A).

MeAsurements. Total length 6.9, carapace length 3.2, width 2.5. Clypeus height 0.1. Eye diameters and interdistances: AME 0.1, ALE 0.14, PME 0.14, PLE 0.14; AME-AME 0.08, AME-ALE 0.1, PMEPME 0.16, PME-PLE 0.16, ALE-PLE 0.04. Chelicerae 2.0 long, with four promarginal teeth and five retromarginal denticles.

LEG MEASUREMENTS. I-femur 2.7 / patella 1.2 /tibia 2.7 /metatarsus $2.3 /$ tarsus $1.1 /$ total 10.0 ; II2.5/1.1/2.5/2.0/1.0/9.1; III—2.0/0.9/1.4/1.7/0.6/6.6; IV—2.4/1.1/2.3/2.7/0.8/9.3.

Leg Spination. I-tibia v1-2-1-1-1, metatarsus v2-0-0; II-tibia v0-2-1; III-tibia v1-2-2, p0-0-1, r0-1-1, metatarsus v2-0-2, p0-1-1, r0-1-1; IV-tibia v1-2-2, r1-1-0, metatarsus v2-0-2.

PALP. Retrolateral tibial apophysis long and curved; cymbium with retrolateral projection; apophysis at the base of the embolus short and furrowed; embolus long; ventral tegular process wide and near the median apophysis; sperm duct with the secondary looping almost reaching apex of tegulum (Fig. 21CE).

AвDOMEN. Length 3.6, epigastric furrow 0.9 from tracheal spiracle, spiracle 1.1 from base of spinnerets.

Female (paratype, IBSP 258183)

Color. Coloration as in males of this species, except for the reddish carapace and chelicerae reddish brown and robust (Fig. 21B). Abdomen gray with spots in dorsal view (Fig. 21B). 
MEASUREMENTS. Total length 7.4, carapace length 3.0, width 2.4. Clypeus height 0.10. Eye diameters and interdistances: AME 0.12, ALE 0.14, PME 0.14, PLE 0.14; AME-AME 0.06, AME-ALE 0.06, PME-PME 0.2, PME-PLE 0.12, ALE-PLE 0.04. Chelicerae 1.2 long, with five promarginal teeth and six retromarginal denticles.

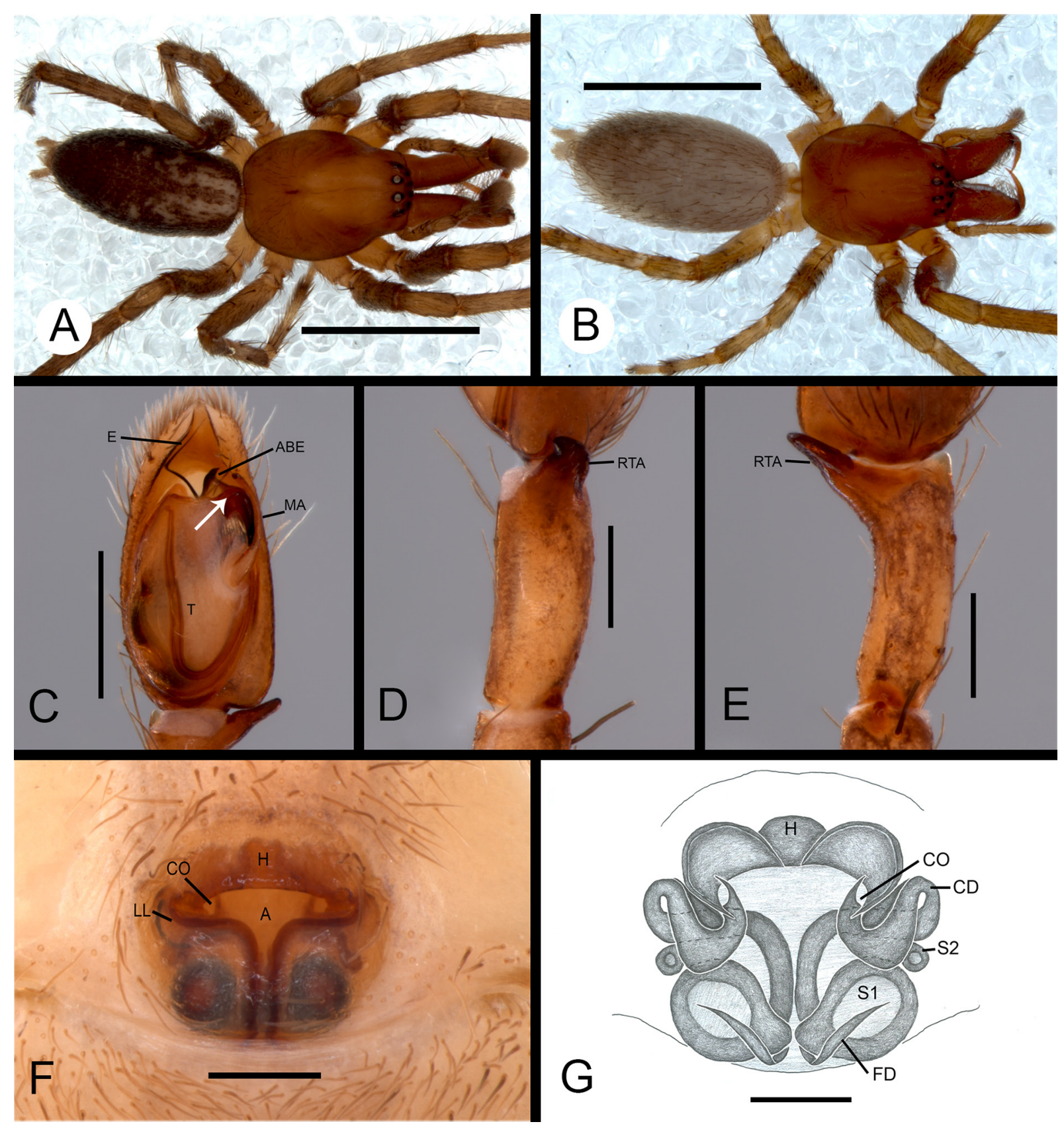

Fig. 21. Tafana ruizi sp. nov. (A, C-E=holotype, $\widehat{O}$, IBSP 258183; B, E-F=paratype, $\uparrow$, IBSP 258183). A. Habitus, dorsal view. B. Habitus, dorsal view. C. Left palp, ventral view (arrow indicating the base of the embolus). D. Left palp, retrolateral view. E. Left palp, dorsal view. F. Epigynum, ventral view. G. Vulva, dorsal view. Abbreviations: $\mathrm{A}=$ atrium; $\mathrm{ABE}=$ apophysis of base of the embolus; $\mathrm{CD}=$ copulatory ducts; $\mathrm{CO}=$ copulatory opening; $\mathrm{E}=$ embolus; $\mathrm{FD}=$ fertilization ducts; $\mathrm{H}=$ hood; $\mathrm{LL}=$ lateral lobes; $\mathrm{MA}=$ median apophysis; RTA= retrolateral tibial apophysis; $\mathrm{S} 1=$ primary spermathecae; $\mathrm{S} 2$ = secondary spermathecae; $T=$ tegulum. Scale bars: $A-B=3.5 \mathrm{~mm} ; C=0.5 \mathrm{~mm} ; \mathrm{D}-\mathrm{G}=0.25 \mathrm{~mm}$. 
Leg MEASUREMENTS. I-femur 2.1 /patella $1.1 /$ tibia 1.9 /metatarsus $1.5 /$ tarsus $0.8 /$ total 7.4 ; II2.0/1.1/1.8/1.5/0.8/7.2; III-1.52/0.9/1.1/1.4/0.5/5.42; IV-2.0/1.0/2.0/2.2/0.6/7.8.

LEG SPINATION. I-tibia v2-2-0, metatarsus v2-0-0; III-metatarsus v2-0-2, p1-0-1, r0-0-1; IV-tibia r0$1-0$, metatarsus v2-0-2, p0-1-1, r0-1-1.

EPigynum. Hood circular; atrial septum present; epigynal plate covered by cuticle in the posterior region; lateral lobes extremely curved in anterior region. Internally, copulatory ducts sinuous and laminar; primary spermathecae large and oval; secondary spermathecae short and rounded in the anterior region on the copulatory ducts; fertilization ducts long over the primary spermathecae (Figs 21F-G, 33B).

AвDOMEn. Length 4.1, epigastric furrow 0.98 from tracheal spiracle, spiracle 1.9 from base of spinnerets.

\section{Distribution}

Colombia (Fig. 34).

\section{The silhavyi group}

\section{Diagnosis}

Males of this group can be recognized by having the apophysis at the base of the embolus curved and laminar (Figs 9C-D, 22C, 23B, 26A-B); the sperm duct forming an inverted 'S-shape' in the male palp not expanded, with secondary looping in the middle of the tegulum (Figs 9A, 22C, 25C). The females can be recognized by having the atrium wide and copulatory ducts large in the anterior region (Figs 22G, 26D, 33D-F).

\section{Included species}

Tafana silhavyi (Caporiacco, 1955), T. chimire sp. nov., T. maracay sp. nov., T. arawak sp. nov., T. pettieri sp. nov.

Tafana silhavyi (Caporiacco, 1955)

Figs $6 \mathrm{E}, 8 \mathrm{~A}-\mathrm{B}, \mathrm{G}-\mathrm{K}, 9 \mathrm{~A}, \mathrm{C}-\mathrm{D}, 22-23,33 \mathrm{C}, 34$

Anyphaena silhavyi Caporiacco, 1955: 386, fig. 51a-b (type: male holotype from El Junquito, Venezuela, deposited in MUCV, examined).

Tafana silhavyi - Brescovit 1997: 90.

\section{Diagnosis}

Males of Tafana silhavyi resemble those of T. chimirae sp. nov., T. maracay sp. nov., T. arawak sp. nov. and T. pittieri sp. nov. by having the laminar apophysis at the base of the embolus, but differ by presenting a secondary looping with wide curvature (Figs 9A, 22C). Females resemble those of T. maracay sp. nov. and $T$. arawak sp. nov. by having the wide atrium, but differ by having the copulatory ducts extremely large in the anterior region (Figs $22 \mathrm{~F}-\mathrm{G}, 33 \mathrm{C}$ ).

\section{Material examined}

\section{Holotype}

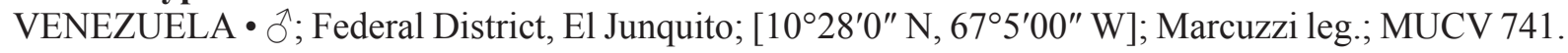

\section{Other material}

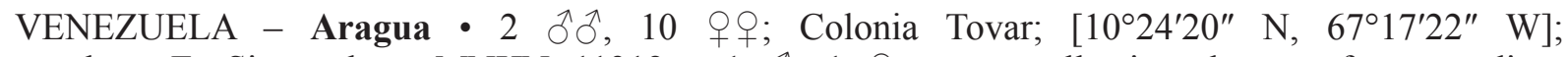

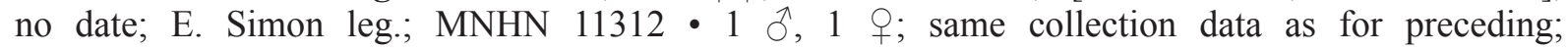
IBSP 258184. 


\section{Description}

Male (MNHN 11312)

CoLor. Exemplar probably discolored. Carapace orange with cephalic region dark (Fig. 22A). Labium,

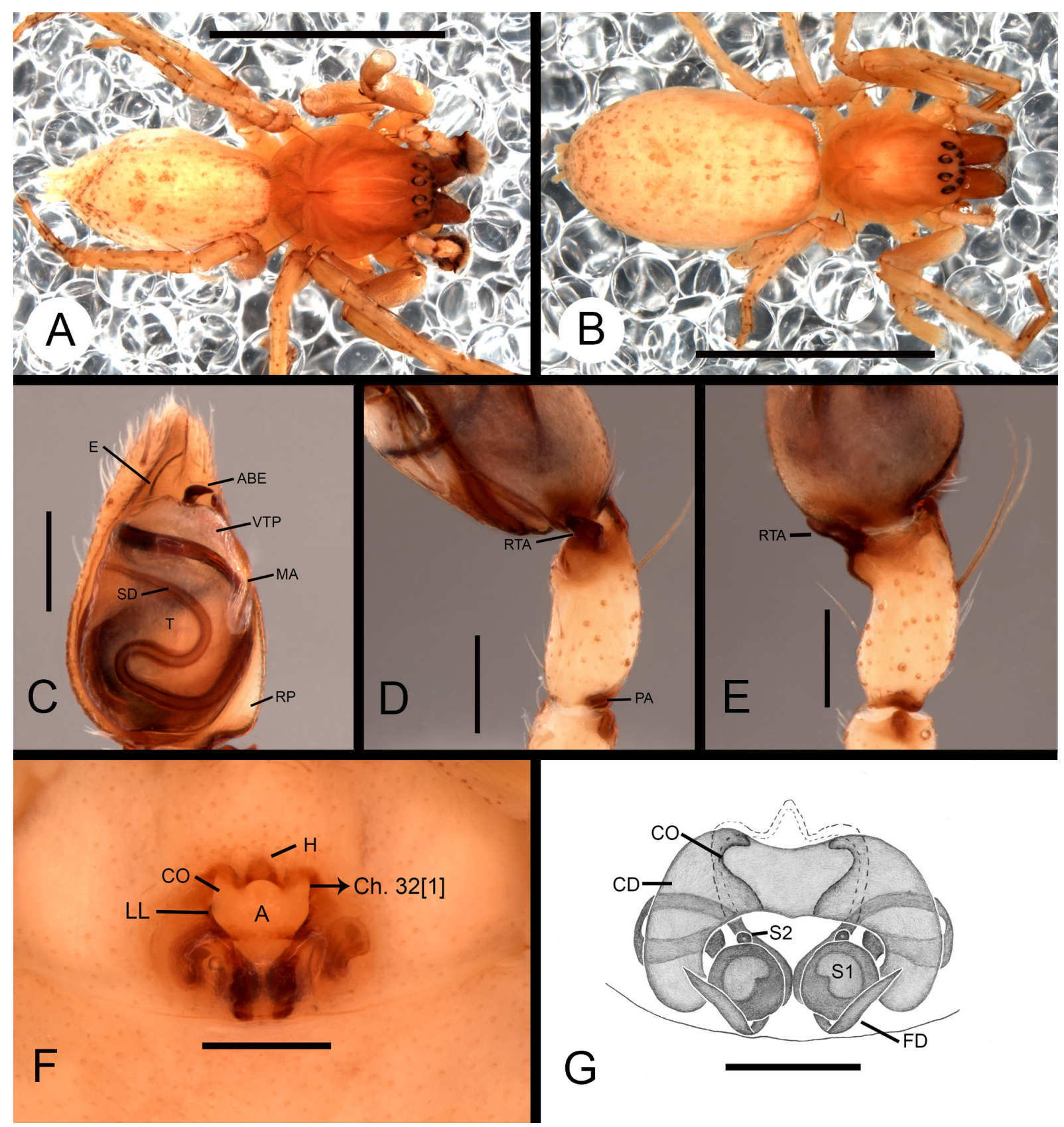

Fig. 22. Tafana silhavyi (Caporiacco, 1955) (A, C-E = $\widehat{O}$, MNHN 11312; $\mathrm{B}, \mathrm{F}-\mathrm{G}=q, \mathrm{MNHN}$ 11312). A. Habitus, dorsal view. B. Habitus, dorsal view. C. Left palp, ventral view. D. Left palp, retrolateral view. E. Left palp, dorsal view. F. Epigynum, ventral view (arrow indicating character). G. Vulva, dorsal view. Abbreviations: $\mathrm{A}=$ atrium; $\mathrm{ABE}=$ apophysis of base of the embolus; $\mathrm{CD}=$ copulatory ducts; $\mathrm{CO}=$ copulatory opening; $\mathrm{Ch}=$ character; $\mathrm{E}=$ embolus; $\mathrm{FD}=$ fertilization ducts; $\mathrm{H}=$ hood; $\mathrm{LL}=$ lateral lobes; $\mathrm{MA}=$ median apophysis; $\mathrm{PA}=$ patellar apophysis; $\mathrm{RP}=$ retrolateral projection; $\mathrm{RTA}=$ retrolateral tibial apophysis; $\mathrm{S} 1$ = primary spermathecae; $\mathrm{S} 2=$ secondary spermathecae; $\mathrm{SD}=$ sperm duct; $\mathrm{T}=$ tegulum; $\mathrm{VTP}=$ ventral tegular process. Scale bars: $\mathrm{A}-\mathrm{B}=2.16 \mathrm{~mm} ; \mathrm{C}-\mathrm{G}=0.25 \mathrm{~mm}$. 
sternum and endites yellow. Chelicerae reddish. Legs I-IV yellow, darker at tarsi. Abdomen gray with dark spots (Fig. 22A).

Measurements. Total length 4.2, carapace length 1.73, width 1.1. Clypeus height 0.06. Eye diameters and interdistances: AME 0.08, ALE 0.12, PME 0.1, PLE 0.1; AME-AME 0.02, AME-ALE 0.02, PMEPME 0.1, PME-PLE 0.06, ALE-PLE 0.04. Chelicerae 0.9 long, with four promarginal teeth and seven retromarginal denticles.

LEG MEASUREMENTS. I-femur 1.9 /patella $0.7 /$ tibia 2.1 /metatarsus $1.8 /$ tarsus $0.7 /$ total $7.2 ;$ II$1.7 / 0.7 / 1.13 / 1.49 / 0.65 / 5.67$;II-1.3/0.5/0.9/1.1/0.4/4.2; IV-1.9/0.7/1.5/1.9/0.5/6.5.

Leg Spination. I-tibia v2-2-2, p1-0-1, r1-0-1, metatarsus v2-0-0, p0-1-0, r0-1-0; II-tibia v2-2-2, p1-0-1, r1-0-1, metatarsus p0-1-0, r0-1-0; III-tibia v1-2-2, p1-1-0, r1-1-0; IV—tibia p1-1-1.

PALP. Retrolateral tibial apophysis short and curved; cymbium with retrolateral projection; projection at the base of the embolus laminar and coiled; embolus long, with large base and narrow apex; median apophysis long and curved apically; ventral tegular process hyaline and short; sperm duct an inverted 'S-shape' (Figs 22C-E, 23A-C).

ABdomEn. Length 2.4, epigastric furrow 0.6 from tracheal spiracle, spiracle 1.2 from base of spinnerets.

\section{Female (MNHN 11312)}

Color. Exemplar probably discolored. Coloration as in males of this species (Fig. 22B).

Measurements. Total length 4.4, carapace length 1.45, width 1.3. Clypeus height 0.04. Eye diameters and interdistances: AME 0.06, ALE 0.08, PME 0.06, PLE 0.08; AME-AME 0.02, AME-ALE 0.02, PME-PME 0.1, PME-PLE 0.04, ALE-PLE 0.04. Chelicerae 0.6 long, with four promarginal teeth and five retromarginal denticles.

LEG MEASUREMENTS. I-femur 1.3 /patella $0.6 /$ tibia 1.3 /metatarsus $1.1 /$ tarsus $0.5 /$ total 4.8 ; II1.2/0.6/1.13/1.0/0.5/4.43; III—1.0/0.4/0.7/0.9/0.4/3.4; IV—1.4/0.5/1.1/1.3/0.48/4.78.
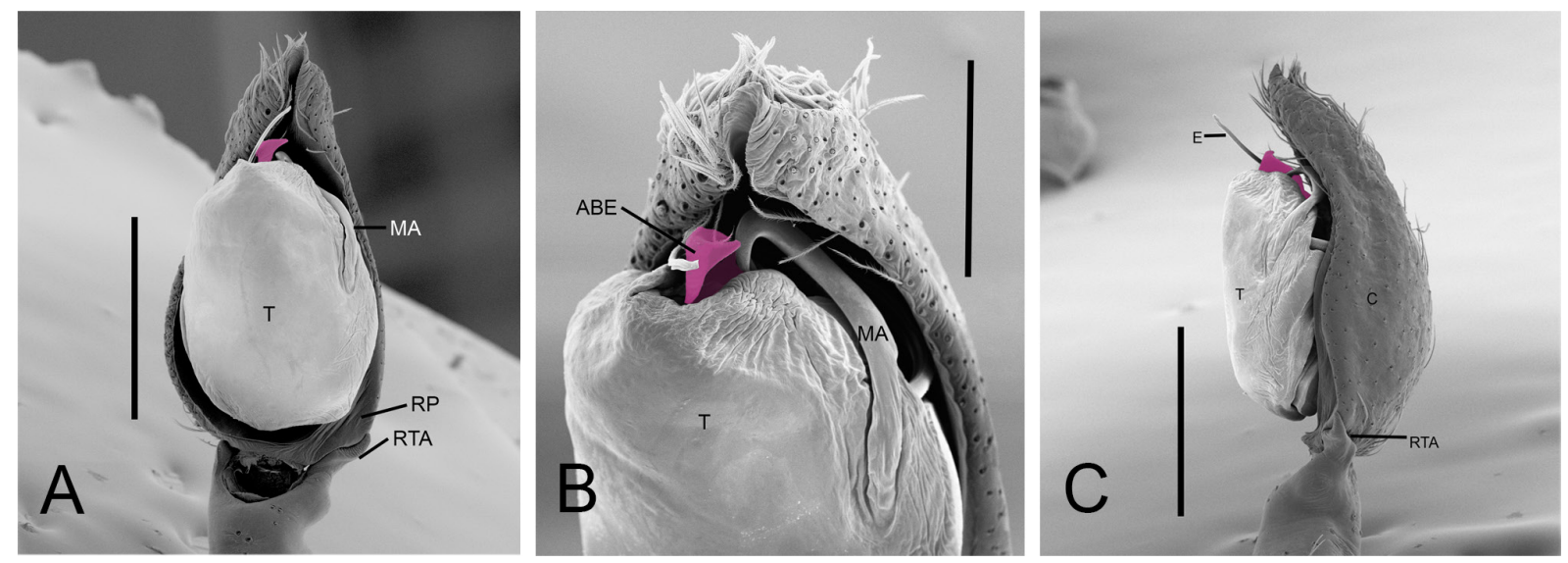

Fig. 23. Tafana silhavyi (Caporiacco, 1955), ठ̊ (MNHN 13312). A. Left palp, ventral view. B. Left palp, frontal view. C. Left palp, retrolateral view. Abbreviations: $\mathrm{ABE}=$ apophysis of base of the embolus; $\mathrm{C}=$ cymbium; $\mathrm{E}=$ embolus; $\mathrm{MA}=$ median apophysis; $\mathrm{RP}=$ retrolateral projection; $\mathrm{RTA}=$ retrolateral tibial apophysis; $\mathrm{T}=$ tegulum. Scale bars: $\mathrm{A}, \mathrm{C}=0.4 \mathrm{~mm} ; \mathrm{B}=0.2 \mathrm{~mm}$. 
Leg SPINATION. I-tibia v2-2-2, p1-1-0, r1-1-0, metatarsus v2-0-0, p1-0-0, r1-0-0; II-tibia v2-2-2, p11-0, r1-1-0, metatarsus p1-0-0, r1-0-0; III-tibia v1-2-2, p1-1-0, r1-1-0, metatarsus v2-1-2; IV-tibia v1-2-2, r1-1-0, metatarsus v2-1-2.

EpIGYNum. Hood triangular and sclerotized, connecting with lateral lobes; atrium large; epigynal plate covered by cuticle in the posterior region; lateral lobes sinuous. Internally, copulatory ducts large in the anterior region; primary spermathecae oval; secondary spermathecae small, above the primary spermathecae; fertilization ducts long (Figs 22F-G, 33C).

ABDOMEN. Length 2.9, epigastric furrow 0.8 from tracheal spiracle, spiracle 1.1 from base of spinnerets.

\section{Variation}

Two males: total length 4.1-4.4; carapace 1.83-1.9; femur I 1.7-1.9. Ten females: total length 4.0-6.2; carapace 1.6-2.3; femur I 1.3-1.9.

\section{Distribution}

Venezuela (Fig. 34).

Tafana chimire sp. nov. urn:Isid:zoobank.org:act:E82DBA67-4582-40CE-878D-AB3F2B6C4351

Figs 24,35

\section{Diagnosis}

Males of Tafana chimire sp. nov. resemble other males of the silhavyi group by the laminar base of the apophysis of the embolus, but differ from them by the base of the retrolateral tibial apophysis with a hook shape apically and the presence of a large basal prominent protuberance on the tegulum (Fig. 24C-E).

\section{Etymology}

The specific name is a noun in apposition taken from the name of the type locality, Chimire.

\section{Material examined}

\section{Holotype}

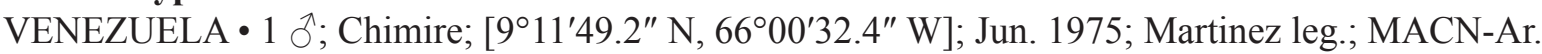

\section{Description}

\section{Male (holotype, MACN-Ar)}

Color. Exemplar probably discolored. Carapace orange with spots on the extremities (Fig. 24A). Labium, sternum and endites orange. Chelicerae reddish. Legs I-IV yellow, darker at tarsi. Abdomen yellow with dark spots (Fig. 24A-B).

MeAsuREmEnTs. Total length 3.8, carapace length 1.8, width 1.5. Clypeus height 0.04. Eye diameters and interdistances: AME 0.06, ALE 0.08, PME 0.08, PLE 0.08; AME-AME 0.02, AME-ALE 0.02, PME-PME 0.08, PME-PLE 0.04, ALE-PLE 0.02. Chelicerae 0.6 long, with four promarginal teeth and six retromarginal denticles. $0.9 / 0.5 / 1.2 / 1.0 / 0.5 / 4.1 ; \mathrm{III}-0.75 / 0.4 / 0.72 / 0.8 / 0.0 / 2.67$ IV— $1.3 / 0.5 / 1.1 / 1.4 / 0.4 / 4.7$. 
Leg SPINATION. I-tibia v2-2-2, p1-0-1, r1-0-1, metatarsus v2-0-0, p0-1-0, r0-1-0; II-tibia v2-2-2, p1-0-1, r1-0-1, metatarsus p0-1-0, r0-1-0; III-tibia v1-2-2, p0-1-1, r0-1-1; IV—tibia p1-1-1.

PALP. Retrolateral tibial apophysis short; cymbium with basal retrolateral projection small; apophysis at the base of the embolus laminar and coiled; embolus long with large base and narrow apex; median apophysis long and curved apically; ventral tegular process hyaline apically in the bulb; sperm duct with secondary looping horizontal position (Fig. 24C-E).

ABDOMEN. Length 1.8, epigastric furrow 0.3 from tracheal spiracle, spiracle 0.8 from base of spinnerets.

\section{Female}

Unknown.

\section{Distribution}

Known only from Chimire, Venezuela (Fig. 35).

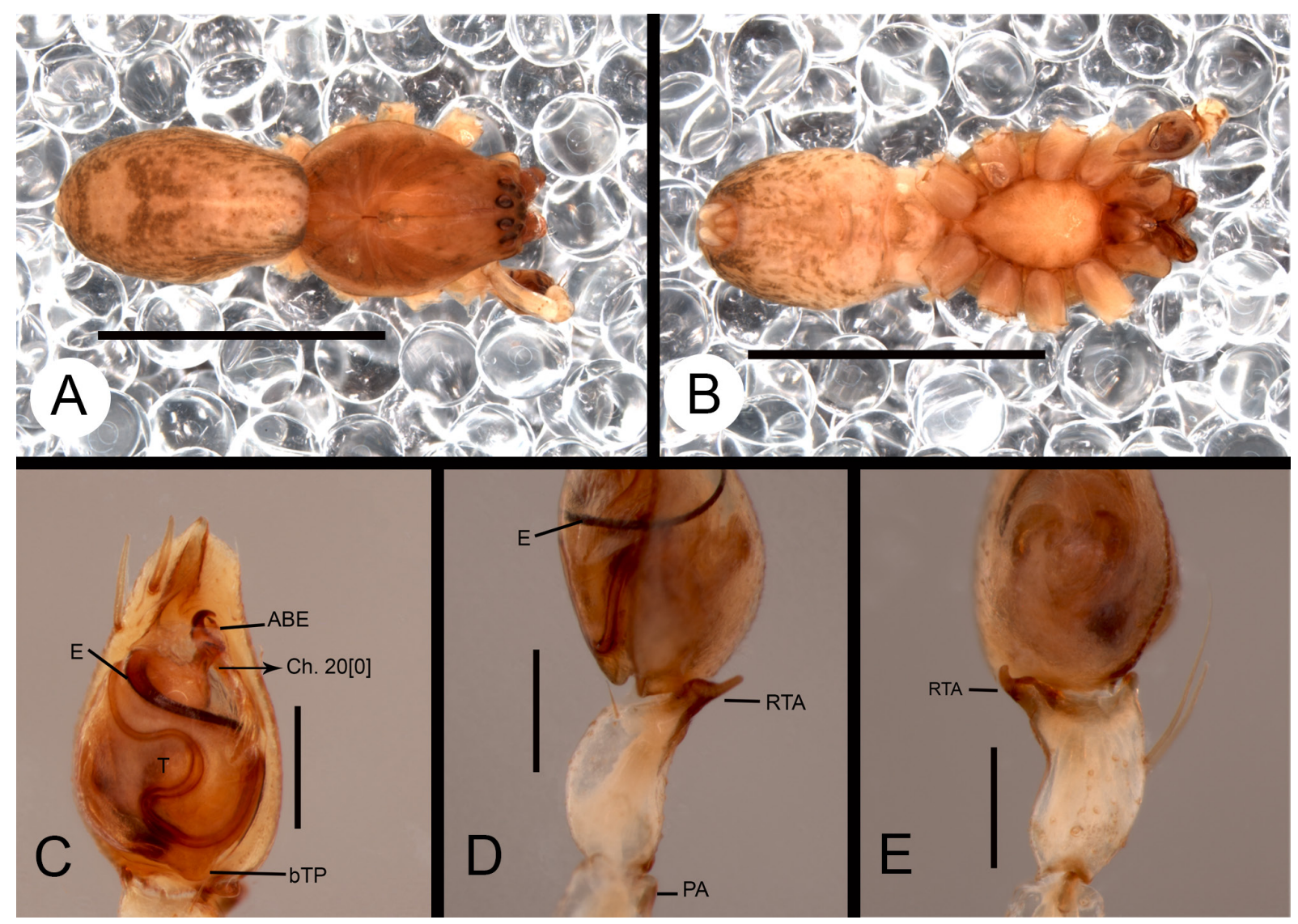

Fig. 24. Tafana chimire sp. nov. (MACN-Ar), $\hat{\jmath}$. A. Habitus, dorsal view. B. Habitus, ventral view. C. Left palp, ventral view (arrow indicating character). D. Left palp, retrolateral view. E. Left palp, dorsal view. Abbreviations: $\mathrm{ABE}=$ apophysis of base of the embolus; $\mathrm{bTP}=$ basal tegular protuberance; $\mathrm{Ch}=$ character; $\mathrm{E}=$ embolus; $\mathrm{PA}=$ patellar apophysis; $\mathrm{RTA}=$ retrolateral tibial apophysis; $\mathrm{T}=$ tegulum. Scale bars: $\mathrm{A}-\mathrm{B}=2.16 \mathrm{~mm}$; $\mathrm{C}-\mathrm{E}=0.25 \mathrm{~mm}$. 
Tafana maracay sp. nov.

urn:1sid:zoobank.org:act:692C24F0-D9ED-4D1B-9831-129C603BB253

Figs $8 \mathrm{C}-\mathrm{F}, 25-26,33 \mathrm{D}, 34$

\section{Diagnosis}

Males of T. maracay sp. nov. resemble those of the silhavyi group by having the apophysis at the base of the embolus laminar, but differ from the other species by having the retrolateral tibial apophysis short, curved apically and presenting a basal projection rounded (Figs 25C-E, 26C). Females resemble those of T. silhavyi and T. arawak sp. nov. by having the epigynal plate with a wide atrium, but differ by having the copulatory ducts slightly narrowing in the anterior region (Figs 25F-G, 33D).

\section{Etymology}

The specific name is a noun in apposition taken from the type locality Maracay, currently the capital of the State of Aragua in Venezuela.

\section{Material examined}

Holotype

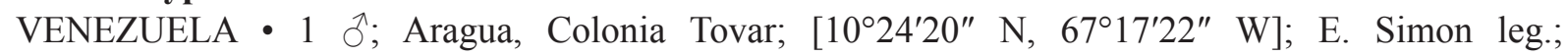
MNHN 11319.

\section{Paratypes}

VENEZUELA • 1 q; same collection data as for holotype; MNHN $11319 \bullet 1 \hat{\jmath}, 1$ q; same collection data as for holotype; IBSP 209871.

\section{Other material}

VENEZUELA - Aragua • 1 ○, 2 우; same collection data as for holotype; MNHN 11314.

\section{Description}

Male (holotype, MNHN 11319)

CoLor. Exemplar probably discolored. Carapace orange with cephalic region dark (Fig. 25A). Labium, sternum and endites yellow. Chelicerae reddish. Legs I-IV yellow, darkest at tarsi. Abdomen yellow with dark spots in dorsal view (Fig. 25A).

Measurements. Total length 4.7, carapace length 2.1, width 1.8. Clypeus height 0.04. Eye diameters and interdistances: AME 0.08, ALE 0.1, PME 0.1, PLE 0.1; AME-AME 0.02, AME-ALE 0.02, PMEPME 0.1, PME-PLE 0.04, ALE-PLE 0.02. Chelicerae 0.6 long, with four promarginal teeth and five retromarginal denticles.

LEG MEASUREMENTS. I-femur 2.0 / patella 0.9 /tibia 2.2 /metatarsus 1.83 /tarsus $0.9 /$ total 7.83 ; II$1.9 / 0.7 / 1.8 / 1.8 / 0.5 / 6.7$; III-1.2/0.6/1.0/1.1/0.4/4.3; IV—1.7/0.6/1.4/1.8/0.49/5.99.

Leg SpinAtion. I-tibia v2-2-2, p0-1-1, r1-1-0, metatarsus v2-0-0, p0-1-0, r0-1-0; II-tibia v2-2-2, p1-1-0, r1-1-0, metatarsus p0-1-0, r0-1-0; III-tibia p1-1-1, r1-1-1; IV—-tibia p1-1-1.

PALP. Retrolateral tibial apophysis short, extremely curved at the apex; cymbium with basal retrolateral projection; apophysis at the base of the embolus laminar and coiled; embolus long with large base and narrow apex; median apophysis long and curved apically; ventral tegular process short and hyaline; subtegulum hardly visible; sperm duct with primary looping large (Figs 25C-E, 26A-C).

AвDOMEN. Length 2.6, epigastric furrow 0.6 from tracheal spiracle, spiracle 1.2 from base of spinnerets. 
Female (paratype, MNHN 11319)

CoLor. Exemplar probably discolored. Coloration as in males of this species (Fig. 25B).

MeAsuREments. Total length 6.6, carapace length 2.5, width 1.95. Clypeus height 0.06. Eye diameters and interdistances: AME 0.08, ALE 0.12, PME 0.1, PLE 0.1; AME-AME 0.02, AME-ALE 0.02, PME-

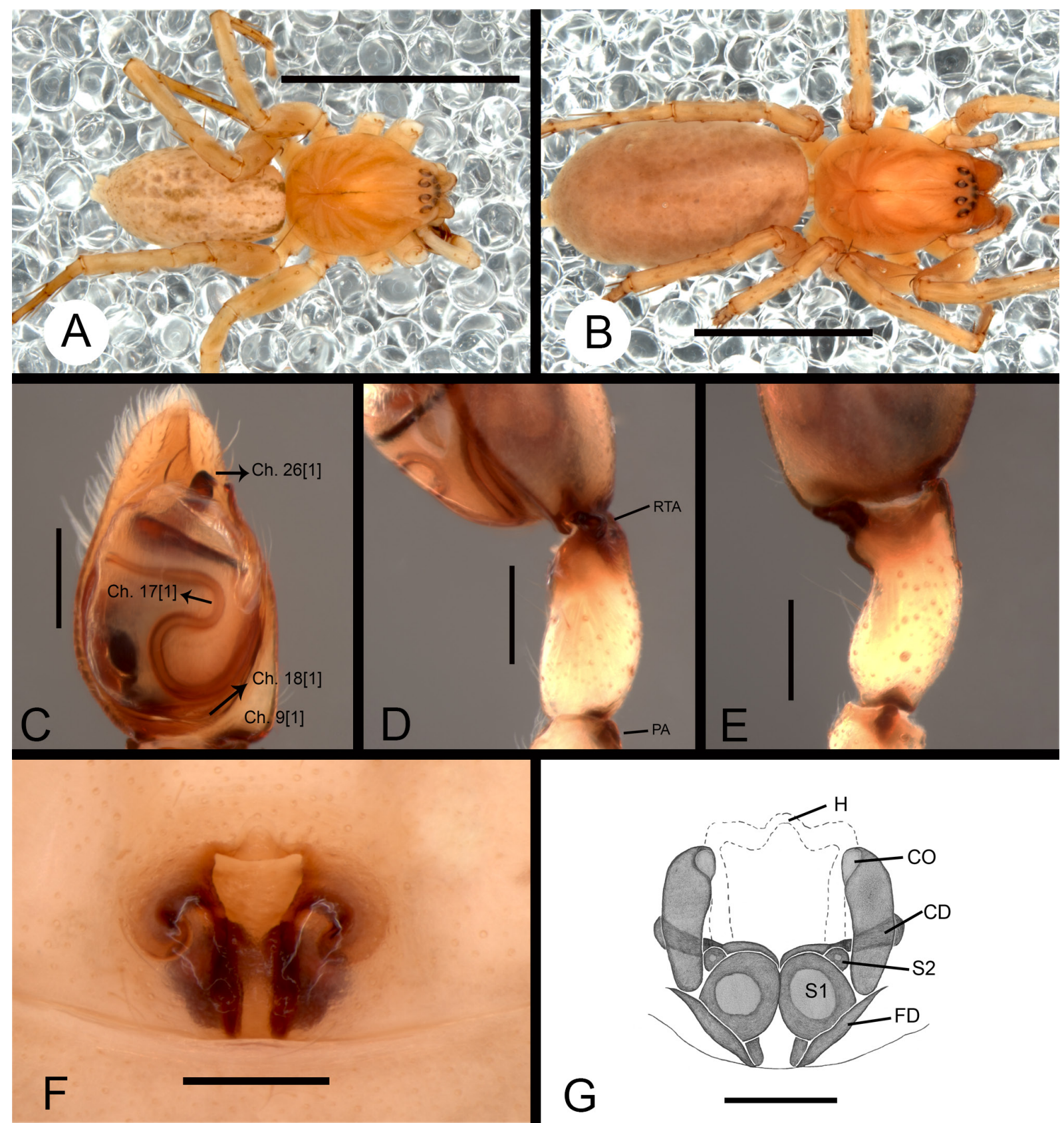

Fig. 25. Tafana maracay sp. nov. (A, $\mathrm{C}-\mathrm{E}=\widehat{\jmath}, \mathrm{MNHN} 11314 ; \mathrm{B}, \mathrm{F}-\mathrm{G}=q$, $\mathrm{MNHN}$ 11314). A. Habitus, dorsal view. B. Habitus, dorsal view. C. Left palp, ventral view (arrow indicating character). D. Left palp, retrolateral view. E. Left palp, dorsal view. F. Epigynum, ventral view. G. Vulva, dorsal view. Abbreviations: $\mathrm{CD}=$ copulatory ducts; $\mathrm{Ch}=$ character; $\mathrm{CO}=$ copulatory opening; $\mathrm{FD}=$ fertilization ducts; $\mathrm{H}=$ hood; $\mathrm{PA}=$ patellar apophysis; $\mathrm{RTA}=$ retrolateral tibial apophysis; $\mathrm{S} 1=$ primary spermathecae; $\mathrm{S} 2=$ secondary spermathecae. Scale bars: $\mathrm{A}=2.16 \mathrm{~mm} ; \mathrm{B}=3.5 \mathrm{~mm} ; \mathrm{C}-\mathrm{G}=0.25 \mathrm{~mm}$. 
PME 0.14, PME-PLE 0.1, ALE-PLE 0.04. Chelicerae 1.0 long, with four promarginal teeth and five retromarginal denticles.

LEG MEASUREMENTS. I-femur 1.8 /patella $0.9 /$ tibia 1.8 /metatarsus $1.5 /$ tarsus $0.8 /$ total 6.8 ; II1.8/0.9/1.6/1.4/0.7/6.4; III—1.5/0.8/1.0/1.22/0.4/4.22; IV—2.0/0.9/1.6/2.2/0.6/7.3.

Leg Spination. I-tibia v2-2-2, p1-1-1, r0-1-0, metatarsus v2-0-0, p0-1-0, r0-1-0; II-tibia v2-2-2, p1-1-1, r0-1-0, metatarsus p0-1-0, r0-1-0; III-tibia p1-1-0, r1-1-0; IV-tibia r1-1-0.

EPIGYNum. Hood triangular and connecting to the lateral lobes; wide atrium; epigynal plate covered by cuticle in the posterior region; lateral lobes sinuous. Internally, copulatory ducts slightly narrow in the anterior region; primary spermathecae oval; secondary spermathecae large, above primary spermathecae; fertilization ducts long (Figs 25F-G, 26D-E, 33D).

AвDomen. Length 4.0, epigastric furrow 1.0 from tracheal spiracle, spiracle 1.7 from base of spinnerets.
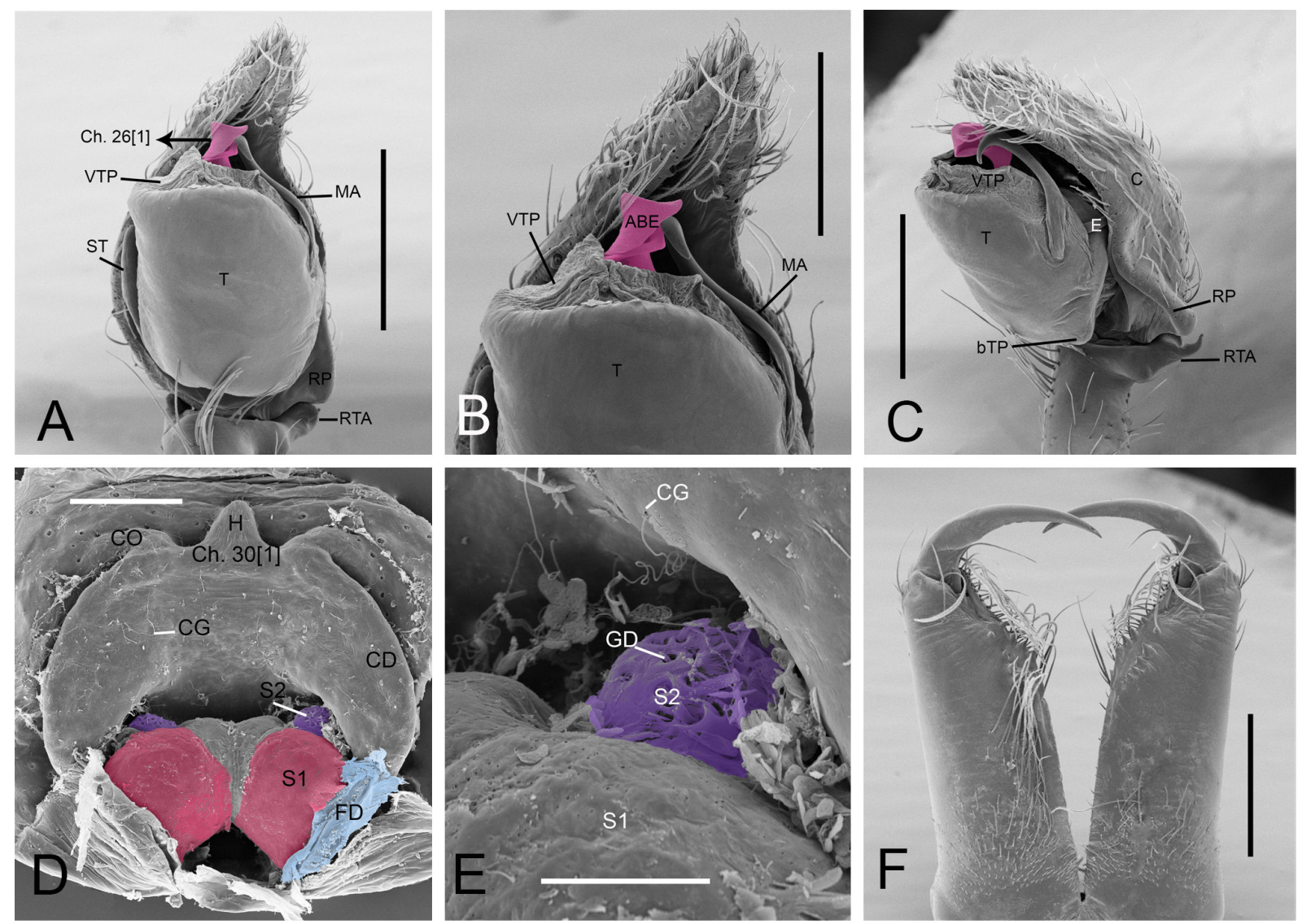

Fig. 26. Tafana maracay sp. nov. (A-C, $\mathrm{F}=\widehat{O}$, MNHN 11314; $\mathrm{D}-\mathrm{E}=q, \mathrm{MNHN}$ 11314). A. Left palp, ventral view (arrow indicating character). B. Left palp, ventral view. C. Left palp, retrolateral view. D. Vulva, dorsal view. E. Vulva, dorsal view, details of spermathecae. F. Chelicerae, ventral view. Abbreviations: $\mathrm{ABE}=$ apophysis of base of the embolus; $\mathrm{bTP}=$ basal tegular protuberance; $\mathrm{C}=$ cymbium; $\mathrm{CD}=$ copulatory ducts; $\mathrm{CG}=$ cuticular glands; $\mathrm{Ch}=$ character; $\mathrm{CO}=$ copulatory opening; $\mathrm{E}=$ embolus; $\mathrm{FD}=$ fertilization ducts; $\mathrm{GD}=$ gland ducts; $\mathrm{H}=$ hood; $\mathrm{MA}=$ median apophysis; $\mathrm{RP}=$ retrolateral projection; $\mathrm{RTA}=$ retrolateral tibial apophysis; $\mathrm{S} 1$ = primary spermathecae; $\mathrm{S} 2=$ secondary spermathecae; $\mathrm{ST}=$ subtegulum; $\mathrm{T}=$ tegulum; $\mathrm{VTP}=$ ventral tegular process. Scale bars: $\mathrm{A}, \mathrm{C}, \mathrm{F}=0.5 \mathrm{~mm} ; \mathrm{B}=0.3 \mathrm{~mm}$; $\mathrm{D}=0.1 \mathrm{~mm} ; \mathrm{E}=0.03 \mathrm{~mm}$. 


\section{Variation}

Three males: total length 4.1-5.3; carapace 1.8-2.4; femur I 1.9-2.5. Four females: total length 4.3-6.6; carapace 1.7-2.3; femur I 1.3-2.0.

\section{Distribution}

Venezuela (Fig. 34).

Tafana arawak sp. nov. urn:1sid:zoobank.org:act:7BF3C0A5-9472-46CF-80F3-AEEDFB9EA022

Figs 27, 33E, 35

\section{Diagnosis}

Males of Tafana arawak sp. nov. resemble others of the silhavyi group by a laminar and coiled apophysis at the base of the embolus, but differ by the retrolateral tibial apophysis bifid (Fig. 27C-E). Females resemble those of T. silhavyi and T. maracay sp. nov. by the epigynal plate with wide atrium, but differ by the atrium extremely wide and the large hood (Figs 27F-G, 33E).

\section{Etymology}

The specific name is derived from the Brazilian Portuguese word 'Aruaques' (in Spanish 'Arahuaco') for the name of an indigenous group from the Americas, named 'Arawak', meaning 'flour eater'. The name should be treated as a noun in apposition.

\section{Material examined}

Holotype

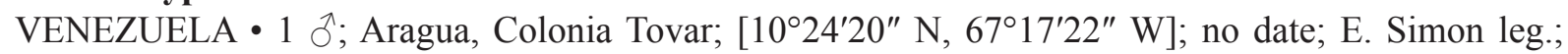
MNHN 11320.

\section{Paratype}

VENEZUELA • 1 \%; same collection data as for holotype; MNHN 11320.

\section{Description}

Male (holotype, MNHN 11320)

COLOR. Exemplar probably discolored. Carapace orange with cephalic region dark (Fig. 27A). Labium, sternum and endites yellow. Chelicerae reddish. Legs I-IV yellow, darkest at tarsi. Abdomen yellow with spots in dorsal view (Fig. 27A).

MEASUREMENTS. Total length 6.1, carapace length 2.7, width 2.2. Clypeus height 0.08 . Eye diameters and interdistances: AME 0.08, ALE 0.12, PME 0.1, PLE 0.12; AME-AME 0.04, AME-ALE 0.02, PMEPME 0.12, PME-PLE 0.06, ALE-PLE 0.04. Chelicerae 1.0 long, with four promarginal teeth and four retromarginal denticles.

Leg MEASUREMENTS. I-femur 3.1/patella $1.1 /$ tibia 3.8/metatarsus $3.27 /$ tarsus $1.3 /$ total 12.57 ; II2.8/1.1/3.1/2.8/1.1/10.9; III—2.0/0.8/1.2/2.0/0.6/6.6; IV—2.8/0.75/2.6/3.2/0.8/10.15.

Leg SpinAtion. I - tibia v2-2-2, p1-1-1, r1-1-1, metatarsus v2-0-0, p0-1-0, r0-1-0; II-tibia v2-2-2, p1-1-0, r1-1-0, metatarsus p0-1-0, r0-1-0; III-tibia v2-2-2, p1-1-0, r1-1-0; IV—tibia p1-1-0.

PALP. Retrolateral tibial apophysis bifid with anterior branch truncated and posterior branch thin; cymbium with retrolateral projection; apophysis at the base of the embolus laminar and coiled; embolus 
long with large base and narrow apex; median apophysis long and curved apically; ventral tegular process long and hyaline; basal protuberance of the tegulum short; sperm duct with secondary looping in oblique position in the tegulum (Fig. 27C-E).

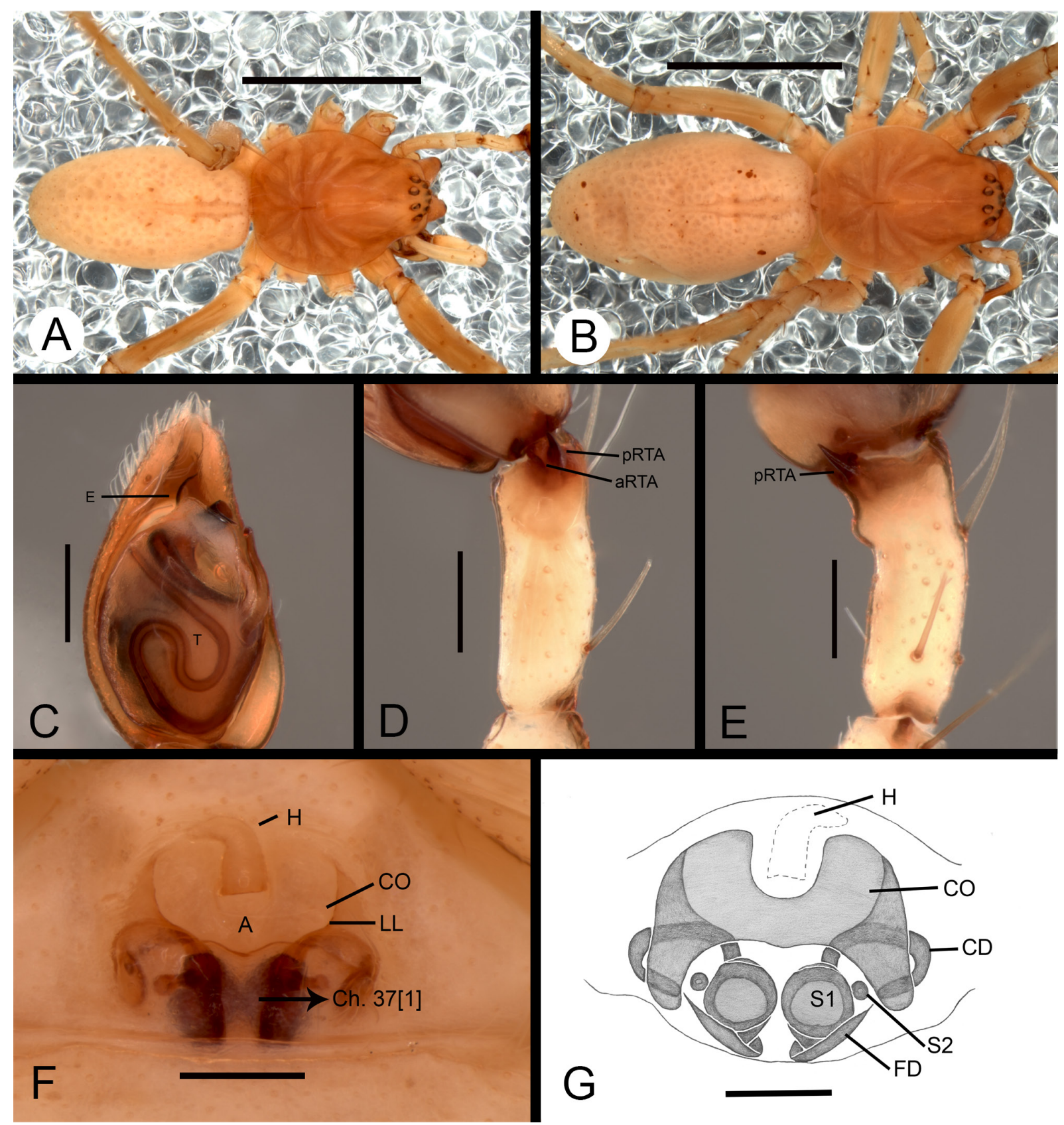

Fig. 27. Tafana arawak sp. nov. (A, C-E=holotype, $\widehat{\partial}$, MNHN 11320; B, F-G=paratype,, , MNHN 11320). A. Habitus, dorsal view. B. Habitus, dorsal view. C. Left palp, ventral view. D. Left palp, retrolateral view. E. Left palp, dorsal view. F. Epigynum, ventral view (arrow indicating character). G. Vulva, dorsal view. Abbreviations: $\mathrm{A}=$ atrium; $\mathrm{aRTA}=$ anterior branch of the retrolateral tibial apophysis; $\mathrm{CD}=$ copulatory ducts; $\mathrm{CO}=$ copulatory opening; $\mathrm{Ch}=$ character; $\mathrm{E}=$ embolus; $\mathrm{FD}=$ fertilization ducts; $\mathrm{H}=$ hood; $\mathrm{LL}=$ lateral lobes; $\mathrm{pRTA}=$ posterior branch of the retrolateral tibial apophysis; $\mathrm{S} 1=$ primary spermathecae; $\mathrm{S} 2=$ secondary spermathecae; $\mathrm{T}=$ tegulum. Scale bars: $\mathrm{A}-\mathrm{B}=3.5 \mathrm{~mm} ; \mathrm{C}-\mathrm{G}=0.25 \mathrm{~mm}$. 
АвDOMEn. Length 3.2, epigastric furrow 0.63 from tracheal spiracle, spiracle 1.6 from base of spinnerets.

Female (paratype, MNHN 11320)

Color. Exemplar probably discolored. Coloration as in males of this species (Fig. 27B).

MEASUREMENTS. Total length 7.1, carapace length 2.9, width 2.2. Clypeus height 0.06. Eye diameters and interdistances: AME 0.08, ALE 0.1, PME 0.1, PLE 0.12; AME-AME 0.02, AME-ALE 0.02, PMEPME 0.14, PME-PLE 0.08, ALE-PLE 0.04. Chelicerae 1.0 long, with four promarginal teeth and six retromarginal denticles.

Leg MEASUREMENTS. I-femur 2.9/patella $1.1 /$ tibia 3.2 /metatarsus $2.59 /$ tarsus $1.1 /$ total 10.89 ; II2.6/1.0/2.75/2.3/1.0/9.65; III-2.0/0.8/1.5/1.7/0.6/6.6; IV-2.8/0.82/2.5/3.1/0.75/9.97.

Leg Spination. I-tibia v2-2-2, p1-1-0, r1-1-0, metatarsus v2-0-0, p0-1-0, r0-1-0; II-tibia v2-2-2, p1-1-0, r1-1-0, metatarsus p0-1-0, r0-1-0; III-tibia p1-1-0, r1-1-0; IV—-tibia r1-1-0.

Epigynum. Hood triangular; wide atrium; epigynal plate covered with hyaline cuticle in the posterior region; lateral lobes sinuous. Internally, copulatory ducts extremely large in the anterior region; primary spermathecae oval and separated; secondary spermathecae small, lateral of the primary spermathecae, and fertilization ducts longer than the primary spermathecae (Figs $27 \mathrm{~F}-\mathrm{G}, 33 \mathrm{E}$ ).

ABDOMEN. Length 4.0, epigastric furrow 0.8 from tracheal spiracle, spiracle 2.2 from base of spinnerets.

\section{Distribution}

Venezuela (Fig. 35).

Tafana pittieri sp. nov.

urn:1sid:zoobank.org:act:5763F405-387A-4B81-B2A2-D2A309390260

Figs $28,33 \mathrm{~F}, 35$

\section{Diagnosis}

Males of Tafana pittieri sp. nov. resemble those of the silhavyi group by having the secondary looping in the middle in the tegulum, but differ from them by having the large laminar, ring-shaped apophysis at the base of the embolus and retrolateral tibial apophysis short and truncated (Fig. 28C-E). Females differ from the other species by having the lateral lobes wing-shaped in the median region, covering part of the atrium, and secondary spermathecae with slender shape (Fig. 28F-G, 33F).

\section{Etymology}

The specific name is a patronym in honor of Henri Pittier, a botanist, geographer and ethnologist who devoted himself to the study of the flora and fauna in the National Park Henri Pittier, where the specimen was collected. In the year of 1953 the park (until then called Rancho Grande) was renamed in honor of H. Pittier.

\section{Material examined}

\section{Holotype}

VENEZUELA - 1 ऽ; Aragua, Rancho Grande, current National Park Henri Pittier; [10 $20^{\prime} 58^{\prime \prime}$ N, 6741'08" W]; 8-15 Apr. 1945; M. Beebe et. al. leg.; AMNH.

\section{Paratype}

VENEZUELA 1 1 ; same collection data as for holotype; AMNH. 


\section{Description}

Male (holotype, AMNH)

Color. Exemplar probably discolored. Carapace orange with cephalic region dark (Fig. 28A). Labium, sternum and endites yellow. Chelicerae reddish. Legs I-IV yellow, darkest at tarsi. Abdomen yellow with spots in dorsal view (Fig. 28A).

MeAsurements. Total length 6.3, carapace length 2.8, width 2.21. Clypeus height 0.08. Eye diameters and interdistances: AME 0.1, ALE 0.12, PME 0.1, PLE 0.12; AME-AME 0.04, AME-ALE 0.04, PMEPME 0.12, PME-PLE 0.1, ALE-PLE 0.04. Chelicerae 1.1 long, with four promarginal teeth and four retromarginal denticles.

LEG MEASUREMENTS. I-femur 3.0/patella 1.1 /tibia 3.5/metatarsus $3.12 /$ tarsus 1.2 /total 11.92 ; II$2.7 / 1.1 / 2.4 / 2.8 / 0.93 / 9.93 ;$ III-1.98/0.8/1.53/2.0/0.6/6.91; IV-2.7/0.9/2.5/3.1/0.7/9.9.

Leg Spination. I-tibia v2-2-2, p1-1-0, r1-1-0, metatarsus v2-0-0, p1-0-0, r1-0-0; II-tibia v2-2-2, p1-1-0, r1-1-0, metatarsus p1-0-0, r1-0-0; III-tibia p1-1-1, r1-1-1; IV—tibia p1-1-1.

PALP. Cymbium with large retrolateral projection, embolus long with large base and narrow apex; median apophysis long and curved apically; ventral tegular process short and hyaline; tegulum without basal protuberance; sperm duct with secondary looping in horizontal position; median apophysis laminar, long and curved at the apex (Fig. 28C-E).

Aвdomen. Length 3.4, epigastric furrow 0.5 from tracheal spiracle, spiracle 1.9 from base of spinnerets.

Female (paratype, AMNH)

Color. Exemplar probably discolored. Coloration as in males of this species, except for chelicerae reddish brown (Fig. 28B).

Measurements. Total length 5.4, carapace length 2.2, width 1.8. Clypeus height 0.06. Eye diameters and interdistances: AME 0.08, ALE 0.1, PME 0.1, PLE 0.1; AME-AME 0.04, AME-ALE 0.02, PMEPME 0.14, PME-PLE 0.08, ALE-PLE 0.04. Chelicerae 2.2 long, with four promarginal teeth and four retromarginal denticles.

LeG MEASUREMENTS. I-femur 1.9 /patella $0.8 /$ tibia 1.8 /metatarsus $1.6 /$ tarsus $0.8 /$ total 6.9 ; II$1.5 / 0.6 / 1.05 / 1.4 / 0.6 / 5.15 ;$ III-1.2/0.5/0.7/1.1/0.4/3.9; IV—1.7/0.7/1.6/2.0/0.52/6.52.

Leg SPINATION. I- tibia v2-2-2, p1-1-0, r1-1-0, metatarsus v2-0-0, p1-0-0, r1-0-0; II-tibia v2-2-2, p0-1-0, r1-1-0, metatarsus p1-0-0, r1-0-1; III-tibia v1-2-2, p1-1-0, r1-1-0, metatarsus v2-1-2, p0-1-1, r0-1-1; IV-tibia v1-2-2, p1-1-1.

EPIGYNUm. Triangular hood with sclerotized border; atrium short; epigynal plate not covered by cuticle, covered in the posterior region; lateral lobes sinuous with wing form in the median region. Internally, copulatory ducts short and curved; primary spermathecae oval and separated; secondary spermathecae small in the posterior region of the copulatory ducts; fertilization ducts longer than primary spermathecae (Figs 28F-G, 33F).

ABdomen. Length 3.2, epigastric furrow 0.6 from tracheal spiracle, spiracle 1.1 from base of spinnerets.

\section{Distribution}

Known only from Aragua, Venezuela (Fig. 33). 


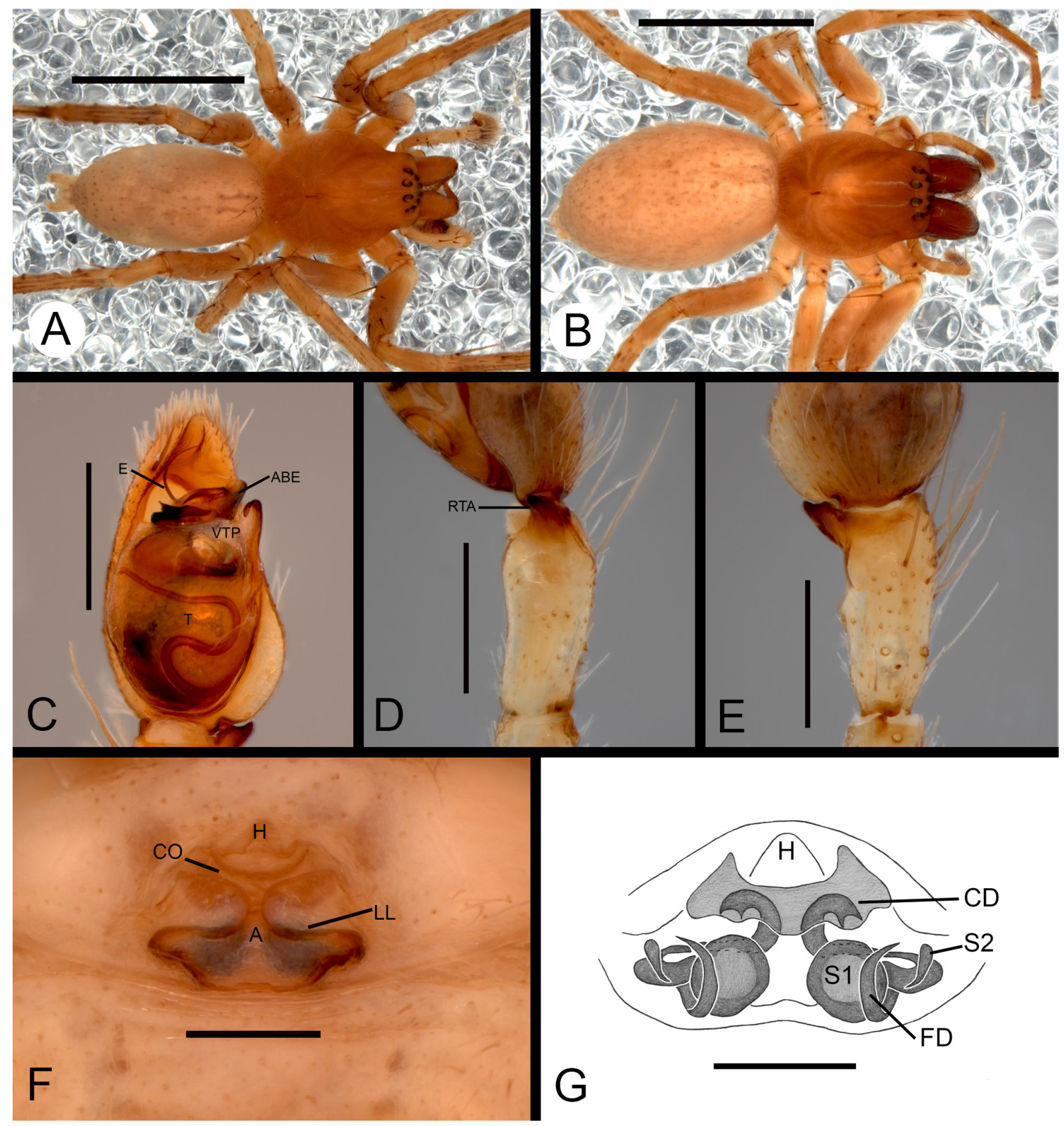

Fig. 28. Tafana pittieri sp. nov. (A, C-E=holotype, $\widehat{\jmath}, \mathrm{AMNH} ; \mathrm{B}, \mathrm{F}-\mathrm{G}=$ paratype, $\left.{ }^{\circ}, \mathrm{AMNH}\right)$. A. Habitus, dorsal view. B. Habitus, dorsal view. C. Left palp, ventral view. D. Left palp, retrolateral view. E. Left palp, dorsal view. F. Epigynum, ventral view. G. Vulva, dorsal view. Abbreviations: $\mathrm{A}=$ atrium; $\mathrm{ABE}=$ apophysis of base of the embolus; $\mathrm{CD}=$ copulatory ducts; $\mathrm{CO}=$ copulatory opening; $\mathrm{E}=$ embolus; $\mathrm{FD}=$ fertilization ducts; $\mathrm{H}=$ hood; $\mathrm{LL}=$ lateral lobes; $\mathrm{RTA}=$ retrolateral tibial apophysis; $\mathrm{S} 1=$ primary spermathecae; $\mathrm{S} 2=$ secondary spermathecae; $\mathrm{T}=$ tegulum; $\mathrm{VTP}=$ ventral tegular process. Scale bars: $A-B=3.5 \mathrm{~mm} ; \mathrm{C}-\mathrm{D}=0.4 \mathrm{~mm} ; \mathrm{F}-\mathrm{G}=0.25 \mathrm{~mm}$. 


\section{Tafana oliviae sp. nov. urn:1sid:zoobank.org:act:A7E716C9-A0F8-4F4E-A451-E6D94A3E82CD}

Figs 29, 33G, 35

\section{Diagnosis}

Males of Tafana oliviae sp. nov. differ from those of the other species in the silhavyi group by having the apophysis at the base of the embolus finger-shaped, retrolateral tibial apophysis bifid with anterior branch short and flattened, posterior branch triangular and median tibial apophysis bifid in dorsal position on the tibia (Fig. 29C-E). Females differ by having the epigynal plate with lateral lobes extremely projected to the sides and by having the small primary spermathecae (Figs $29 \mathrm{~F}-\mathrm{G}, 33 \mathrm{G}$ ).

\section{Etymology}

The specific name is a matronymic in memory of Olivia de Moura Oliveira, the first author's mother.

\section{Material examined}

\section{Holotype}

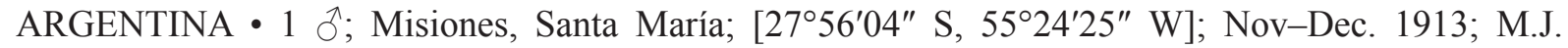
Viana leg.; MACN-Ar 3565.

\section{Paratype}

ARGENTINA • 1 \%; Misiones, Cataratas del Iguazú, near the Puerto Iguazú; [ $25^{\circ} 41^{\prime} 43^{\prime \prime}$ S, 54²6'12" W]; Nov. 1970; M.E. Galiano leg.; MCZ.

\section{Remark}

The male and female were matched by their close localities in Misiones, Argentina. Despite the different colorations of the male and female, the morphology of the genitalia suggests that both exemplars belong to Tafana oliviae sp. nov.

\section{Description}

\section{Male (holotype, MACN-Ar 3565)}

CoLor. Exemplar probably discolored. Carapace orange, darker in cephalic region (Fig. 29A). Labium, sternum and endites yellow. Chelicerae reddish. Legs I-IV yellow. Abdomen yellow with lateral dark spots and a yellow spot in the middle (Fig. 29A).

MeAsuRements. Total length 3.9, carapace length 1.7, width 1.4. Clypeus height 0.04. Eye diameters and interdistances: AME 0.06, ALE 0.08, PME 0.08, PLE 0.06; AME-AME 0.02, AME-ALE 0.04, PME-PME 0.1, PME-PLE 0.06, ALE-PLE 0.02. Chelicerae 1.0 long, with four promarginal teeth and six retromarginal denticles.

LEG MEASUREMENTS. I-femur 2.1 /patella $0.7 /$ tibia 2.5 /metatarsus $2.2 /$ tarsus $1.1 /$ total 8.6 ; II1.6/0.5/1.7/1.5/0.7/6.0; III-1.3/0.6/0.9/1.2/0.4/4.4; IV—2.0/0.6/1.3/2.1/0.6/6.6.

Leg SPINATION. I-tibia v2-2-0, metatarsus v2-0-1; II-tibia v1-2-0; III-tibia v1-1-0, p1-1-0, r1-1-0, metatarsus v2-1-2, r1-0-1; IV-tibia v0-1-1, p1-1-1, r1-1-0.

PALP. Retrolateral tibial apophysis bifid; cymbium without retrolateral projection; embolus short and bifurcate at the apex; median apophysis long and curved apically; sperm duct with secondary looping reaching the apex of the tegulum (Fig. 29C-E).

ABDOMEN. Length 2.1, epigastric furrow 0.6 from tracheal spiracle, spiracle 1.0 from base of spinnerets. 
Female (paratype, MCZ)

Color. Exemplar probably discolored. Coloration as in males of this species except for legs yellow, darker at tarsi. Abdomen yellow (Fig. 29B).

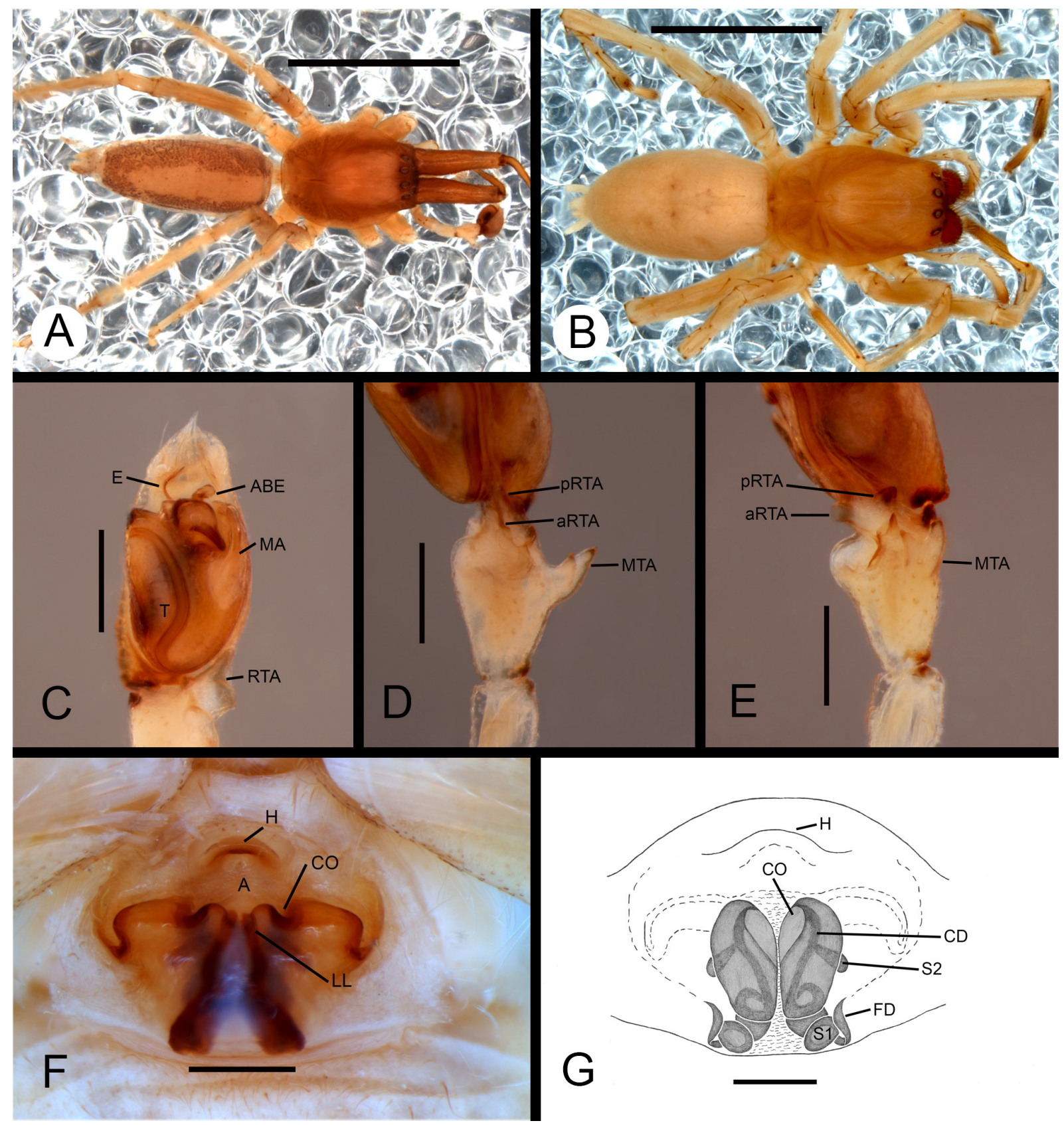

Fig. 29. Tafana oliviae sp. nov. (A, $\mathrm{C}-\mathrm{E}=$ holotype, $\mathrm{O}, \mathrm{MACN}-\mathrm{Ar} 3565 ; \mathrm{B}, \mathrm{F}-\mathrm{G}=$ paratype,, , MCZ). A. Habitus, dorsal view. B. Habitus, dorsal view. C. Left palp, ventral view. D. Left palp, retrolateral view. E. Left palp, retrolateral view. F. Epigynum, ventral view. G. Vulva, dorsal view. Abbreviations: $\mathrm{A}=$ atrium; $\mathrm{ABE}=$ apophysis of base of the embolus; $\mathrm{aRTA}=$ anterior branch of the retrolateral tibial apophysis; $\mathrm{CD}=$ copulatory ducts; $\mathrm{CO}=$ copulatory opening; $\mathrm{E}=$ embolus; $\mathrm{FD}=$ fertilization ducts; $\mathrm{H}=$ hood; $\mathrm{LL}=$ lateral lobes; $\mathrm{MA}=$ median apophysis; $\mathrm{MTA}=$ median tibial apophysis; $\mathrm{pRTA}=$ posterior branch of the retrolateral tibial apophysis; RTA= retrolateral tibial apophysis; $\mathrm{S} 1=$ primary spermathecae; $\mathrm{S} 2=$ secondary spermathecae; $\mathrm{T}=$ tegulum. Scale bars: $\mathrm{A}-\mathrm{B}=3.5 \mathrm{~mm} ; \mathrm{C}-\mathrm{G}=0.25 \mathrm{~mm}$. 
MeAsurements. Total length 5.7, carapace length 2.7, width 1.8. Clypeus height 0.04. Eye diameters and interdistances: AME 0.08, ALE 0.08, PME 0.1, PLE 0.1; AME-AME 0.08, AME-ALE 0.08, PMEPME 0.18, PME-PLE 0.16, ALE-PLE 0.04. Chelicerae 1.1 long, with four promarginal teeth and four retromarginal denticles.

Leg MEASUREMENTS. I-femur 2.0 /patella $0.9 /$ tibia $1.8 /$ metatarsus $1.4 /$ tarsus $0.8 /$ total 6.9 ; II1.9/0.9/1.1/1.3/0.63/5.83; III-1.5/0.72/1.1/1.23/0.5/5.05; IV-2.25/0.8/1.72/2.1/0.7/7.57.

Leg Spination. I-tibia v2-2-0, metatarsus v2-0-0; II-tibia v2-2-0; III-tibia v1-1-2, p0-0-1, r0-0-1, metatarsus v2-1-2; IV-tibia v1-1-2, p1-1-1.

EPIGYNum. Hood semicircular and thick; lateral lobes curved in anterior region; wide atrium; epigynal plate covered by cuticle in the posterior region. Internally, copulatory ducts long and narrow; secondary spermathecae in the anterior region of the copulatory ducts; primary spermathecae small and fertilization ducts longer than primary spermathecae (Figs 29F-G, 33G).

AвDOMEN. Length 2.9, epigastric furrow 0.7 from tracheal spiracle, spiracle 1.4 from base of spinnerets.

\section{Distribution}

Known only from Misiones, Argentina (Fig. 35).

Tafana orinoco sp. nov. urn:1sid:zoobank.org:act:34463201-9F72-43FF-886B-A9EFCE74C526

Figs $30-31,33 \mathrm{H}, 34$

\section{Diagnosis}

Males of Tafana orinoco sp. nov. resemble those of T. pastaza sp. nov. by having the shape of the apophysis at the base of the embolus bifid, but differ by the primary apophysis conical and curved in the apex and secondary apophysis furrowed, median tibial apophysis short and triangular in retrolateral position (Figs 30C-E, 31A-C). Females differ from those of the other species in the silhavyi group by having quadrangular atrium and copulatory ducts extremely large and short in anterior region of the vulva (Figs 30G, 33H).

\section{Etymology}

The specific name, a noun in apposition, is a tribute to 'River Orinoco', one of the most important rivers of the South American continent.

\section{Material examined}

\section{Holotype}

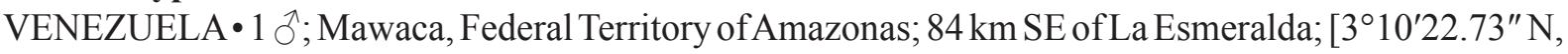
65³2'32.39" W]; 5 Mar. 1985; J. Latke and R. Candia leg.; MIZA 07062.

\section{Paratype}

VENEZUELA • 1 \%; same collection data as for holotype; MIZA 07062.

\section{Other material}

VENEZUELA - Amazonas Division - 1 त̂; Federal Territory of Amazonas, Cerro de La Neblina;

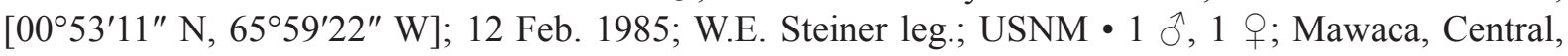

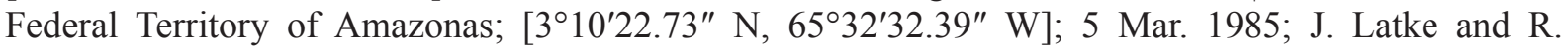
Candia leg.; MIZA 07062. 


\section{Description}

Male (holotype, MIZA 07062)

COLOR. Exemplar probably discolored. Carapace reddish brown (Fig. 30A). Labium, sternum and endites
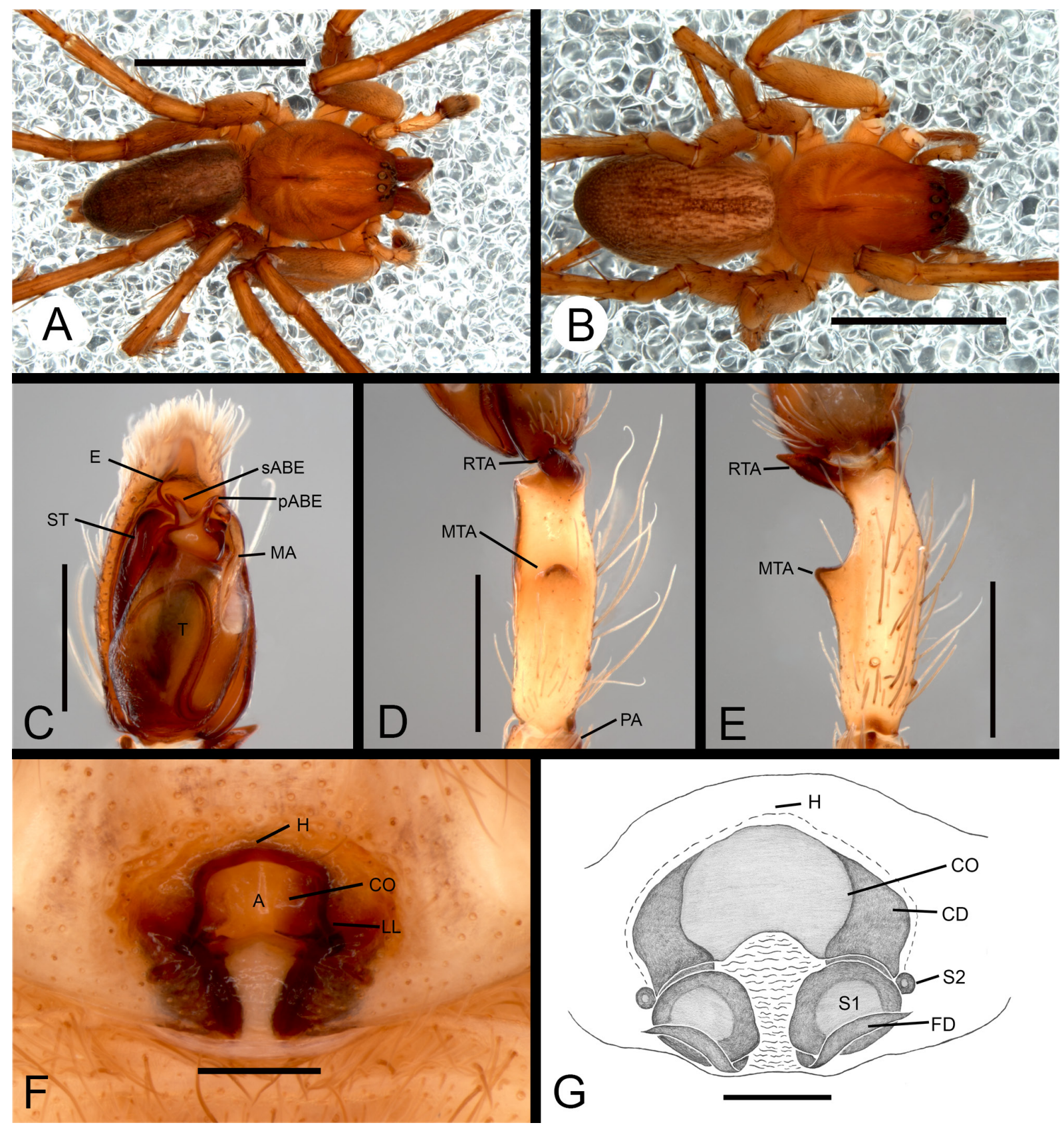

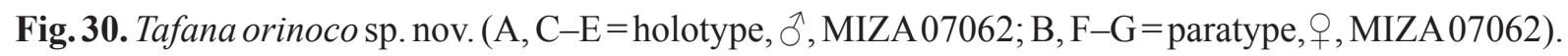
A. Habitus, dorsal view. B. Habitus, dorsal view. C. Left palp, ventral view. D. Left palp, retrolateral view. E. Left palp, dorsal view. F. Epigynum, ventral view. G. Vulva, dorsal view. Abbreviations: A=atrium; $\mathrm{CD}=$ copulatory ducts; $\mathrm{CO}=$ copulatory opening; $\mathrm{E}=$ embolus; $\mathrm{FD}=$ fertilization ducts; $\mathrm{H}=$ hood; $\mathrm{LL}=$ lateral lobes; $\mathrm{MA}=$ median apophysis; $\mathrm{MTA}=$ median tibial apophysis; $\mathrm{PA}=$ patellar apophysis; $\mathrm{ABE}=$ primary apophysis of base of the embolus; $\mathrm{RTA}=$ retrolateral tibial apophysis; $\mathrm{S} 1=$ primary spermathecae; $\mathrm{S} 2=$ secondary spermathecae; $\mathrm{sABE}=$ secondary apophysis of base of the embolus; $\mathrm{ST}=$ subtegulum; $\mathrm{T}=$ tegulum. Scale bars: $\mathrm{A}-\mathrm{B}=3.5 \mathrm{~mm} ; \mathrm{C}=0.5 \mathrm{~mm} ; \mathrm{D}-\mathrm{E}=0.66 \mathrm{~mm} ; \mathrm{F}-\mathrm{G}=0.25 \mathrm{~mm}$. 
reddish brown. Chelicerae reddish. Legs I-IV reddish with spots on the articles. Abdomen with dark spots (Fig. 30A).

MeAsurements. Total length 7.9, carapace length 3.7, width 3.0. Clypeus height 0.1. Eye diameters and interdistances: AME 0.12, ALE 0.18, PME 0.16, PLE 0.16; AME-AME 0.04, AME-ALE 0.02, PMEPME 0.1, PME-PLE 0.08, ALE-PLE 0.02. Chelicerae 1.5 long, with four promarginal teeth and seven retromarginal denticles.

LEG MEASUREMENTS. I-femur 4.0/patella 1.6 /tibia 4.2 /metatarsus $3.9 /$ tarsus $1.9 /$ total 15.6 ; II3.9/1.59/3.8/3.6/1.5/14.39; III-3.2/1.4/2.5/3.1/1.09/11.29; IV—4.1/1.5/3.6/4.5/1.3/15.0.

Leg SPINATIOn. I-tibia v2-2-2, p1-1-0, r1-1-0, metatarsus v2-0-0, p0-1-0, r0-1-0; II - tibia v2-2-2, p1-1-0, r1-1-0, metatarsus p0-1-0, r0-1-0; III-tibia p1-1-1, r1-1-1; IV—-tibia p1-1-1.

PALP. Retrolateral tibial apophysis short and curved; cymbium without retrolateral projection; apophysis at the base of the embolus bifid with secondary apophysis furrowed; embolus short; median apophysis long and curved apically; sperm duct with secondary looping not reaching the apex of the tegulum; subtegulum strongly projected; ventral tegular process inconspicuous (Figs 30C-E, 31A-C).

Abdomen. Length 4.1, epigastric furrow 1.0 from tracheal spiracle, spiracle 2.0 from base of spinnerets.

Female (paratype, MIZA 07062)

Color. Coloration as in males of this species (Fig. 30B).

Measurements. Total length 7.5, carapace 3.4, width 2.6. Clypeus height 0.1. Eye diameters and interdistances: AME 0.12, ALE 0.14, PME 0.14, PLE 0.12; AME-AME 0.02, AME-ALE 0.02, PMEPME 0.18, PME-PLE 0.12, ALE-PLE 0.04. Chelicerae 1.6 long, with four promarginal teeth and five retromarginal denticles.

LeG MEASUREMENTS. I-femur 3.1/patella 1.4 / tibia 3.22 /metatarsus $2.9 /$ tarsus $1.1 /$ total 11.72 ; II3.1/1.2/3.0/2.72/1.1/11.12; III-2.1/1.1/1.6/2.2/0.73/7.73; IV-3.3/1.24/2.9/3.3/0.84/11.58.
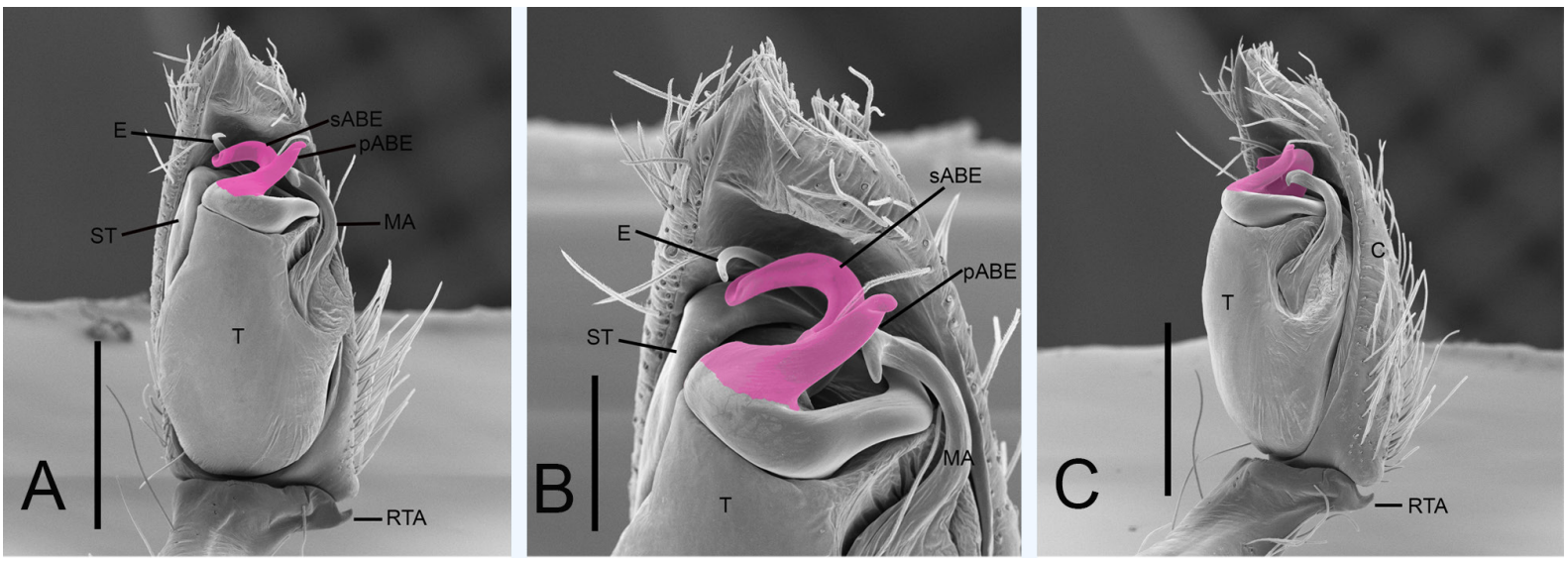

Fig. 31. Tafana orinoco sp. nov., $\lesssim$ (MIZA 07062). A. Left palp, ventral view. B. Left palp, ventral view. C. Left palp, retrolateral view. Abbreviations: $\mathrm{C}=$ cymbium; $\mathrm{E}=$ embolus; $\mathrm{MA}=$ median apophysis; $\mathrm{pABE}=$ primary apophysis of base of the embolus; $\mathrm{RTA}=$ retrolateral tibial apophysis; $\mathrm{sABE}=$ secondary apophysis of base of the embolus; $\mathrm{ST}=$ subtegulum; $\mathrm{T}=$ tegulum. Scale bars: $\mathrm{A}, \mathrm{C}=0.5 \mathrm{~mm} ; \mathrm{B}=0.2 \mathrm{~mm}$. 

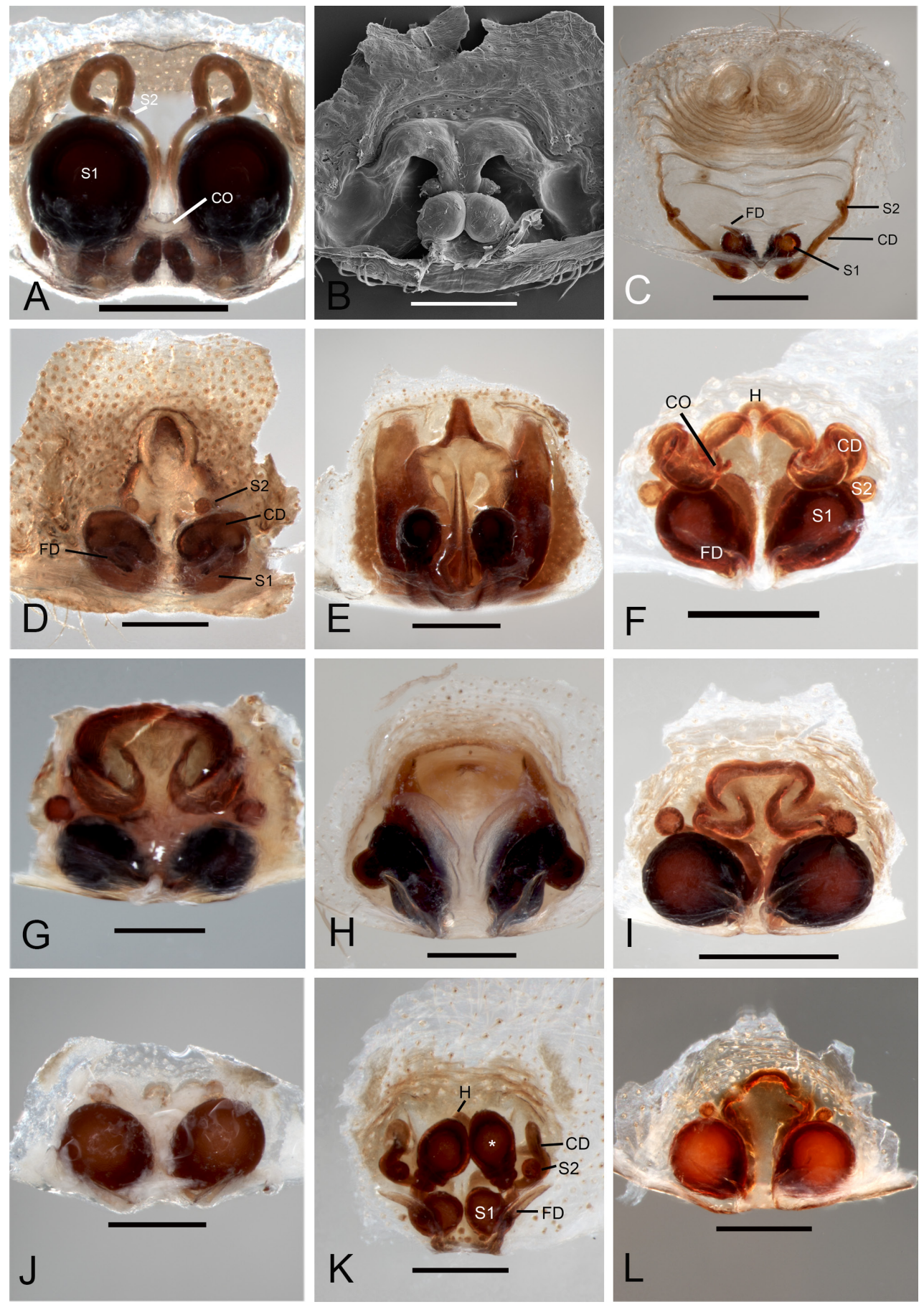

Fig. 32. Female genitalia, digested. A. Arachosia praesignis (Keyserling, 1891) (Amaurobioidinae) (IBSP 87975). B. Xiruana gracilipes (Keyserling, 1891) (Anyphaeninae) (IBSP 166120). C. Aysha prospera Keyserling, 1891 (IBSP 19783). D. Anyphaena accentuata (Walckenaer, 1802) (MCN). E. Patrera fulvastra Simon, 1903 (MCN 24208). F. Tafana riveti Simon, 1903 (MCZ). G. Tafana straminea (L. Koch, 1866) (AMNH). H. Tafana quelchi (Pocock, 1895) (IBSP 32131). I. Tafana kunturmarqa sp. nov. (ICN-Ar). J. Tafana humahuaca sp. nov. (MACN-Ar 41788). K. Tafana pastaza sp. nov. (AMNH). L. Tafana nevada sp. nov. (AMNH). Abbreviations: $\mathrm{CD}=$ copulatory ducts; $\mathrm{CO}=$ copulatory opening; $\mathrm{FD}=$ fertilization ducts; $\mathrm{H}=$ hood; $\mathrm{S} 1=$ primary spermathecae; $\mathrm{S} 2=$ secondary spermathecae. Asterisks to globose membranous extension of proximal copulatory ducts. Scale bars: A-B, D-I, K-L $=0.25 \mathrm{~mm} ; \mathrm{C}=0.3 \mathrm{~mm} ; \mathrm{J}=0.5 \mathrm{~mm}$. 
Leg Spination. I-tibia v2-2-2, p1-1-0, r1-1-0, metatarsus v2-0-0, p0-1-0, r0-1-0; II-tibia v2-2-2, p1-1-0, r1-1-0, metatarsus p0-1-0, r0-1-0; III-tibia p1-1-1, r1-1-1; IV—-tibia p1-1-1.

EpIGYNum. Hood narrow and rounded, connected to the lateral lobes; wide atrium; epigynal plate not covered by hyaline cuticle in the posterior region; sinuous and narrow lateral lobes. Internally, copulatory
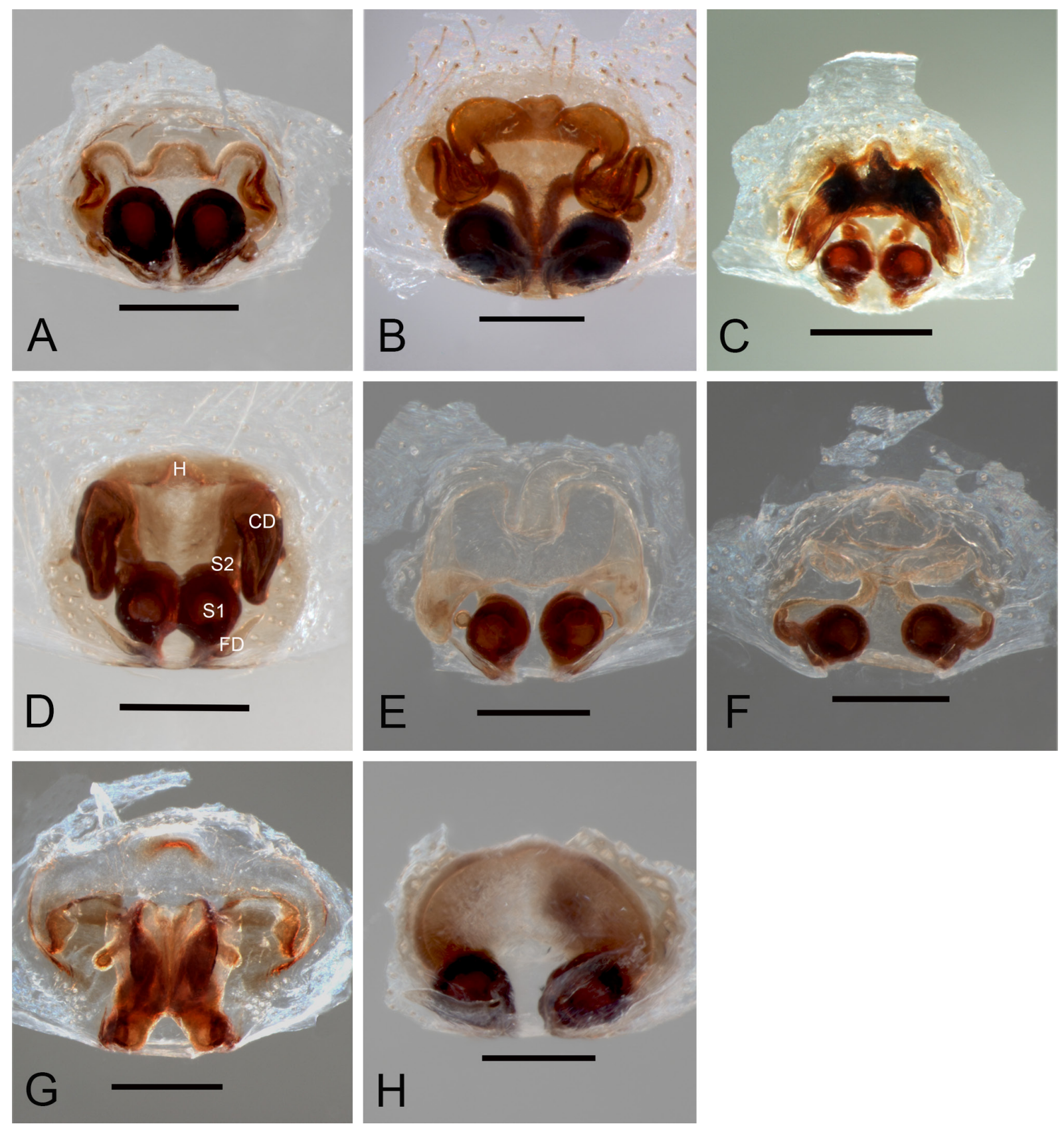

Fig. 33. Female genitalia, digested. A. Tafana huatanay sp. nov. (MUSM). B. Tafana ruizi sp. nov. (IBSP 258183). C. Tafana silhavyi (Caporiacco, 1955) (MNHN). D. Tafana maracay sp. nov. (MNHN 11314). E. Tafana arawak sp. nov. (MNHN 11320). F. Tafana pittieri sp. nov. (AMNH). G. Tafana oliviae sp. nov. (MCZ). H. Tafana orinoco sp. nov. (MIZA 07062). Abbreviations: $\mathrm{CD}=$ copulatory ducts; $\mathrm{FD}=$ fertilization ducts; $\mathrm{H}=$ hood; $\mathrm{S} 1=$ primary spermathecae; $\mathrm{S} 2=$ secondary spermathecae. Scale bars: $\mathrm{A}-\mathrm{H}=0.25 \mathrm{~mm}$. 


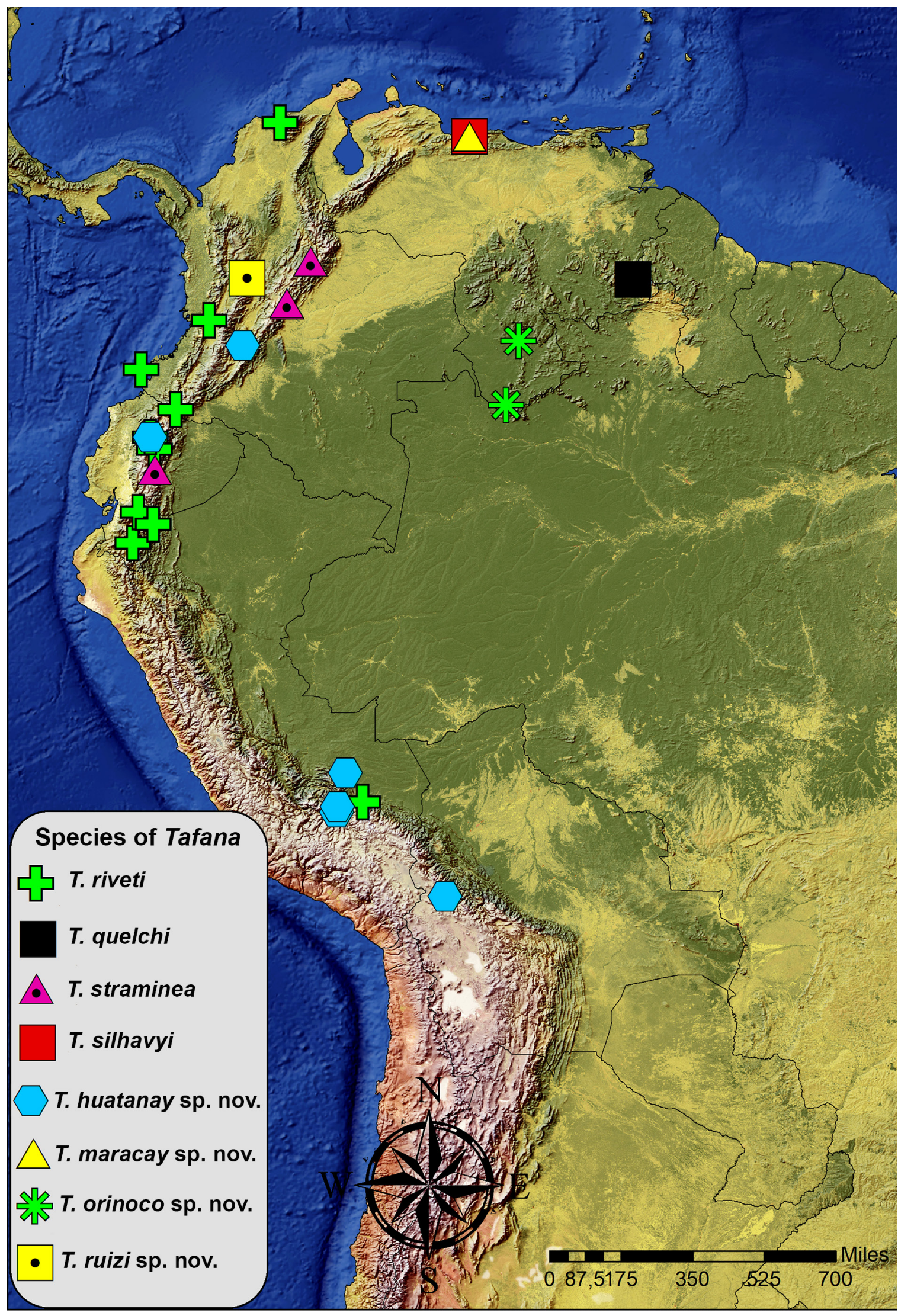

Fig. 34. Distribution map of species of Tafana. 


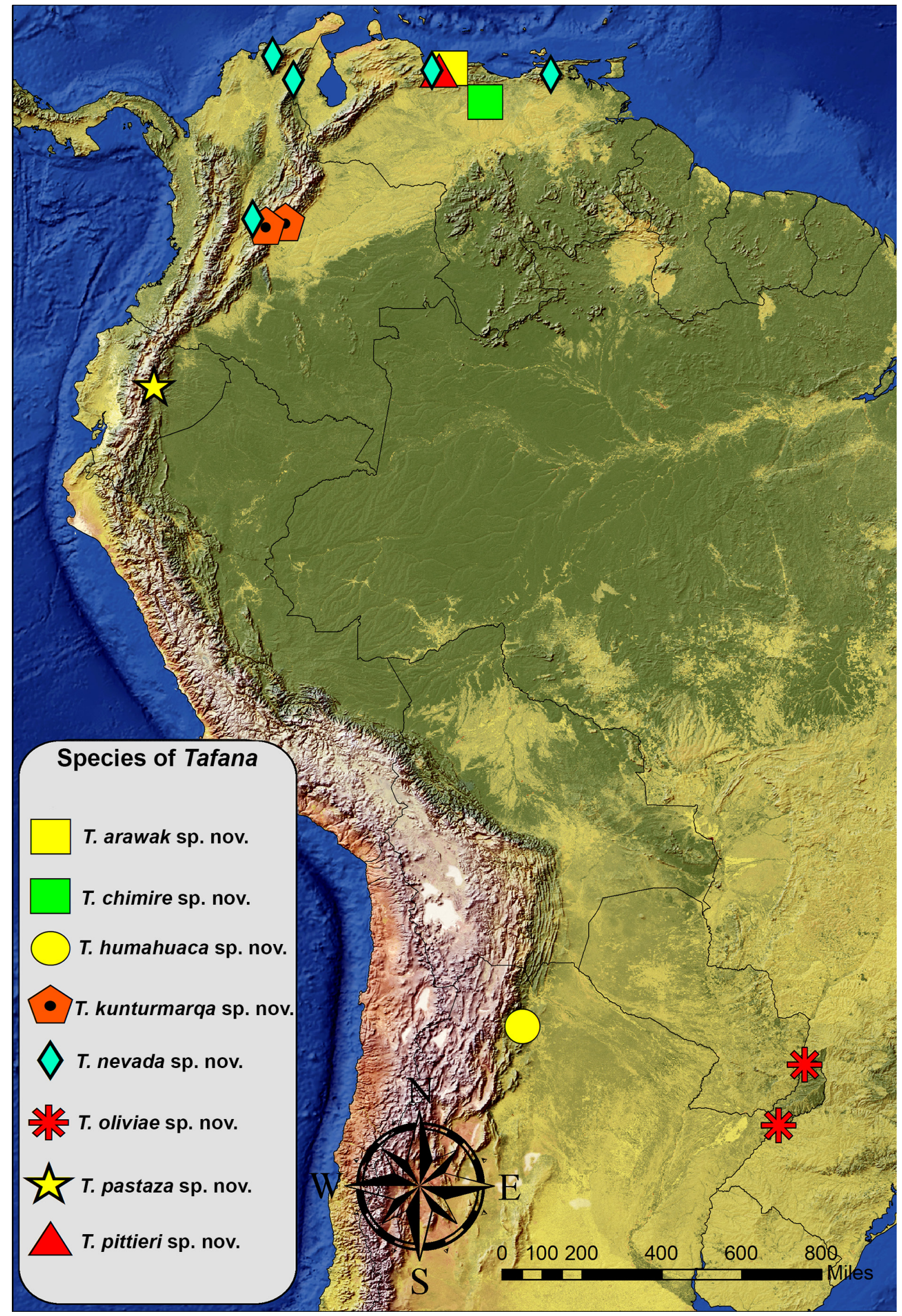

Fig. 35. Distribution map of species of Tafana. 
ducts large and short; secondary spermathecae above the primary spermathecae; primary spermathecae separated; fertilization ducts long, superimposed on the primary spermathecae (Figs 30F-G, 33H).

ABDOMEN. Length 4.0, epigastric furrow 0.5 from tracheal spiracle, spiracle 2.1 from base of spinnerets.

\section{Distribution}

Known only from Venezuela (Fig. 34).

\section{Discussion}

The genus Tafana is predominantly distributed along the northern and western edges of South America, with some species associated with high elevation regions of the Andes mountain range (Figs 34-35). Tafana oliviae sp. nov., the sister species of all Tafana, occurs in the lowland regions of Misiones, Argentina. The next species to diverge from the main clade, Tafana orinoco sp. nov., occurs in both lowland and high elevation areas like Cerro de La Neblina at $1690 \mathrm{~m}$ a.s.l. in Venezuela. One of the major species groups of Tafana, the silhavyi group, includes species that occur in lowland regions of far northern Venezuela. The other, the riveti group, includes species endemic to the Andean region (T. riveti, $T$. straminea, $T$. huatanay sp. nov., $T$. nevada sp. nov.), with those species generally occurring at elevations from 800 to $3600 \mathrm{~m}$, as well as species from the Amazonian region (T. quelchi and T. pastaza sp. nov.). Tafana humahuaca sp. nov., also in this group, occurs in the Argentinian region of Jujuy, at altitudes from 1259 to $4000 \mathrm{~m}$. To fully understand the distributional patterns of the genus, inclusion of more species and a biogeographical analysis are needed.

The monophyly of the genus Tafana is strongly supported, although the internal branches have low support values for several monophyletic groups (Figs 3-4). Our results and topology are corroborated by other works based on morphological data (Ramírez 1995b; Izquierdo \& Ramírez 2008; Werenkraut \& Ramírez 2009; Soto \& Ramírez 2012; Cabra-García \& Brescovit 2016). In addition, our results recovered the close relationship of Aysha and Xiruana, based on the features of the embolic process in the male bulb copulatory. The close relationship of these species is also found in other works (Brescovit 1997; Ramírez 2003, 2007; Labarque et al. 2015).

\section{Evolution of morphological characters}

\section{Median tibial apophysis}

In Tafana, the median tibial apophysis has a triangular shape as, e.g., in T. orinoco sp. nov. (Fig. 30DE). This shape is shared by other Anyphaeninae groups such as Xiruana gracilipes (see Oliveira \& Brescovit 2015a: 205, fig. 2d-f). In Aysha prospera, it is long and keel-shaped (Fig. 6I), whereas in T. oliviae sp. nov. (Fig. 29D-E), it is bilobed and positioned on the dorsal region of the tibia.

\section{Embolic process}

In a genus-level taxonomic review, Brescovit (1997: 118) suggested that Tafana belonged to the "Aysha group", supported by the putative synapomorphy of the embolic process on the apical region of the copulatory bulb in males. The Aysha group is composed of ten genera: Umuara Brescovit, 1997; Aysha Keyserling, 1891; Xiruana Keyserling, 1891; Osoriella Mello-Leitão, 1922; Hibana Brescovit, 1991; Aljassa Brescovit, 1997; Pippuhana Brescovit, 1997; Hatitia Brescovit, 1997, Temnida Simon, 1896 and Tafana Simon, 1903. Our analysis recovered the Aysha group as monophyletic; however, the inclusion of more genera is further needed to confirm the existence of this group. In our analysis, this process is conical in both Xiruana gracilipes and Tafana, and is ring-shaped in Aysha prospera (Brescovit 1992b: 79; 1997: 79, figs 8-11). 
Apophysis at the base of the embolus

After revising the genus-level taxonomy, we found that all known species are diagnosed by the presence of an apophysis at the base of the embolus (Figs $18 \mathrm{~A}-\mathrm{C}, 23 \mathrm{~A}-\mathrm{C}, 31 \mathrm{~A}-\mathrm{C}$ ). This character is shared by all species of Tafana, but it is not restricted to this genus. Some species of Anyphaeninae, such as Xiruana tetraseta (see Oliveira \& Brescovit 2015a: 209, fig. 5a-b), which were not included in this analysis, also have this structure. In the phylogeny of the genus presented here, T. orinoco sp. nov. and T. pastaza sp. nov. present a bilobed apophysis at the base of the embolus, and in T. orinoco sp. nov. the secondary apophysis (Fig. 31B-C) has a furrow, which we suggest may function as a conductor. In the silhavyi group, species only have one apophysis, with a laminar shape, while in the riveti group, species also have one apophysis, generally with a conical shape (except in T. pastaza sp. nov.).

\section{Cymbium, retrolateral projection}

Another character that is not limited to Tafana is the retrolateral projection on the cymbium (Figs 10C, $12 \mathrm{~A}, 22 \mathrm{C}, 26 \mathrm{~A}, \mathrm{C})$. The absence of this character is plesiomorphic for Tafana and the structure is absent in T. oliviae sp. nov., T. orinoco sp. nov. and T. quelchi, although it is present in all other species in the genus. Some other genera of the Anyphaeninae also present some retrolateral projection on the cymbium, as in the genera Katissa Brescovit, 1997 and Osoriella Mello-Leitão, 1922. For these genera, the retrolateral projection is restricted to the basal region of the cymbium (Brescovit 1997: 180, fig. 270). Apparently, this retrolateral projection is associated with a repose of the retrolateral tibial apophysis in the cymbium and would likely not be homologous to the paracymbium of others families, but deeper analysis would be necessary to test this (Platnick \& Gertsch 1976; Coddington 1990; Griswold et al. 1998).

\section{Ventral tegular process}

The genus was originally diagnosed by Brescovit (1997: 88) based on sexual characters such as a distal ventral tegular process. The ventral tegular process (Figs 6J, 10C, 12B, 22C, 26A-B) is present in most Anyphaeninae, and changes position on the copulatory bulb. In Xiruana gracilipes and Anyphaena accentuate, it is located on the apical portion of the copulatory bulb. The silhavyi group also shares this apical position. Yet, the position of the ventral tegular process near the median apophysis (Figs 9B, 10C, $12 \mathrm{~B}-\mathrm{C}, 18 \mathrm{~B}-\mathrm{C}$ ) is present in the riveti group (Clade G) and could be homologous to the one found, for example, in the genus Umuara (see Oliveira \& Brescovit 2015b: 438, fig. 2a-c).

\section{Hood}

The hood of the epigynum (Figs 7D, 10F, 22F, 32E-F, 33D-E) supports Anyphaena accentuata and Patrera fulvastra as the fist lineages to diverge in Anyphaeninae. Although Anyphaena and Patrera are not part of the Aysha group, as they do not have an embolic process on the male copulatory bulb, the anterior region of the epigyne, however, is provided with a hood. This was mentioned by Brescovit (1997: 119), who stated that the hood in the female genitalia is not restricted to the Aysha group, but is also present in the genera Anyphaena and Patrera. This character is plesiomorphic in Tafana and may be homologous to the anterior pouch of the median field present in many Amaurobioidinae such as Monapia Simon, 1897, Gayenna Nicolet, 1849 and Oxysoma Nicolet, 1849 (Ramírez 1995a: 92, figs 18-20; 1999: 423, figs 4-5; 2003: 21; Ramírez et al. 2004: 6, figs 6-7).

\section{Lateral lobes, shape}

The shape of the lateral lobes is difficult to standardize in the Anyphaeninae, because they have a great variation in female genitalia (Brescovit 1997). However, all species of Tafana are united by having a sinuous shape of the lateral lobes (Figs 10F, 11F, 15F, 27F), while in Anyphaena accentuata, Patrera fulvastra and Aysha prospera the shape is straight (Fig. 7D), and in Xiruana gracilipes the lateral lobes are curved (Fig. 7E).

We agree that secondary and primary spermathecae are homologous in all species included in this analysis, as according to Ramírez (2014). 


\section{Acknowledgments}

The authors would like to thank all curators of collections who allowed us to examine material. To Beatriz Mauricio from the Laboratório de Biologia Celular of the Instituto Butantan for helping with SEM images. To the laboratory friends Andria de Paula, André M. Giroti, Cristina Anne Rheims, Yuji Lemos, Rafael P. Indicatti, Luiz Felipe Iniesta, Rodrigo Bouzan, Paulo A.M. Goldoni, Bruno Rodrigues and Carla Matos Viegas for all their assistance in developing this work. Thanks to Jeremy Wilson for the help, suggestions and valuable revisions of the English in the manuscript. In addition, thanks to the editor and the anonymous reviewers for their suggestions and valuable revisions on the manuscript. This study was financed by the Coordenação de Aperfeiçoamento de Pessoal de Nível Superior - Brasil (CAPES to LFMO) - Finance Code 001, Fundação de Amparo à Pesquisa do Estado de São Paulo (FAPESP grant 2015/13815-8 to LFMO), Programa de Pós-Graduação em Zoologia-IB-USP (N USP 9195209 to LFMO) and Conselho Nacional do Desenvolvimento Científico (CNPq grant 303903/2019-8 to ADB).

\section{References}

Azevedo G.H.F., Griswold C.E. \& Santos A.J. 2018. Systematics and evolution of ground spiders revisited (Araneae, Dionycha, Gnaphosidae). Cladistics 34: 579-626. https://doi.org/10.1111/cla.12226

Berland L. 1913. Araignées. In: Service géographique de l'Armée. Mission du Service géographique de l'Armée pour la mesure d'un arc du méridien équatorial en Amérique du Sud (1899-1906) 10: 78-119. Gauthier-Villars, Paris. https://doi.org/10.5962/bhl.title.980

Bonaldo A.B. 2000. Taxonomia da subfamília Corinninae (Araneae, Corinnidae) nas regiões Neotropical e Neártica. Iheringia 89: 3-148.

Bonnet P. 1955. Bibliographia araneorum. Analyse méthodique de toute la littérature aranéologique jusqu'en 1939. Tome II. Systématique des araignées (Étude par ordre alphabétique) [1e partie: A-B]: 1-918. Douladoure, Toulouse.

Bonnet P. 1959. Bibliographia araneorum. Analyse méthodique de toute la littérature aranéologique jusqu'en 1939. Tome II. Systématique des araignées (Étude par ordre alphabétique) (5e partie: T-Z): 4231-5058. Douladoure, Toulouse.

Brescovit A.D. 1991a. Revalidação do gênero Isigonia Simon, com descrição de uma espécie nova (Araneae, Anyphaenidae). Revista Brasileira de Entomologia 35 (4): 721-727.

Brescovit A.D. 1991b. Hibana, novo gênero de aranhas da família Anyphaenidae (Arachnida, Araneae). Revista Brasileira de Entomologia 35 (4): 729-744.

Brescovit A.D. 1992a. Revisão das aranhas do gênero Macrophyes O. Pickard-Cambridge, da região Neotropical (Araneae, Anyphaenidae). Revista Brasileira de Entomologia 36 101-106.

Brescovit A.D. 1992b. Revisão do grupo prospera do gênero Aysha Keyserling, 1891 na região Neotropical (Araneae, Anyphaenidae). Iheringia Série Zoológica: 72: 23-104.

Brescovit A.D. 1993a. Novas espécies do gênero Macrophyes O.P.-Cambridge da região Neotropical (Araneae, Anyphaenidae). Iheringia 75: 113-116.

Brescovit A.D. 1993b. Thaloe e Bromelina, novos gêneros de aranhas neotropicais da família Anyphaenidae (Arachnida, Araneae). Revista Brasileira de Entomologia 37: 693-703.

Brescovit A.D. 1997. Revisão de Anyphaeninae Bertkau a nível de gêneros na região Neotropical (Araneae, Anyphaenidae). Revista Brasileira de Zoologia 13: 1-187.

https://doi.org/10.1590/S0101-81751996000500001 
Brescovit A.D. 1999. Revisão das aranhas do gênero Lupettiana Brescovit (Araneae, Anyphaenidae, Anyphaeninae). Revista Brasileira de Zoologia 16: 63-76.

https://doi.org/10.1590/S0101-81751999000600008

Brescovit A.D. \& Oliveira L.F.M. 2019. Three new species of Thaloe Brescovit (Araneae: Anyphaenidae, Anyphaeninae), with descriptions of the first known females of the genus. Zootaxa 4624 (2): 256-266. https://doi.org/10.11646/zootaxa.4624.2.8

Bremer K. 1988. The limits of amino acid sequence data in angiosperm phylogenetic reconstruction. Evolution 42: 795-803.

Bremer K. 1994. Branch support and tree stability. Cladistics 10: 295-304.

Cabra-García J. \& Brescovit A.D. 2016. Revision and phylogenetic analysis of the orb-weaving spider genus Glenognatha Simon, 1887 (Araneae, Tetragnathidae). Zootaxa 4069 (1): 1-183.

https://doi.org/10.11646/zootaxa.4069.1.1

Caporiacco L. Di. 1955. Estudios sobre los aracnidos de Venezuela 2a parte: Araneae. Acta biologica Venezuelica 1 (16): 245-448.

Ceccarelli F.S., Opell B.D., Haddad C.R., Raven R.J., Soto E.M. \& Ramírez M.J. 2016. Around the world in eight million years: historical biogeography and evolution of the spray zone spider Amaurobioides (Araneae: Anyphaenidae). PLoS One 11 (10): e0163740.

https://doi.org/10.1371/journal.pone.0163740

Ceccarelli F.S., Koch M.N., Soto E.M., Barone M.L., Arnedo M.A. \& Ramírez M.J. 2019. The grass was greener: repeated evolution of specialized morphologies and habitat shifts in ghost spiders following grassland expansion in South America. Systematics Biology 68 (1): 63-77.

https://doi.org/10.1093/sysbio/syy028

Coddington J.A. 1990. Ontogeny and homology in the male palpus of orb-weaving spiders and their relatives, with comments on phylogeny (Araneoclada: Araneoidea, Deinopoidea). Smithsonian Contributions to Zoology 496: 1-52.

Dupérré N. \& Tapia E. 2016. Overview of the Anyphaenids (Araneae, Anyphaeninae, Anyphaenidae) spider fauna from the Choco forest of Ecuador, with the description of thirteen new species. European Journal of Taxonomy 255: 1-50. https://doi.org/10.5852/ejt.2016.255

Fitch W.M. 1971. Toward defining the course of evolution: minimum change for a specific tree topology. Systematic Zoology 20 (4): 404-416.

Goodman M., Olson C.B., Beeber J.E. \& Czelusniak J. 1982. New perspectives in the molecular biological analysis of mammalian phylogeny. Acta Zoologica Fennica 169: 19-35.

Goloboff P.A. 2008. Calculating SPR distances between trees. Cladistics 24: 591-597.

Goloboff P.A. \& Catalano S.A. 2016. TNT version 1.5, including a full implementation of phylogenetic morphometrics. Cladistics 32: 1-18.

Goloboff P. \& Farris J. 2001. Methods for quick consensus estimation. Cladistics 17: S26-S34. https://doi.org/10.1006/clad.2000.0156

Goloboff P.A., Farris J.S., Källersjö M., Oxelman B., Ramírez M.J. \& Szumik C.A. 2003. Improvements to resampling measures of group support. Cladistics 19: 324-332.

Goloboff P.A., Farris S. \& Nixon K. 2008. TNT, a free program for phylogenetic analysis. Cladistics 24: 774-786. 
Gonzalez Marquez M.E. \& Ramírez M.J. 2012. A revision and phylogenetic analysis of the spider genus Aysenia Tullgren (Araneae: Anyphaenidae, Amaurobioidinae). Zootaxa 3201 (1): 1-26. https://doi.org/10.11646/zootaxa.3201.1.1

Griswold C.E., Coddington J.A., Hormiga G. \& Scharff N. 1998. Phylogeny of the orb-web building spiders (Araneae, Orbiculariae: Deinopoidea, Araneoidea). Zoological Journal of the Linnean Society 123 (1): 1-99. https://doi.org/10.1111/j.1096-3642.1998.tb01290.x

Izquierdo M.A. \& Ramırez M.J. 2008. Two new spider species of the genera Aysenia and Aysenoides from southern Chile and Argentina: description and phylogenetic relationships (Araneae: Anyphaenidae, Amaurobioidinae). Zootaxa 1861 (1): 29-43. https://doi.org/10.11646/zootaxa.1861.1.3

Järvi T.H. 1912. Das Vaginalsystem der Sparassiden. Annales Academiae Scientiarum Fennicae (A) 4: $1-131$

Koch L. 1866. Die Arachniden - Familie der Drassiden. Parts 1-6: 1-304.

Labarque F.M., Soto E.M., Ramírez M.J. \& Arnedo M.A. 2015. Chasing ghosts: the phylogeny of Amaurobioidinae ghost spiders (Araneae, Anyphaenidae). Zoologica Scripta 44 (5): 550-561.

Laborda A., Ramırez M.J. \& Pizarro-Araya J. 2013. New species of the spider genera Aysenia and Aysenoides from Chile and Argentina: description and phylogenetic relationships (Araneae: Anyphaenidae, Amaurobioidinae). Zootaxa 3731: 133-152. https://doi.org/10.11646/zootaxa.3731.1.6

Nixon K.C. 2002. Winclada, ver. 1.00.08. Published by the author, Ithaca, NY.

Oliveira L.F.M. \& Brescovit A.D. 2015a. A taxonomic revision of the Neotropical spider genus Xiruana Brescovit 1997 (Araneae: Anyphaenidae, Anyphaeninae). Zootaxa 3980 (2): 201-229.

https://doi.org/10.11646/zootaxa.3980.2.3

Oliveira L.F.M. \& Brescovit A.D. 2015b. Two new species of the Neotropical spider genus Umuara Brescovit (Araneae, Anyphaenidae, Anyphaeninae) from Brazil. Zootaxa 3980 (3): 435-441. https://doi.org/10.11646/zootaxa.3980.3.7

Oliveira L.F.M. \& Brescovit A.D. 2016. The first male of the spider genus Temnida Simon, 1896 (Araneae: Anyphaenidae: Anyphaeninae). Arachnology 17 (1): 47-51.

https://doi.org/10.13156/arac.2006.17.1.47

Petrunkevitch A. 1911. A synonymic index-catalogue of spiders of North, Central and South America with all adjacent islands, Greenland, Bermuda, West Indies, Terra del Fuego, Galapagos, etc. Bulletin of the American Museum of Natural History 29: 1-791.

Petrunkevitch A. 1928. Systema Aranearum. Transactions of the Connecticut Academy of Arts and Sciences 29: 1-270.

Platnick N.I. \& Gertsch W.J. 1976. The suborders of spiders: a cladistic analysis (Arachnida, Araneae). The American Museum of Natural History 2607: 1-15.

Pocock R.I. 1895. Description of two new species obtained by Messrs J.J. Quelch and F. Mc Connell on the summit of Mount Roraima, in Demerara, with a note upon the systematic position of the genus Desis. Annals and Magazine of Natural History 16 (6): 139-143. https://doi.org/10.1080/00222939508680241

Pocock R.I. 1900. Myriapoda and Arachnida. In: Report on a Collection made by M. M. F.V. McConnell and J.J. Quelch at Mount Roraima in British Guiana. Transactions of the Linnean Society of London 2 (8): 64-71. https://doi.org/10.1111/j.1096-3642.1900.tb00308.x

Ramírez M.J. 1995a. A phylogenetic analysis of the subfamilies of Anyphaenidae (Arachnida, Araneae). Entomologica Scandinavica 26: 361-384. 
Ramírez M.J. 1995b. Revisión y filogenía del género Monapia, con notas sobre otras Amaurobioidinae (Araneae, Anyphaenidae). Boletin de la Sociedad de Biologia de Concepcion 66: 71-102.

Ramírez M.J. 1999. New species and cladistic reanalysis of the spider genus Monapia (Araneae: Anyphaenidae, Amaurobioidinae). Journal of Arachnology 27: 415-431.

Ramírez M.J. 2003. The spider subfamily Amaurobioidinae (Araneae: Anyphaenidae): A phylogenetic revision at generic level. Bulletin of the Museum of Natural History 277: 1-262. https://doi.org/fv3bxr

Ramírez M.J. 2007. Homology as a parsimony problem: a dynamic homology approach for morphological data. Cladistics 23: 588-612. https://doi.org/10.1111/j.1096-0031.2007.00162.x

Ramírez M.J. 2014. The morphology and phylogeny of dionychan spiders (Araneae: Araneomorphae). Bulletin of the American Museum of Natural History 390: 1-374. https://doi.org/10.1206/821.1

Ramírez M.J., Ansaldi M.J. \& Puglisi A.F. 2004. Description of the females of Oxysoma itambezinho Ramírez and Monapia tandil Ramírez, and their effects on the generic relationships of Gayennini (Araneae, Anyphaenidae, Amaurobioidinae). Zootaxa 668 (1): 1-8.

Roewer C.F. 1954. Katalog der Araneae von 1758 bis 1940. Vol. 2: 1-923. Royal Belgian Institute of Natural Sciences, Brussels.

Rubio G.D. \& Ramírez M.J. 2015. Taxonomic revision of the American spider genus Arachosia (Araneae: Anyphaenidae). Zootaxa 3932 (1): 1-105. https://doi.org/10.11646/zootaxa.3932.1.1

Sereno P.C. 2007. Logical basis for morphological characters in phylogenetics. Cladistics 23: 565-587.

Sierwald P. 1989. Morphology and ontogeny of female copulatory organs in American Pisauridae, with special reference to homologous features (Arachnida: Araneae). Smithsonian Contributions to Zoology 484: $1-24$.

Simon E. 1903. Descriptions d'Arachnides nouveaux. Annales de la Société entomologique de Belgique 47: 21-39.

Soto M.E. \& Ramírez M.J. 2012. Revision and phylogenetic analysis of the spider genus Philisca Simon (Araneae: Anyphaenidae, Amaurobioidinae). Zootaxa 3443 (1): 1-65.

https://doi.org/10.11646/zootaxa.3443.1.1

Soto M.E., Labarque M.F., Ceccarelli S.F., Arnedo A.M., Pizarro-Araya J. \& Ramírez M. 2017. The life and adventures of an eight-legged castaway: colonization and diversification of Philisca ghost spiders on Robinson Crusoe Island (Araneae, Anyphaenidae). Molecular Phylogenetics and Evolution 107: 132-141. https://doi.org/10.1016/j.ympev.2016.10.017

Werenkraut V. \& Ramírez M.J. 2009. A revision and phylogenetic analysis of the spider genus Coptoprepes Simon (Araneae: Anyphaenidae, Amaurobioidinae). Zootaxa 2212 (1): 1-40.

https://doi.org/10.11646/zootaxa.2212.1.1

World Spider Catalog. 2020. World Spider Catalog. Version 20.0. Natural History Museum Bern. Available from http://wsc.nmbe.ch [accessed 26 Jun. 2020].

Manuscript received: 26 August 2020

Manuscript accepted: 9 February 2021

Published on: 31 March 2021

Topic editor: Rudy Jocqué

Desk editor: Kristiaan Hoedemakers 
Printed versions of all papers are also deposited in the libraries of the institutes that are members of the EJT consortium: Muséum national d'histoire naturelle, Paris, France; Meise Botanic Garden, Belgium; Royal Museum for Central Africa, Tervuren, Belgium; Royal Belgian Institute of Natural Sciences, Brussels, Belgium; Natural History Museum of Denmark, Copenhagen, Denmark; Naturalis Biodiversity Center, Leiden, the Netherlands; Museo Nacional de Ciencias Naturales-CSIC, Madrid, Spain; Real Jardín Botánico de Madrid CSIC, Spain; Zoological Research Museum Alexander Koenig, Bonn, Germany; National Museum, Prague, Czech Republic. 


\section{Appendix 1}

Species used in the phylogenetic analysis

Outgroup: Amaurobioidinae Hickman, 1949

Arachosia praesignis Keyserling, 1891

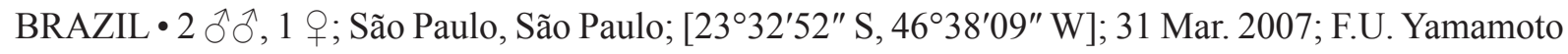
leg.; IBSP 87975.

Outgroup: Anyphaeninae Bertkau, 1878

Anyphaena accentuata Walckenaer, 1802

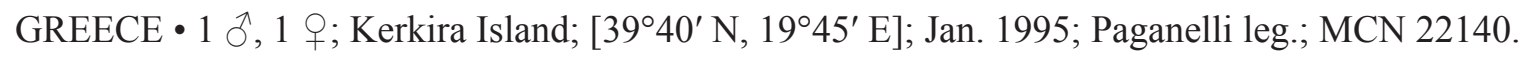

Patrera fulvastra Simon, 1903

COLOMBIA • 1 ô, 1 क; Cundinamarca, Ricaurte, Nariño, Reserva Natural La Planada; [ $4^{\circ} 16^{\prime} 45^{\prime \prime} \mathrm{N}$, 7446'22" W]; 14 Mar. 1992; C. Valderrama leg.; MCN 24208.

$$
\text { Aysha prospera Keyserling, } 1891
$$

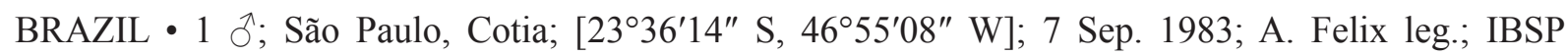

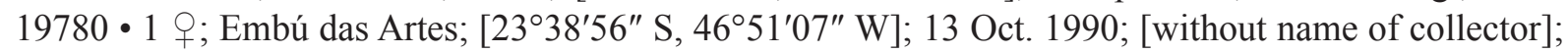
IBSP 19783.

\section{Xiruana gracilipes Keyserling, 1891}

BRAZIL • 1 P; São Paulo, São Paulo, Parque Estadual do Jaraguá; [2332'51" S, 46³8'10" W]; 28 Mar. 2014; J.L. Chavari and R. Indicatti leg.; IBSP 166120 • 1 đ'; Santa Catarina, Florianópolis; $27^{\circ} 35^{\prime} 49^{\prime \prime}$ S, 48³2'56" W; 12 Feb. 2007; R.S. Melo leg.; IBSP 72660.

Ingroup: Anyphaeninae Bertkau, 1878; genus Tafana Simon, 1903

Tafana riveti Simon, 1903

COLOMBIA • 1 ठ̊; Valle del Cauca, Lago Calima; [353'40.44" N, 76²9'41.58" W]; Jan. 1979; W. Eberhard leg.; MCZ.

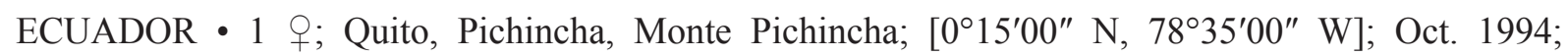
G.W. Prescott leg.; MCZ.

\section{Tafana quelchi (Pocock, 1895)}

VENEZUELA • 1 क; Bolívar, Parque Nacional Canaima, Monte Roraima; [5²0'00" N, 6130'00" W]; [without date]; M.O. Gonzaga leg.; IBSP 32131.

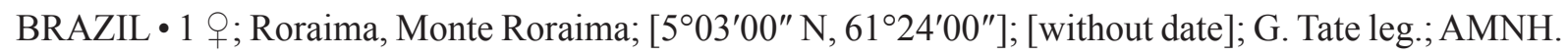

\section{Tafana straminea (L. Koch, 1866)}

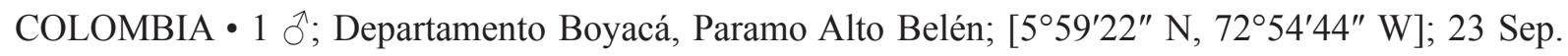
1985; H. Sturn leg.; MCZ. 
ECUADOR • 2 우; Tungurahua Province, Baños; [1²3'47" N, 78²5'29" W]; 2 May 1939; Clarke and Macintyre leg.; AMNH.

\section{Tafana silhavyi (Caporiacco, 1955)}

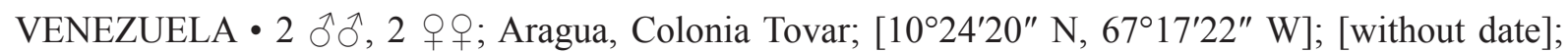
E. Simon leg.; MNHN 11312.

\section{Tafana chimire sp. nov.}

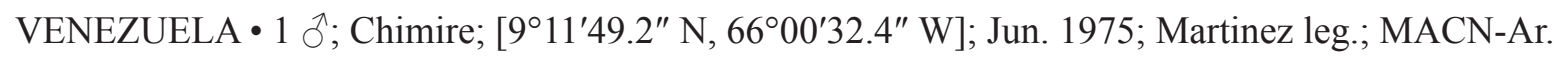

\section{Tafana maracay sp. nov.}

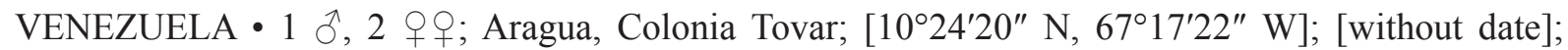
E. Simon leg.; MNHN 11314.

\section{Tafana arawak sp. nov.}

VENEZUELA • 1 ô, 1 क; Aragua, Colonia Tovar; [10 $24^{\prime} 20^{\prime \prime} \mathrm{N}, 67^{\circ} 17^{\prime} 22^{\prime \prime} \mathrm{W}$ ]; [without date]; E. Simon leg.; MNHN 11320.

\section{Tafana pittieri sp. nov.}

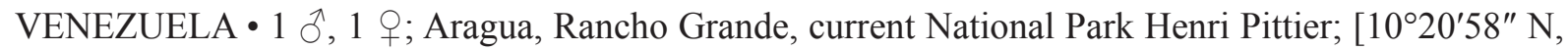
6741'08" W]; 8-15 Apr. 1945; W. Beebe et al. leg.; AMNH.

\section{Tafana kunturmarqa sp. nov.}

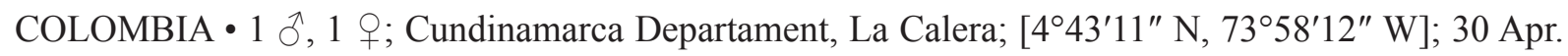
1978; C. Hernandez leg.; ICN-Ar.

\section{Tafana oliviae sp. nov.}

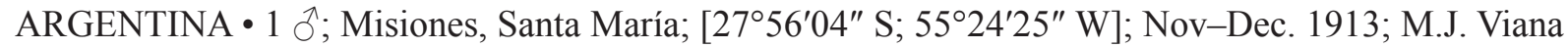

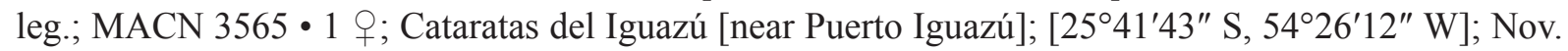
1970; M.E. Galiano leg.; MCZ.

\section{Tafana humahuaca sp. nov.}

ARGENTINA • 1 ơ; Jujuy Province, Santa Bárbara; [2418'31" S; 6439'37" W]; Oct. 1969; Williner

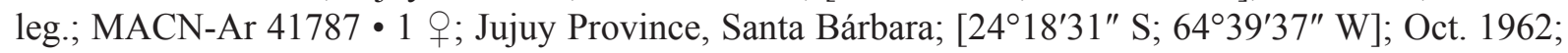
Williner leg.; MACN-Ar 41788.

\section{Tafana orinoco sp. nov.}

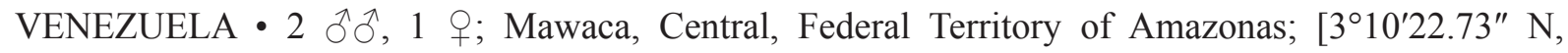
65³2'32.39" W]; 5 Mar. 1985; J. Lattke and R. Candia leg.; MIZA 07062.

\section{Tafana pastaza sp. nov.}

ECUADOR • 1 ภ, 1 \&; Tungurahua Province, Pastaza Valley [between Baños and Mero]; [01 $04^{\prime} 00^{\prime \prime} \mathrm{N}$, 7800'24" W]; 1 Mar. 1949; W.C. Macintyre leg.; AMNH. 
Tafana nevada sp. nov.

COLOMBIA 1 o ; Departament Magdalena, Santa Marta, San Pedro, Carmelo, Sierra Nevada de Santa Marta; [1052'00" N, 7343'12" W]; 7 Feb. 1974; J.A. Kochalka leg.; IBNP.

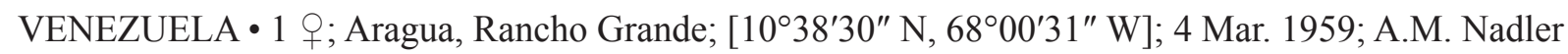
leg.; AMNH.

Tafana huatanay sp. nov.

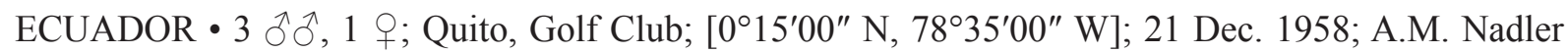
leg.; AMNH.

Tafana ruizi sp. nov.

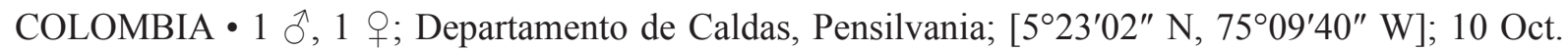
2003; Sánchez-Ruiz leg.; IBSP 258183. 


\section{Appendix 2}

\section{Characters used in the phylogenetic analysis}

Bibliographic references are given for characters already employed in previous phylogenetic analyses. Characters that have not been employed so far in phylogenetic analyses are identified by an asterisk and all alternative states are referenced on figures presented here. Values of length (L), consistency index (ci), retention index (ri) and Fit (F) are indicated for each character based on the topology under implicit weighing (IW), with value of concavity $(k=7)$ (Fig. 5).

\section{Cephalothorax}

0*. Cephalothorax, carapace, dorsal, anterior margin shape: (0) rounded (Fig. 6A); (1) square (Figs $6 \mathrm{~B}, 8 \mathrm{~A}$ ). $\mathrm{L}=1 ; \mathrm{ci}=1 ; \mathrm{ri}=1 ; \mathrm{F}=1$. The anterior margin of carapace optimized as square is a synapomorphy for Anyphaeninae.

1*. Cephalothorax, carapace, ratio clypeus/AME: (0) clypeus<AME; (1) clypeus=AME; (2) clypeus $>$ AME. $\mathrm{L}=7 ; \mathrm{ci}=0.28 ; \mathrm{ri}=0.28 ; \mathrm{F}=0.58$. Most anyphaenid species present differences in shape and size of eyes, but the clypeus is conservative in shape. This character is very homoplastic, the (state 2) is a synapomorphy for Amaurobioidinae, but appears as an autapomorphy in Tafana quelchi. The (state 0) is an apomorphy for Anyphaeninae, with reversion in Aysha prospera and other groups of Tafana and (state 1) appears independently in other species of Anyphaeninae.

2. Cephalothorax, carapace, cephalic area, posterior eye row (Ramírez 2003, character 12, modified): (0) procurved or straight (Figs 6B, 10A, 11A); (1) extremely procurved (Fig. 6A). L=1; ci=1; ri=1; $\mathrm{F}=1$. The state procurved in posterior eyes is generalized in Anyphaenidae according to Ramírez (1995b: 75). Anyphaenids not included in this analysis have posterior eyes recurved (Ramírez 1995b, 2003). The (state 0 ) is recovered as a synapomorphy for species of Anyphaeninae.

\section{Chelicerae}

3. Chelicerae, paturon, number of retromarginal teeth (Ramírez 2003, character 20): (0) two (Fig. 6C); (1) four or more (Figs $8 \mathrm{~B}, 20 \mathrm{~F}, 26 \mathrm{~F}$ ). $\mathrm{L}=1 ; \mathrm{ci}=1 ; \mathrm{ri}=1 ; \mathrm{F}=1$. The (state 1 ) is a synapomorphy for Anyphaeninae.

4. Chelicerae, paturon, number of promarginal teeth (Ramírez 2003, character 23): (0) three (Fig. 6C); (1) four (Fig. 20F); (2) five or more (Fig. 26F). L=2; ci=1; ri=1; F=1. The number of teeth has been used in phylogeny studies within Anyphaenidae (Ramírez 2003). This character shows a great variation in the groups studied herein. The (state 1) is recovered as a synapomorphy for Anyphaeninae, but reversed in Anyphaena accentuata and Patrera fulvastra. The (state 2) is a synapomorphy for the clade Tafana maracay sp. nov. + Tafana arawak sp. nov.

\section{Scopulae}

5. Scopulae on anterior tibiae (Ramírez 2003, character 33): (0) absent (Fig. 6G); (1) present (Fig. 6F). $\mathrm{L}=5 ; \mathrm{ci}=0.20 ; \mathrm{ri}=0.55 ; \mathrm{F}=0.63$. As in the analysis of Ramírez (2003), the scapulae in this analysis also features lost in several groups. The (state 0 ) is recovered as a synapomorphy for silhavyi group + riveti group, but reversed in Anyphaena accentuata, Tafana silhavyi, Tafana pastaza sp. nov. and Tafana straminea.

\section{Spines}

6. Female palpal femur with a line of ventral spines (Ramírez 2003, character 130): (0) absent (Fig. 6E); (1) present (Fig. $6 \mathrm{D}$ ). $\mathrm{L}=4 ; \mathrm{ci}=0.25 ; \mathrm{ri}=0.66 ; \mathrm{F}=0.70$. The character is recovered as homoplastic. The (state 1) appears as an autapomorphy in Aysha prospera and synapomorphic for clades B and G. In clade $\mathrm{G}$ a reversion is observed in Tafana humauaca sp. nov. 
Tracheae

7. Position of first bifurcation of median trachea (Ramírez 1995a, 2003, character 40): (0) separate from lateral trachea (Ramírez 1995a: 363, fig. 5); (1) contiguous (Ramírez 1995a: 364, fig. 6; Fig. 4L). $\mathrm{L}=1 ; \mathrm{ci}=1 ; \mathrm{ri}=1 ; \mathrm{F}=1$. The (state 1 ) is recovered as synapomorphic for Anyphaeninae species.

\section{Male palp}

8*. Palp, cymbium, retrolateral projection: (0) absent (Fig. 29C); (1) present (Figs 10C, 25C). L=1; $\mathrm{ci}=1 ; \mathrm{ri}=1 ; \mathrm{F}=1$. The retrolateral projection is an extension of the cymbium and starting basally and continuing up to half region. The presence of this structure is recovered as synapomorphic for clade B.

9. Palp, tibiae, retrolateral tibial apophysis (Ramírez 2003, character 42): (0) absent (Fig. 6H); (1) present (Figs 6I, 9A, 10D). $\mathrm{L}=1 ; \mathrm{ci}=1 ; \mathrm{ri}=1 ; \mathrm{F}=1$.

10*. Palp, tibiae, shape of retrolateral tibial apophysis: (0) unbranched (Fig. 10D-E); (1) branched (Figs $13 \mathrm{C}, 27 \mathrm{D}$ ). $\mathrm{L}=5 ; \mathrm{ci}=0 ; \mathrm{ri}=0 ; \mathrm{F}=0$. The branches of the branched retrolateral tibial apophysis may be placed either at the base of the tegument or at its apex. It is recovered as highly homoplastic, appearing several times in Anyphaeninae.

11*. Palp, tibiae, median tibial apophysis: (0) absent (Figs 10D, 22D); (1) present (Figs 29D, 30D). $\mathrm{L}=2 ; \mathrm{ci}=0.50 ; \mathrm{ri}=0.66 ; \mathrm{F}=0.87$. The median tibial apophysis is treated here as projections, which arise in the middle of the tibia of the palp in males independently of the position. Several Anyphaeninae present these structures in tibia in the male palp. In the genus Tafana they appear at the base as a plesiomorphy, and later are lost in clades D and G.

12*. Palp, tibiae, position of median tibial apophysis: (0) retrolateral (Fig. 30D-E); (1) dorsal (Fig. 29D-E). $\mathrm{L}=1 ; \mathrm{ci}=1 ; \mathrm{ri}=1 ; \mathrm{F}=1$. The dorsal position is an autapomorphy for Tafana oliviae sp. nov.

13*. Palp, tibiae, shape of median tibial apophysis: (0) conical (Fig. 30D); (1) bilobed (Fig. 29D); (2) keel (Fig. 6I). $\mathrm{L}=2 ; \mathrm{ci}=1 ; \mathrm{ri}=1 ; \mathrm{F}=1$.

\section{Copulatory bulb}

14. Bulb, tegulum, basal notch on tegulum (Ramírez 2003, character 60): (0) absent (Figs 10C, 11C); (1) present (Fig. $6 \mathrm{~J}$ ). $\mathrm{L}=1 ; \mathrm{ci}=1 ; \mathrm{ri}=1 ; \mathrm{F}=1$. The presence of a basal notch on the tegulum is a synapomorphy for Amaurobioidinae.

15*. Bulb, tegulum, ventral position, shape sperm duct: (0) oblique (Fig. 6J); (1) U-shaped (Figs 9B, 10C); (2) inverted S-shaped (Figs 9A, 22C). $\mathrm{L}=4 ; \mathrm{ci}=0.50 ; \mathrm{ri}=0.66 ; \mathrm{F}=0.77$. Both Anyphaenidae and other families have a variation of shape in the sperm duct. For example, the standard for the Corinninae sperm duct in the tegulum is helicoidal (Bonaldo 2000). We agree to consider the standard for several Anyphaeninae as semi-circular or 'U-shaped' in the unexpanded male palp, the oblique sperm duct is synapomorphic for Amaurobioidinae and the 'S-shaped' sperm duct is homoplastic, appearing independently in Aysha prospera and in the silhavyi group (clade D).

16*. Bulb, tegulum, ventral position, secondary horizontal loop of the SD: (0) absent (Figs 9B, F, 10C); (1) present (Figs 9A, D, 25C). $\mathrm{L}=2$; $\mathrm{ci}=0.50 ; \mathrm{ri}=0.80 ; \mathrm{F}=0.87$. The (state 1) appears as homoplastic for Aysha prospera and the silhavyi group (clade D).

$17^{*}$. Bulb, tegulum, basal protuberance of tegulum: (0) absent (Figs 10C, 12A, 18A); (1) present (Figs $24 \mathrm{C}, 26 \mathrm{C}$ ). $\mathrm{L}=1 ; \mathrm{ci}=1 ; \mathrm{ri}=1 ; \mathrm{F}=1$. The protuberance corresponds to an extension of the tegulum located in the prolateral basal region. The (state 1) is recovered as synapomorphic in the silhavyi group (clade D). 
18*. Bulb, tegulum, ventral tegular process: (0) absent (Fig. 6J, L); (1) present (Figs 6K, 10C, 11C). $\mathrm{L}=4 ; \mathrm{ci}=0.25 ; \mathrm{ri}=0.40 ; \mathrm{F}=0.70$. As defined by Brescovit (1997), the ventral tegular process corresponds to an extension of the tegulum presenting several shapes and positions, sometimes playing the role of conductor. It can be totally or partially sclerotized. We consider the structure as not being homologous to the conductor, either in Amaurobioidinae or in Anyphaeninae. The structure appears several times in the analysis: in Xiruana gracilipes it is more hyaline and in Anyphaena accentuata it is more massive. In the riveti and silhavyi groups, it appears as apomorphic, but reversed in Tafana pastaza sp. nov.

19*. Bulb, tegulum, ventral tegular process, position: (0) apical margin of tegulum (Figs 6J, 24C, 26A-B); (1) near median apophysis (Figs 9B, 10C, 12B). L=1; ci=1; ri=1; F=1. In Tafana, the position of the ventral tegular process near the median apophysis is recovered as synapomorphic in the riveti group (clade G).

20. Bulb, shape of median apophysis (Ramírez 2003, character 65): (0) relatively thick (Fig. 6K); (1) slender and elongate (Figs $6 \mathrm{~L}, 12 \mathrm{~B}-\mathrm{C}$ ). $\mathrm{L}=2 ; \mathrm{ci}=0.50 ; \mathrm{ri}=0 ; \mathrm{F}=0.87$.

21*. Bulb, tegulum, embolic process: (0) absent (Fig. 6J, L); present (Figs 6I, K, 9C-F). L=1; ci=1; $\mathrm{ri}=1 ; \mathrm{F}=1$. We consider the embolic process as a sclerite apart from that formed at the base of the tegulum, in which the sperm duct runs up to the apex and connects to the embolus. The process is usually located behind the tegulum and it is better seen when the male copulatory bulbs are expanded (see Brescovit 1997: 11). The structure is apomorphic for Anyphaeninae, but lost in Anyphaena accentuata and Patrera fulvastra. This structure is a putative homology for at least ten genera of Anyphaeninae.

22*. Bulb, tegulum, shape of embolic process: (0) ring (Brescovit 1992b: 79, figs 8-11); (1) conical (Fig. 9C-F). $\mathrm{L}=1 ; \mathrm{ci}=1 ; \mathrm{ri}=1 ; \mathrm{F}=1$. The (state 0 ) is autapomorphic for Aysha prospera.

23*. Bulb, embolus, apophysis at the base of the embolus: (0) absent (Fig. 6J, K); (1) present (Figs 9A-F, 12B, C , 23B-C). L =1; ci=1; ri=1; F=1. The RTA clade presents an articulated embolus free or fixed in the copulatory bulb (Ramírez 2003: 277; 2014: 247). This base can be in the apical region as in most Anyphaeninae or in the basal region as for example in Patrera. We consider that a large embolar base is a region sclerotized with or without apophysis. When present the apophysis can be unique or bifid and its form can be laminar or conical. The (state 1) is recovered as synapomorphic for Tafana.

24*. Bulb, embolus, lobes on apophysis at the base of the embolus: (0) simple (Figs 9C, D, 18B, C); (1) bilobed (Figs 16C, 31A-C). $\mathrm{L}=2 ; \mathrm{ci}=0.50 ; \mathrm{ri}=0 ; \mathrm{F}=0.87$. The (state 1) appears independently in Tafana orinoco sp. nov. and in Tafana pastaza sp. nov.

$25^{*}$. Bulb, embolus, shape of apophysis at the base of the embolus: (0) conical (Figs 9B, 12C, 18B, 20B); (1) laminar (Figs 9C, D, 23B, 26B, C). $\mathrm{L}=1$; $\mathrm{ci}=1$; $\mathrm{ri}=1 ; \mathrm{F}=1$. The (state 1) is a synapomorphy for the silhavyi group.

26*. Bulb, tegulum, conductor: (0) absent (Figs 10C, 22C, 23B-C); (1) present (Fig. 6J-K). L=2; $\mathrm{ci}=0.50 ; \mathrm{ri}=0 ; \mathrm{F}=0.87$. The conductor is common in the Dionycha groups of spiders and its homology is contentious (Ramírez 2014: 249). In Anyphaeninae, the conductor is a sclerotized structure of tegular origin that conducts and supports the embolus totally or partially (Brescovit 1997: 10). The structure presents a potential homology to the "primary conductor" mentioned by Ramírez $(2003: 19,2007)$. The (state 1) is a synapomorphy for Amaurobioidinae. In Anyphaeninae the conductor is plesiomorphic, being lost in many groups such as the genus Tafana. 
27*. Bulb, embolus, length of embolus: (0) long (Figs 6L, 9D); (1) short, up to half as long as embolus (Figs $10 \mathrm{C}, 14 \mathrm{C}$ ). $\mathrm{L}=3 ; \mathrm{ci}=0.33 ; \mathrm{ri}=0.66 ; \mathrm{F}=0.77$. The (state 0 ) appears three times independently in this analysis. In Tafana it is a synapomorphy for the silhavyi group.

28*. Bulb, embolus, shape of embolus: (0) laminar (Figs 6I, 29C); (1) filiform (Figs 6L, 10C, 12C). $\mathrm{L}=2 ; \mathrm{ci}=0.50 ; \mathrm{ri}=0.50 ; \mathrm{F}=0.87$. The laminar condition of the embolus is its flattening in more than half or totally. Sometimes, just the apex of the embolus is filiform in some groups. The (state 1) is plesiomorphic for Tafana with an autapomorphy for Tafana pastaza sp. nov. The (state 0) appears several times in the topology.

\section{Genitalia of female}

29. Epigynum, anterior fold, hood (Azevedo et al. 2018, character 98): (0) absent (Figs 7C, E, 32A-D) (1) present (Figs 7D, 10F, 20E, 22F, 32E-L, 33A-I). L =2; ci $=0.50$; ri $=0.50 ; \mathrm{F}=0.87$. The hood is a structure that covers part of the epigynal plate. The (state 1) is plesiomorphic for Tafana with loss in Aysha prospera and Xiruana gracilipes.

30*. Epigynum, anterior fold, shape of hood: (0) semicircular (Figs 11F, 14F, 32H, J, 33A); (1) triangular (Figs 7D, 10F-G, 22F, G, 26D, 32F-G, 33D-H); (2) circular (Figs 12F-G, 29F-G, 31I, 32I). $\mathrm{L}=7 ; \mathrm{ci}=0.28 ; \mathrm{ri}=0.28 ; \mathrm{F}=0.58$.

31. Epigynum, anterior fold, posterior extension forming the lateral lobe (Azevedo et al. 2018, character 97, modified): (0) absent (Figs 7C, E, 11F, 14F, 16F, 32F, I-J, 33G, I); (1) present (Figs $15 \mathrm{~F} ; 17 \mathrm{~F}, 19 \mathrm{~F}, 26 \mathrm{D}, 32 \mathrm{G}, 33 \mathrm{~A}) . \mathrm{L}=4 ; \mathrm{ci}=0.25 ; \mathrm{ri}=0.40 ; \mathrm{F}=0.70$. This character was coded differently from the phylogeny of Gnaphosidae proposed by Azevedo et al. (2018). In Anyphaeninae there are no lateral tips with longitudinal furrows. However, this character is interesting due to the lateral lobes being homologous to "die epigynale Falte (Furche)" in Järvi (1912) or the "lateral folds" by Sierwald (1989), and it is associated with the internal copulatory ducts and openings. We consider that the lateral lobes extend from the posterior region to the anterior region connecting to the hood. The (state 1) is recovered independently several times within the topology.

32*. Epigynum, shape of lateral lobes: (0) straight (Fig. 7C-D); (1) sinuous (Figs 10G, 13F, 17F, 27F, 28F); (2) curved (Fig. 7E). $\mathrm{L}=2 ; \mathrm{ci}=1 ; \mathrm{ri}=1 ; \mathrm{F}=1$.

33. Epigynum, median depression on epigynum (Ramírez 2003, character 108): (0) absent (Fig. 7C, E); (1) present (Figs 7D, 13F). $\mathrm{L}=2 ; \mathrm{ci}=0.50 ; \mathrm{ri}=0.50 ; \mathrm{F}=0.87$. The epigynal plate presents an excavation on the median field that extends from the anterior region to the posterior region.

34*. Epigynum, median field, shape of atrium: (0) wide (Figs 22F, 27F, 32F, I, 33E-F); (1) narrow (Figs 7C, 10F, 15F). $\mathrm{L}=3 ; \mathrm{ci}=0.33 ; \mathrm{ri}=0.71 ; \mathrm{F}=0.77$.

35*. Epgynum, atrial septum: (0) absent (Figs 10F, 13F, 22F, 27F); (1) present (Figs 11F, 14F-G, 21F, $32 \mathrm{H}, \mathrm{J}, 33 \mathrm{C}) . \mathrm{L}=1 ; \mathrm{ci}=1 ; \mathrm{ri}=1 ; \mathrm{F}=1$. The atrial septum is a cuticular elevation in the excavation of the median field.

36*. Epigynum, posterior region covered by cuticle: (0) absent (Figs 13F, 15F, 16F); (1) present (Figs $10 \mathrm{~F}, 17 \mathrm{~F}, 19 \mathrm{~F}, 21 \mathrm{~F}, 33 \mathrm{~F}-\mathrm{G}) . \mathrm{L}=3$; $\mathrm{ci}=0.33$; $\mathrm{ri}=0.75 ; \mathrm{F}=0.77$. The posterior region of the epigynal plate sometimes presents a cuticle covering the lateral lobes without division (see Brescovit 1997: 174, fig. 238, Tafana riveti). In the species that do not have this cuticle, an excavation of the median field is present (see above character 33). The (state 1) is recovered as apomorphic in Tafana, but it is reversed in the two major groups. 
37. Vulva, copulatory duct, lumen of proximal part of duct (Ramírez 2003, character 119): (0) thin (Figs 15G, 16G, 17G, 32B, D, 33G); (1) wide (Figs 22G, 26D, 27G, 30G, 33D-F). L=3; ci=0.33; $\mathrm{ri}=0.71 ; \mathrm{F}=0.77$. The wide condition is homoplastic, appearing independently in clades $\mathrm{B}, \mathrm{E}$ and Tafana riveti + clade $\mathrm{H}$.

38. Vulva, primary spermathecae contiguous (Ramírez 2003, character 125, modified): (0) separate, $1 / 2$ to 1 diameter (Figs 13G, 28G, 29G, 32I, 33G-I); (1) contiguous, up to $1 / 3$ diameter (Figs 10G, $15 \mathrm{G}, 19 \mathrm{G}, 20 \mathrm{E}, 32 \mathrm{G}-\mathrm{H}, 33 \mathrm{~A}-\mathrm{F}) . \mathrm{L}=4 ; \mathrm{ci}=0.25 ; \mathrm{ri}=0.25 ; \mathrm{F}=0.70$. Several anyphaenid species present variation in size and shape of the primary spermathecae. Herein, we compared the separation with its circumference. The (state 1) is highly homoplastic.

39. Vulva, primary spermathecae, shape (Ramírez 2003, character 124): (0) irregular (Fig. 32 A, D, I); (1) approximately oval (Figs 32B, G, H, J, 32D-E). L = 2 ; ci $=0.50 ; \mathrm{ri}=0 ; \mathrm{F}=0.87$.

40. Vulva, receptacle in copulatory duct, in addition to primary and secondary spermathecae (Ramírez 2014, character 374): (0) absent (Figs 20E, 22G, 26D, 32G); (1) present (Figs 16G, 32L). $\mathrm{L}=1 ; \mathrm{ci}=1 ; \mathrm{ri}=1 ; \mathrm{F}=1$. The receptacles in the primary and secondary spermathecae are common in spiders of the Entelegynes condition (Ramírez 2014: 251, 390, fig. 179E).

41 *. Vulva, secondary spermathecae, position: (0) proximal lumen of CD (Figs 32B, 33C, H); (1) middle lumen of CD (Fig. 32C, G, L); (2) distal lumen of CD (Figs 32E-F, 33B, F). L=8; ci=0.25; $\mathrm{ri}=0.25 ; \mathrm{F}=0.53$. The secondary spermathecae are receptacles with large glandular pores and ducts. They have different shapes and positions in the copulatory ducts. We consider their position as homologous as suggested by Ramírez (2014: 251).

42*. Vulva, secondary spermathecae, shape: (0) irregular (Figs 32B, D, F, 33G-H); (1) approximately rounded (Figs $32 \mathrm{C}, \mathrm{G}-\mathrm{H}, \mathrm{J}, 33 \mathrm{D}, \mathrm{F}$ ). $\mathrm{L}=3 ; \mathrm{ci}=0.33 ; \mathrm{ri}=0.60 ; \mathrm{F}=0.77$. The spherical condition appears twice in the analysis in Xiruana gracilipes and in the other groups of Tafana, with reversal in Tafana pittieri sp. nov. The irregular condition is plesiomorphic for Tafana. 


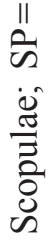

¿

I

羸

$\frac{0}{\pi}$

$\stackrel{\Sigma}{\Sigma}$

迎

岁

㗘

苛

$\stackrel{\Perp 1}{ \pm}$

范

$\sum^{\|}$

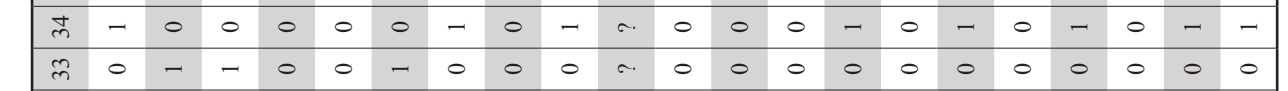

\begin{tabular}{|lllllllllllllllllllllll|}
\hline$\tilde{m}$ & 0 & 0 & 0 & 0 & 1 & - & - & - & - & $\cdots$ & - & - & - & - & - & - & - & - & - & - & - \\
\hline $\bar{m}$ & 0 & 0 & 0 & 0 & 0 & 0 & 0 & - & 0 & - & - & 0 & 0 & 0 & - & 0 & - & 0 & - & - & 0 \\
\hline 0 & 1 & 0 & - & 1 & 1 & 1 & - & - & 0 & - & - & - & - & 0 & 0 & 0 & 1 & - & 0 & - & 0 \\
\hline
\end{tabular}

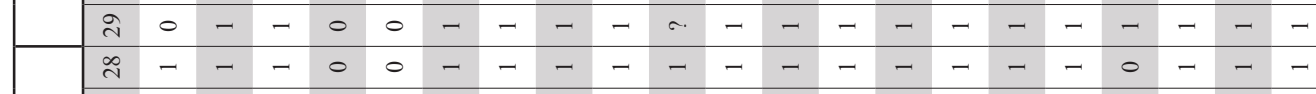

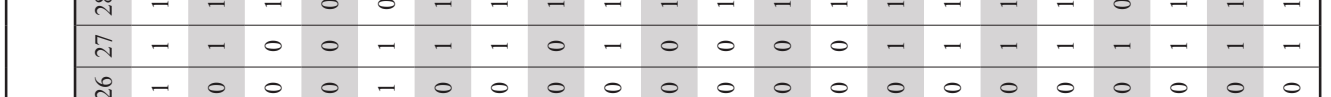

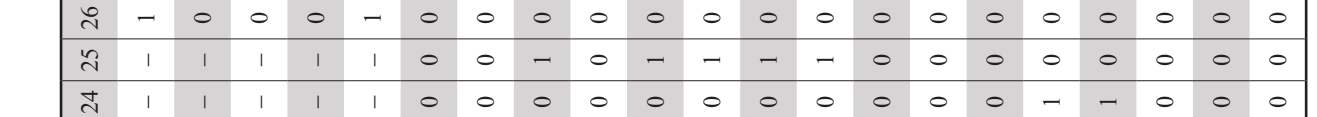

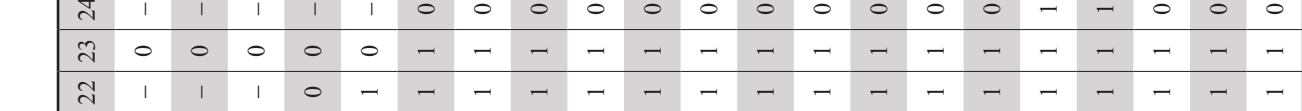

己

\begin{tabular}{llllllllllllllllllllllllll}
4 & 1 & 1 & 1 & 0 & - & - & - & - & - & - & - & - & - & - & - & - & - & - & - & - \\
\hline & 0 & 0 & 0 & - & - & - & - & - & - & - & - & - & - & - & - & - & - & - & - & -
\end{tabular}

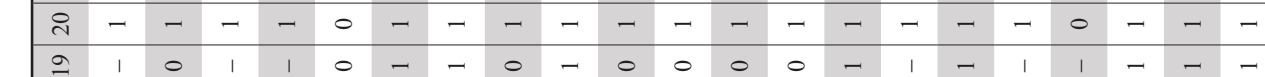

\begin{tabular}{|llllllllllllllllllllllll}
\hline$\infty$ & 0 & - & 0 & 0 & - & - & - & - & - & - & - & - & - & - & 0 & - & 0 & 0 & - & - & - \\
\hline & 0 & 0 & 0 & 0 & 0 & 0 & 0 & - & 0 & - & - & - & 0 & 0 & 0 & 0 & 0 & 0 & 0 & 0 & 0 \\
\hline & 0 & 0 & 0 & - & 0 & 0 & 0 & - & 0 & - & - & - & - & 0 & 0 & 0 & 0 & 0 & 0 & 0 & 0 \\
\hline
\end{tabular}

\begin{tabular}{llllllllllllllllllllllll|}
\hline$\underline{1}$ & 0 & 0 & 0 & - & 0 & 0 & 0 & - & 0 & - & - & - & - & 0 & 0 & 0 & 0 & 0 & 0 & 0 & 0 \\
\hline & 0 & 0 & 0 & 0 & 0
\end{tabular}

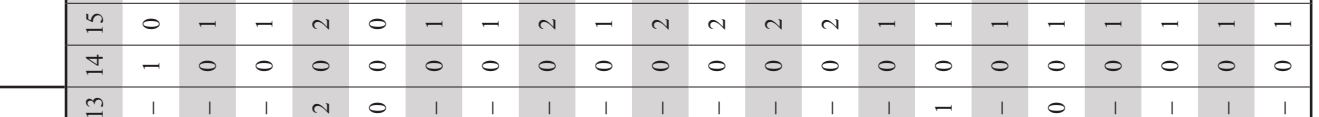

$\underset{0}{2}$

范

$\ddot{\overrightarrow{3}}$

要

\begin{tabular}{|llllllllllllllllllllllllll|}
\hline$\simeq$ & 1 & 1 & 1 & 0 & 0 & 1 & 1 & 1 & 1 & 1 & 1 & 1 & 1 & 1 & - & 1 & 0 & 1 & 1 & 1 & 1 \\
\hline$=$ & 0 & 0 & 0 & - & - & 0 & 0 & 0 & 0 & 0 & 0 & 0 & 0 & 0 & - & 0 & - & 0 & 0 & 0 & 0 \\
\hline & 1 & - & 0 & 0 & - & - & 0 & 0 & 0 & 0 & 0 & - & 0 & 0 & - & 0 & 0 & 0 & 0 & 0 & 0 \\
\hline
\end{tabular}

ह

8

8

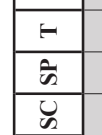

$\circ \quad 0 \quad 000$

-
-
-

0
-
-

0
-
-

$-$

$\begin{array}{llllllll}0 & - & 0 & 0 & 0 & 0 & 0 & 0 \\ - & - & - & - & - & - & - & -\end{array}$

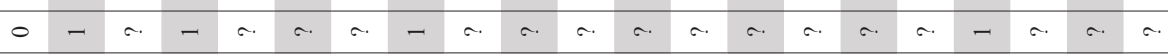

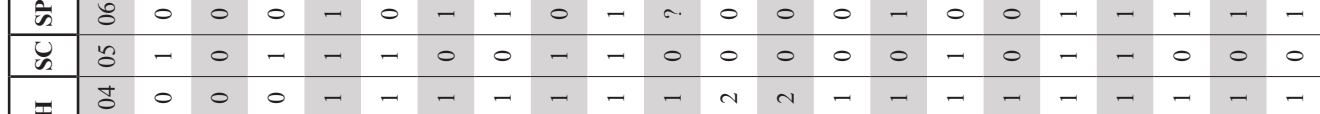

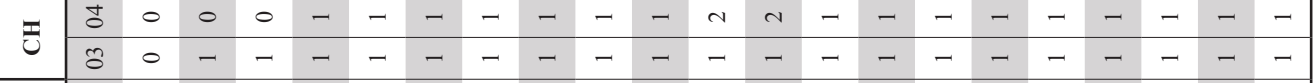

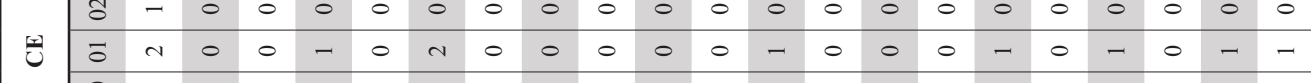

$80-\rightarrow-\rightarrow-$

$\frac{\vec{t}}{\vec{t}}$

$\| \dot{\delta}$

$\stackrel{\vec{\Phi}}{\rightarrow}$

ֻิ

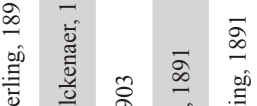

苨

$\ddot{m}$

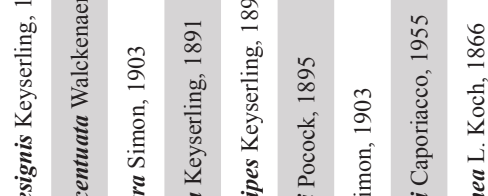




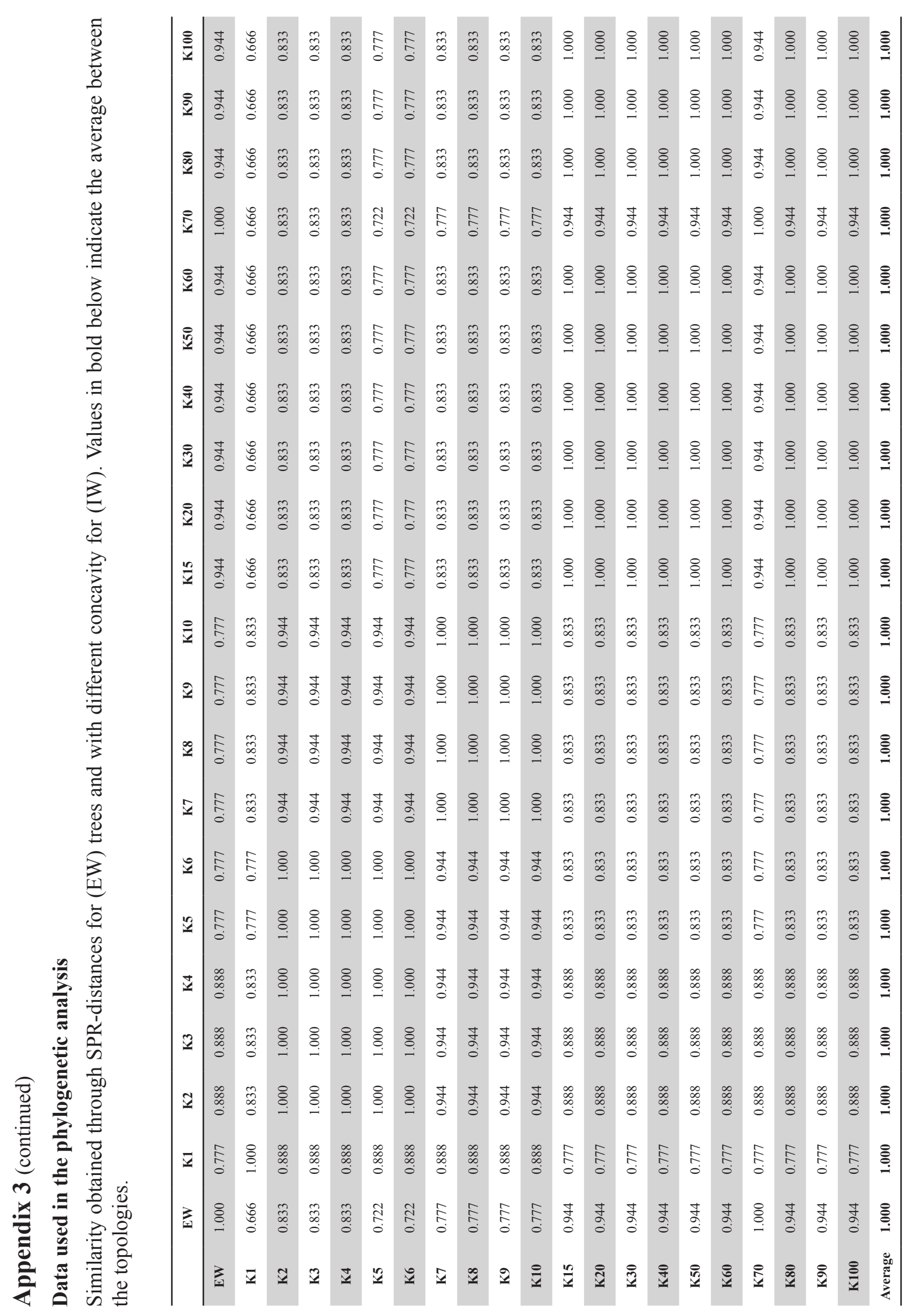

